Seton Hall University eRepository@Seton Hall

Seton Hall University Dissertations and Theses (ETDs)

Seton Hall University Dissertations and Theses

Fall 2015

\title{
Asymmetric Transfer Hydrogenation of Secondary Allylic Alcohols
}

Christopher Olugbenga Olusegun Shoola

christopher.shoola@student.shu.edu

Follow this and additional works at: https://scholarship.shu.edu/dissertations

Part of the Organic Chemistry Commons

\section{Recommended Citation}

Shoola, Christopher Olugbenga Olusegun, "Asymmetric Transfer Hydrogenation of Secondary Allylic Alcohols" (2015). Seton Hall University Dissertations and Theses (ETDs). 2118.

https://scholarship.shu.edu/dissertations/2118 


\title{
Asymmetric Transfer Hydrogenation of Secondary Allylic Alcohols
}

A dissertation submitted in partial fulfillment of the requirements for the degree of Doctor of Philosophy

By

Christopher Olugbenga Olusegun Shoola

\author{
Seton Hall University \\ Department of Chemistry and Biochemistry \\ South Orange, New Jersey USA
}

December, 2015 
(C) 2015 Christopher Olugbenga Olusegun Shoola 
We certify that we have read this thesis and that in our opinion it is adequate in scientific scope and quality as a dissertation for the degree of Doctor of Philosophy.

\section{APPROVED}
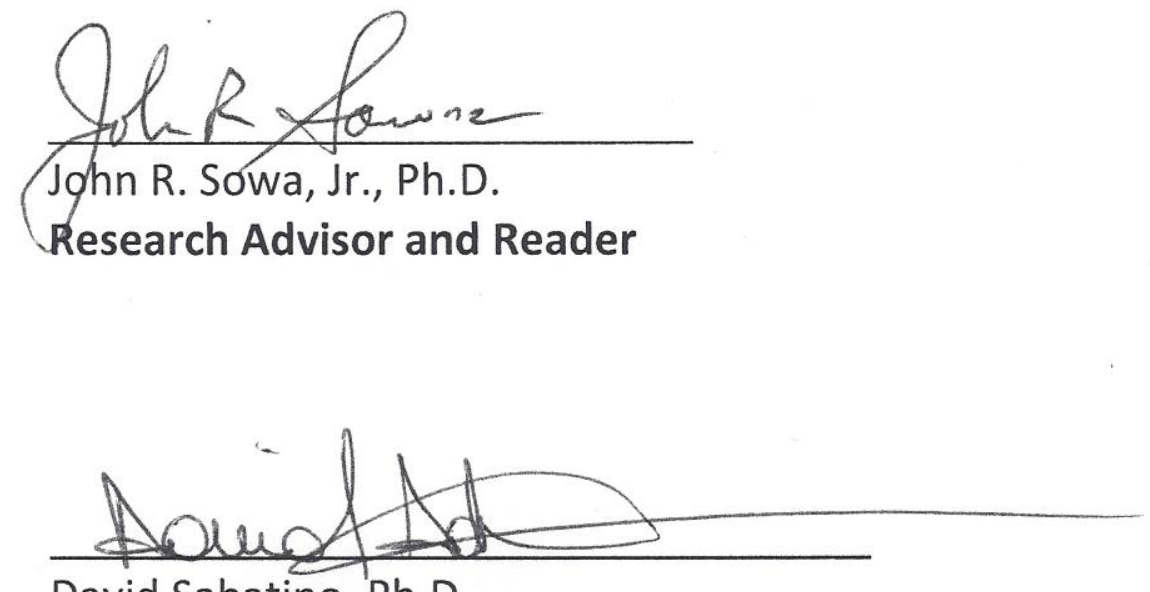

David Sabatino, Ph.D.

Member of Dissertation Committee

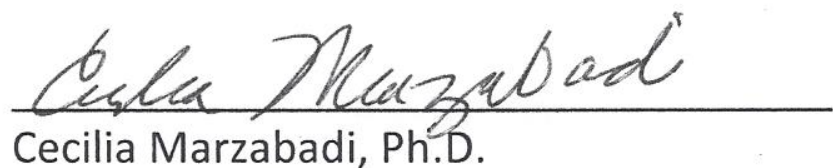

Member of Dissertation Committee

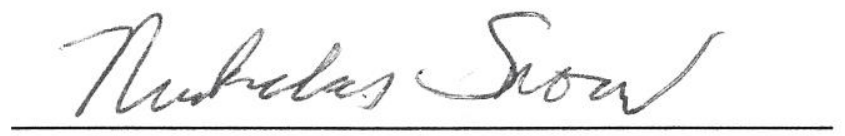

Nicholas Snow, Ph.D.

Chairperson, Department of Chemistry and Biochemistry 


\begin{abstract}
This dissertation highlights the developments and optimization of a new reaction method that transforms racemic secondary allylic alcohols into optically active secondary alcohols. The key step in this methodology occurs through a ruthenium catalyzed tandem isomerization and asymmetric transfer hydrogenation reaction. This reaction is a one pot, twostep process, which utilizes the unique ability of a transition metal catalyst to effect a combined reduction of the $\mathrm{C}-\mathrm{C}$ double bond and the carbonyl group in a selected class of secondary allylic alcohols.
\end{abstract}

With $\alpha$-vinyl benzyl alcohol as substrate, the optimal catalyst for this reaction was generated in situ from a di- $\mu$-chlorobis[(p-cymene)chlororuthenium (II)] complex and the chiral ligand $(S, S)-T S D P E N$ in the presence of potassium hydroxide as a base to afford yields of up to $97 \%$ and up to $93 \%$ enantiomeric excess (ee) for the desired chiral secondary benzyl alcohol.

Moreover, a series of substituted $\alpha$-vinyl benzyl alcohols with electron-donating groups (EDG) and electron withdrawing groups (EWG) were tested under the optimized asymmetric transfer hydrogenation (ATH) conditions in order to explore their effects on chemical reactivity. Interestingly, the ortho-methyl substituent in $\alpha$-vinyl tolyl alcohol and the sterically encumbered internal alkene in trans-1,3-diphenyl-2-propen-1-ol had the most adverse effects on chemical reactivity (77-86\% yields) and enantioselectivities (30-40\% ee). Both EWG and EDG at the para-positions were found to be well tolerated and exhibited good product yields (>80\%) 
and enantioselectivities (>90\%) underscoring the influence of steric crowding on the reactivity of starting materials.

The mechanism for the isomerization and ATH reaction was proposed to proceed through the transposition of the allylic double bond to generate a carbonyl compound. This reactive intermediate was then reduced to the corresponding chiral secondary alcohol through a metal-ligand bifunctional pathway.

Taken altogether, this thesis describes an important development in the isomerization and ATH reaction of the challenging secondary allylic alcohols. This discovery is not only an essential contribution to this broad reaction class but also in its application towards the synthesis of important targets, such as the $\mathrm{LTD}_{4}$ antagonist currently marketed as Singulair ${ }^{\mathrm{TM}}$. 


\section{Dedication}

To all my TEACHERS, at every level of my education, your great work has brought me this far.

I remain forever grateful. 


\section{Acknowledgements}

My profound gratitude goes to Prof. John R. Sowa Jr. for his commitment, encouragement, and selfless contribution toward my academic development. I am fortunate to have him as my mentor and research advisor.

I thank Prof. David Sabatino for being the chair of my matriculation examination committee, and a member of my dissertation committee, and importantly, for reviewing each chapter of this thesis and providing useful comments.

I also thank Prof. Cecilia Marzabadi for being a member of my dissertation committee and for her support and guidance at various times during my research work.

I thank Profs. Stephen Kelty, Sergiu Gorun and Suliya de-Silva of the College of Science and Mathematics at Montclair State University, Montclair, NJ. They were members of my matriculation examination committee, and provided useful comments early on in my research work.

I thank all the faculty members and the secretaries at the Department of Chemistry and Biochemistry at Seton Hall University, South Orange, NJ for their support and inspirations.

I thank the members of the Sowa research group for their support and good wishes.

I am very grateful to my wife, Imelda, whose support and understanding all through the years of my studies have been my greatest source of inspiration and strength to accomplish this degree.

Likewise, I am very thankful for the birth of our son, Luke, whose presence in our lives has crowned all my efforts towards this degree with brilliant success. 


\section{Table of Contents}

$\begin{array}{ll}\text { Abstract } & 6 \\ \text { Dedication } & 7 \\ \text { Acknowledgements } & 8 \\ \text { Table of Contents } & 11 \\ \text { List of Figures } & 12 \\ \text { List of Schemes } & 15 \\ \text { List of Tables } & 16 \\ \text { Abbreviations } & \end{array}$

Chapter One: Transfer Hydrogenation Reactions $\quad 18$

$\begin{array}{ll}\text { 1.1: Introduction } & 18\end{array}$

1.2: Reaction Variables in Transfer Hydrogenation $\quad 22$

1.2.1: Organic Hydrogen Atom Donor 22

1.2.2: Effect of Solvents $\quad 23$

1.2.3: Effect of Temperature 24

1.2.4: Effect of Promoters 25

1.3: Catalysts in Transfer Hydrogenation 26

1.4: Asymmetric Transfer Hydrogenation (ATH) 28

1.5: Mechanisms of TH and ATH 32

$\begin{array}{ll}\text { 1.6: Ligands for ATH } & 37\end{array}$

1.7: Catalytic Hydrogenation of Allylic Alcohols 39

1.8: Conclusions 42

$\begin{array}{ll}\text { References } & 43\end{array}$ 


\section{Chapter Two: Accounts of Chemical Research from the Sowa Group}

on the ATH of Allylic Alcohols $\quad 46$

2.1: ATH of primary allylic alcohols $\quad 46$

2.1.1: Introduction $\quad 46$

2.1.2: Isomerization-Hydrogenation mechanism - the discovery of ATH reaction of allylic alcohols $\quad 48$

2.1.3: The development of ATH reaction of allylic alcohols 52

2.1.4: Mechanistic Studies of ATH of allylic alcohols 57

2.1.5: Summary and Outlook $\quad 61$

2.2. Research objectives of ATH reaction of secondary allylic alcohols 62

2.2.1: Research Objectives $\quad 62$

2.3: Conclusions 66

$\begin{array}{ll}\text { References } & 67\end{array}$

Chapter Three: Development and Optimization of the ATH Reaction of Secondary Allylic Alcohols $\quad 70$

3.1: Development of the ATH reaction of secondary allylic alcohols 70

3.2: Optimization of the ATH reaction of secondary allylic alcohols 77

3.3: Postulated mechanism of ATH reaction of secondary allylic alcohols 82

3.2: ATH reaction of derivatives of $\alpha$-vinyl benzyl alcohol 84

3.3: Evaluation of the Electronic Effects 88

3.4: Conclusions $\quad 89$

3.5: Experimental Section $\quad 90$

$\begin{array}{ll}\text { 3.5.1: General Information } & 90\end{array}$

3.5.2: Procedure for Isomerization/Asymmetric Transfer 
3.5.3: Procedure for Synthesis of Allylic Alcohols Derivatives 93

3.6: Experimental Data $\quad 94$

3.6.1: ATH Product of Model Substrate - $\alpha$-vinylbenzyl alcohol 94

3.6.2: Synthesis of Intermediates - Derivatives of the model substrate 95

3.6.3: Isomerization/Asymmetric Transfer Hydrogenation Products 98

$\begin{array}{ll}\text { References } & 102\end{array}$

Chapter Four: Conclusions and Future Work 103

4.1: General Conclusions 103

4.2: Mechanistic Rationale 105

4.3: Future Work 106

4.4: Publication and Presentations $\quad 110$

$\begin{array}{ll}\text { Reference } & 111\end{array}$

$\begin{array}{ll}\text { Appendix } & 113\end{array}$ 


\section{List of Figures}

Figure 1.1. Representative structures of Noyori's ATH catalysts, 1.17-1.19.

Figure 1.2. Representative concerted transition state mechanism of the MPV reduction process.

Figure 1.3. Transition states representing chiral recognition in ATH.

Figure 1.4. $C_{2}$-symmetry representation of privileged ligands.

Figure 1.5. Examples of $C_{2}$-symmetrical ligands used for ATH.

Figure 3.1. Chiral separation of the first attempted ATH reaction of secondary allylic alcohol.

Figure 3.2. Structures of precatalyst, ligand, and presumed metal-ligand catalyst complex.

Figure 3.3. Plot of enantioselectivity vs. energy difference of the diastereomeric transition states.

Figure 3.4. Chiral separation of products of isomerization/ATH reaction of secondary allylic alcohol.

Figure 3.5. ${ }^{1} \mathrm{H}$ NMR spectrum of 1-phenyl-1-propanol (3.5).

Figure 3.5. FT-IR spectrum of 1-phenyl-1-propanol (3.5).

Figure 3.6. trans-1,3-diphenyl-2-propen-1-ol.

Figure 3.7. Comparative trend of relative rates of ATH reaction of secondary allylic alcohols. 


\section{List of Schemes}

Scheme 1.1. Hydrogen atom transfer of (+)-reynosin, 1.2 .

Scheme 1.2. Hydrogen disproportionation reactions of benzaldehyde.

Scheme 1.3. General reaction scheme of a concerted transfer hydrogenation.

Scheme 1.4. First observation of transfer hydrogenation of dimethyl 1,4-dihydroterephthalate, 1.7 into dimethyl terephthalate, 1.8 , and dimethyl hexahydroterephthalate.

Scheme 1.5. Aromatization reaction via transfer hydrogenation of cyclohexane and benzene derivatives.

Scheme 1.6. General scheme for the MPV transfer hydrogenation process.

Scheme 1.7. Transfer hydrogenation of acetophenone.

Scheme 1.8. The ATH reactions of aromatic carbonyl compounds, 1.20 , to their corresponding chiral secondary alcohols, 1.20-1.28 using IPA as hydrogen atom donor.

Scheme 1.9. The ATH reactions of aromatic carbonyl compounds, 1.20 , to their corresponding chiral alcohols, 1.29-1.40 using formic acid as hydrogen atom donor.

Scheme 1.10. Mechanism of hydride transfer from a donor source to acceptor.

Scheme 1.11. Conventional mechanism of transfer hydrogenation with IPA.

Scheme 1.12. ATH mechanism with chiral ruthenium-diamine catalyst complex.

Scheme 1.13. Asymmetric hydrogenation of a chiral allylic alcohol.

Scheme 1.14. Two-point binding of ruthenium complex to allylic substrate.

Scheme 1.15. Asymmetric hydrogenation of geraniol.

Scheme 2.1. Redox isomerization of allylic alcohol to carbonyl compound.

Scheme 2.2. Postulated reaction mechanism for the transformation of secondary allylic alcohols to their corresponding secondary alcohols. 
Scheme 2.3. Isomerization-hydrogenation mechanism.

Scheme 2.4. Proposed mechanism for isomerization of geraniol to $\gamma$-geraniol.

Scheme 2.5. ATH reaction of geraniol under optimized conditions.

Scheme 2.6. ATH reaction of nerol under optimized conditions.

Scheme 2.7. ATH reaction of 3-phenyl-2-buten-1-ol, 2.9, under optimized conditions.

Scheme 2.8. ATH reaction of geraniol using commercial catalyst complex.

Scheme 2.9. ATH of geraniol without IPA.

Scheme 2.10. ATH reaction of geraniol with deuterated IPA.

Scheme 2.11. ATH reaction of geraniol with mono deuterated IPA.

Scheme 2.12. ATH reaction of deuterated geraniol.

Scheme 2.13. Proposed mechanism of the ATH reaction of primary allylic alcohols.

Scheme 2.14. Proposed model reaction for the ATH reaction of secondary allylic alcohols.

Scheme 2.15. Representative substrate of interest in our investigation.

Scheme 2.16. Evaluation of electronic effects in the ATH of $\alpha$-vinyl benzylic alcohols 2.21-2.24.

Scheme 2.17. Secondary allylic alcohols of interest in our investigation.

Scheme 3.1. Optimized reaction conditions for primary allylic alcohols.

Scheme 3.2. First attempted ATH reaction of secondary allylic alcohols.

Scheme 3.3. Enantioselective isomerization/transfer hydrogenation mechanism of geraniol.

Scheme 3.4. Isomerization/ATH of secondary allylic alcohol.

Scheme 3.5. Optimized conditions for isomerization/ATH reaction of secondary allylic alcohol.

Scheme 3.6. Proposed mechanism for isomerization/ATH reaction of secondary allylic alcohol. 
Scheme 3.7. Charge distribution in the transition state via $\mathrm{H}$-bonding.

Scheme 3.8. Synthesis of derivatives 3.15-3.18 of $\alpha$-vinyl benzyl alcohol.

Scheme 3.9. Evaluation of electronic effects using competition experiments.

Scheme 4.1. Substituent (a) EWG and (b) EDG effects on the rate of reaction for the ATH of substituted $\alpha$-vinyl benzyl alcohols.

Scheme 4.2. Proposed mechanism of the chiral ATH of $\alpha$-vinyl benzyl alcohols.

Scheme 4.3. Proposed synthesis of ibuprofen.

Scheme 4.4. Stereoselective synthesis step for the LTD4 antagonist. 


\section{List of Tables}

Table 2.1. ATH of geraniol in different hydrogen donors/solvents.

Table 2.2. ATH of geraniol with different chiral ligands.

Table 3.1. Study of the catalytic activity and selectivity.

Table 3.2. Derivatives of $\alpha$-vinyl benzyl alcohols.

Table 3.3. Isomerization/ATH of substrates under the optimized conditions. 


\section{Abbreviations}

\begin{tabular}{|c|c|c|}
\hline ATH & - & Asymmetric Transfer Hydrogenation \\
\hline BINAP & - & 2,2'-bis(diphenylphosphino)-1,1'-binaphthyl \\
\hline BINOL & - & {$\left[1,1^{\prime}\right.$-binaphthalene]-2,2'-diol } \\
\hline BIPYRIDINES & - & (S)-6-(sec-butyl)-2,2'-bipyridine \\
\hline $\mathrm{BOX}$ & - & (4S,4'S)-4,4'-diisopropyl-4,4',5,5'-tetrahydro-2,2'-bioxazole \\
\hline $\mathrm{DH}$ & - & Direct Hydrogenation \\
\hline DIOP & - & $\begin{array}{l}\text { [(4S,5S)-2,2-dimethyl-1,3-dioxolane-4,5- } \\
\text { diyl)bis(diphenylphosphine] }\end{array}$ \\
\hline DOI & - & Digital Object Identifier \\
\hline ee & - & enantiomeric excess \\
\hline EDG & - & Electron donating group \\
\hline equiv. & - & Equivalent \\
\hline EWG & - & Electron withdrawing group \\
\hline FA & - & Formic acid \\
\hline GC-MS & - & Gas Chromatography - Mass Spectroscopy \\
\hline HPLC & - & High Pressure Liquid Chromatography \\
\hline IPA, i-PrOH & - & Isopropyl alcohol \\
\hline i-Pr-DuPHOS & - & 1,2-bis((2S,5S)-2,5-di-i-propylphospholano)benzene \\
\hline $\mathrm{LTD}_{4}$ & - & Leukotriene $\mathrm{D}_{4}$ \\
\hline $\mathrm{mmol}$ & - & Millimole \\
\hline MeDuPHOS & - & 1,2-bis((2S,5S)-2,5-dimethylphospholano)benzene \\
\hline
\end{tabular}




\begin{tabular}{|c|c|c|}
\hline $\mathrm{mol}$ & - & Mole \\
\hline M-S & - & Metal-solvent complex \\
\hline$m / z$ & - & mass to charge ratio \\
\hline OD-RH & - & Chiracel reverse phase column \\
\hline PHANEPHOS & - & (S)-4,12-bis(diphenylphosphino)-[2.2]-paracyclophane \\
\hline $\mathrm{R}$ & - & $8.3144 \mathrm{~g} \mathrm{~mol}^{-1} \mathrm{~K}^{-1}$ \\
\hline RT & - & room temperature \\
\hline $\mathrm{RuCl}_{2}$-(p-cymene) & - & di- $\mu$-chlorobis[(p-cymene)chlororuthenium (II)] complex \\
\hline $\mathrm{Ru} / \mathrm{MeO}-\mathrm{BIPHEP}$ & - & $\begin{array}{l}\text { Ruthenium complex of (S)-(+)-2,2'-bis[di(3,5-di-t-butyl-4- } \\
\text { methoxyphenyl)phosphino]-6,6'-dimethoxy-1,1'-biphenyl, }\end{array}$ \\
\hline $\mathrm{Ru}\left(\mathrm{OOCCF}_{3}\right)_{2} / \mathrm{BINAP}$ & - & $\begin{array}{l}\text { Ruthenium bis-trifluoroacetic complex of 2,2'- } \\
\text { bis(diphenylphosphino)-1,1'-binaphthyl }\end{array}$ \\
\hline SALEN & - & $\begin{array}{l}\text { 2,2'-Ethylenebis(nitrilomethylidene)diphenol, N,N'- } \\
\text { ethylenebis(salicylimine) }\end{array}$ \\
\hline $\mathrm{T}$ & - & Temperature \\
\hline TEMPO & - & $(2,2,6,6$-Tetramethylpiperidin-1-yl)oxyl \\
\hline $\mathrm{TH}$ & - & Transfer Hydrogenation \\
\hline THF & - & Tetrahydrofuran \\
\hline TLC & - & Thin Layer Chromatography \\
\hline TMS & - & Tetramethylsilane \\
\hline tol-BINAP & - & (S)-2,2'-bis(di-p-tolylphosphosphino)-1,1'-binaphthyl \\
\hline TsDPEN & - & $\mathrm{N}$ - $p$-toluenesulfonyldiphenylethylenediamine \\
\hline UV & - & Ultraviolet \\
\hline$\Delta \Delta \mathrm{G}^{\ddagger}$ & - & Free energy difference in the transition state \\
\hline
\end{tabular}




\section{Chapter One: Transfer Hydrogenation Reactions}

\section{1: Introduction}

Hydrogenation is a process by which hydrogen atoms are added to an unsaturated organic compound, usually in the presence of a metal catalyst. This addition takes place across the $\pi$-bond of unsaturated compounds such as acetylenes, olefins, carbonyls, imines and nitriles. Since usable hydrogenation reactions require the presence of an organometallic catalyst, studies on hydrogenation has long been interwoven with that of catalysis. For example, the first commercialized hydrogenation processes dates back to the seminal works of Dobereiner, applied in the generation of hydroplatinic lamps in 1823 and that of Paul Sabatier in 1897 which led to the production of margarine. ${ }^{1}$ These examples have been used as historical reference points in the studies of heterogeneous catalytic hydrogenation processes. Thus, hydrogenation of unsaturated organic compounds is one of the most fundamental classes of reactions in organic chemistry that has been employed in the synthesis of commodity and fine chemicals, with widespread applications in the petrochemical, perfumery, pharmaceutical, functional material and food industries. ${ }^{2}$

The strategies for hydrogenation are divided into two categories: direct hydrogenation and transfer hydrogenation. ${ }^{3}$ Direct hydrogenation $(\mathrm{DH})$ is the reduction of multiple bonds using pressurized hydrogen gas as the source of hydrogen atoms - a technique that is very familiar to all organic chemists. Transfer hydrogenation $(\mathrm{TH})$ is the addition of hydrogen atoms to unsaturated compounds using an organic molecule as a hydrogen atom donor in the presence 
of a catalyst. This technique is commonly referred to as catalytic transfer hydrogenation or simply, TH. It is one of the possible methods of hydrogen atom transfer reactions aptly classified by Braude and Linstead in 1954, into three main categories: ${ }^{4}$

a. Hydrogen atom migrations, occurring within one molecule. For example, thermal mediated hydride shifts in carbocation rearrangements or transition metal mediated radical cyclization reactions. ${ }^{5}$

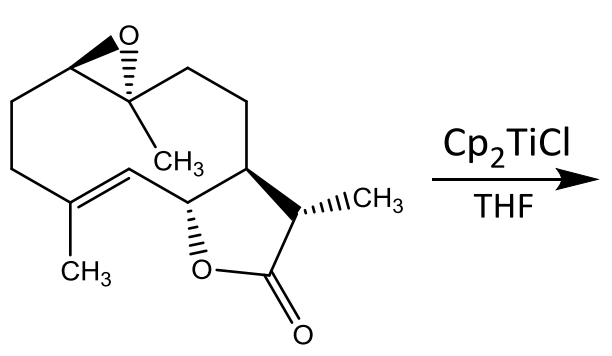

1.1

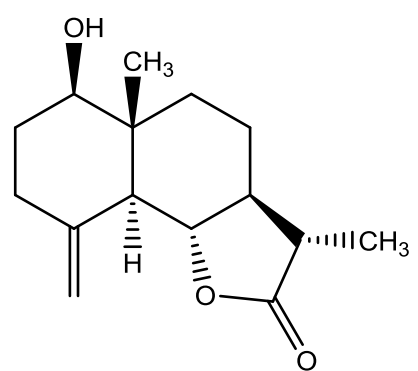

1.2

Scheme 1.1. Hydrogen atom transfer of (+)-reynosin, $1.2 .^{5}$

b. Hydrogen atom disproportionation, involving hydrogen atom transfer between two identical donor and acceptor molecules, for example, the Cannizzaro reaction or the Tishchenko reaction. ${ }^{6}$

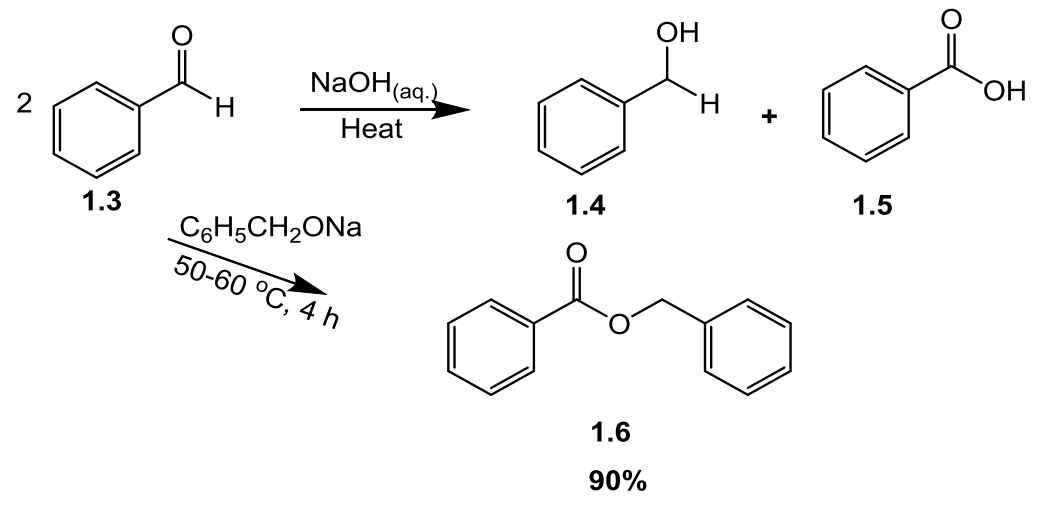

Scheme 1.2. Hydrogen disproportionation reactions of benzaldehyde. ${ }^{6}$ 
c. Hydrogen atom transfer during a concerted transfer hydrogenation - dehydrogenation processes between two different donor and acceptor molecules, mediated by a metal catalyst complex.

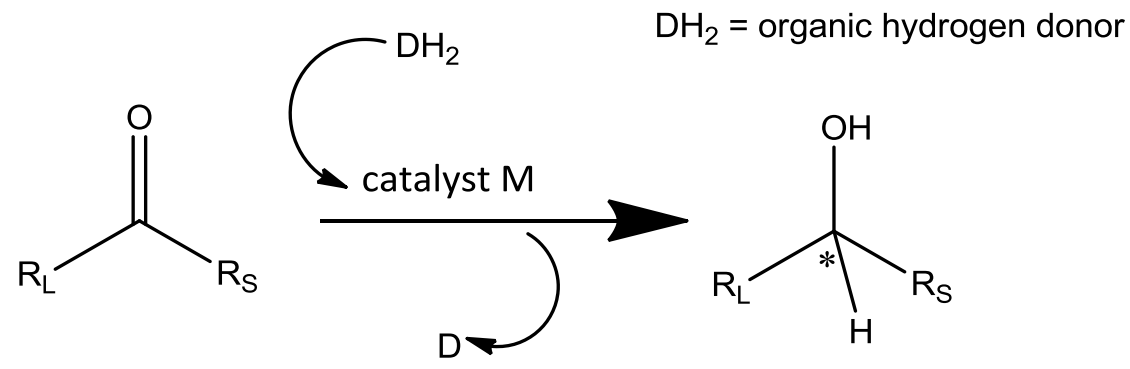

Scheme 1.3. General reaction scheme of a concerted transfer hydrogenation. ${ }^{7}$

This TH reaction was first observed by Knoevenagel in 1903, during the transformation of dimethyl 1,4-dihydroterephthalate into dimethyl terephthalate and hexahydroterephthalate in the presence of palladium black. ${ }^{8}$

2<smiles>COC(=O)C1C=CC(C(=O)OC)C=C1</smiles>

1.7<smiles>COC(=O)c1ccc(C(=O)OC)cc1</smiles>

1.8<smiles>COC(=O)C1CCC(C(=O)OC)CC1</smiles>

1.9

Scheme 1.4. First observation of transfer hydrogenation of dimethyl 1,4-dihydroterephthalate,

$\mathbf{1 . 7}$ into dimethyl terephthalate, $\mathbf{1 . 8}$, and dimethyl hexahydroterephthalate. ${ }^{8}$

Subsequent studies by Wieland and others including the trio of Meerwein-PonndorfVerley further confirmed this observation. ${ }^{9}$ Systematic studies of the TH reaction was undertaken by Braude and co-workers, who then suggested in 1952, that catalytic hydrogen 
transfer from an organic donor molecule to a variety of organic acceptors might be possible under mild conditions. It also demonstrated the practicality of this reaction through the discovery that multiple bonds of ethylenic and acetylenic systems could be reduced in high yield and purity by refluxing with cyclohexene in tetrahydrofuran at $65{ }^{\circ} \mathrm{C}$ in the presence of palladium black. ${ }^{10}$ Studies following this discovery further established the scope of this reaction as several functional groups including nitro, azo, nitrile and carbonyl groups were reduced. ${ }^{4}$

Since then, transfer hydrogenation became an important and attractive area of research, with diverse subsets of reactions being developed. These were based on the type of catalyst and other variables such as the nature of the organic hydrogen atom donor, solvent effects, temperature, as well as the nature of the functional groups to be reduced. ${ }^{4}$ Each of these variables must be carefully studied in order to develop an efficient transfer hydrogenation process.

The operational simplicity and convenience of TH has made the methodology a powerful alternative to $\mathrm{DH}$, as it does not require the hazardous pressurized hydrogen gas and specialized experimental equipment for reactivity. The availability of the organic alcohol, as hydrogen atom donor coupled with their inexpensive cost and ease of handling have made this reaction widely applicable to a broad range of substrates. Moreover, the side products may be recycled into usable materials and moisture sensitive catalysts have made $\mathrm{TH}$ reactions a more advantageous and safer alternative than the DH reactions. ${ }^{11}$ As a drawback, large amounts of solvent is typically required for this reaction in order to overcome unfavorable thermodynamics, especially, when the alcohol is used as both solvent and hydrogen atom donor. ${ }^{12}$ 


\section{2: Reaction Variables in Transfer Hydrogenation}

\subsection{1: Organic Hydrogen Atom Donor}

An organic compound with a sufficiently low oxidation potential would be a good hydrogen atom donor in a TH reaction under mild conditions. However, at higher temperature and in the presence of a suitable catalyst, almost any organic compound can donate hydrogen atoms - a process referred to as catalytic cracking. Nonetheless, this would be a wasteful and dangerous effort due the difficulty associated with the uncontrolled reactivity of certain classes of organic compounds. ${ }^{4}$ The choice of organic donor, is therefore, generally determined by the reactivity, (that is, the ease of the donor to release hydrogen atom) and availability. Hence, organic donors tend to be hydroaromatics (ability to become aromatic upon releasing hydrogen atoms), unsaturated terpenes, alcohols and triethyl ammonium formate (TEAF). Early research work identified cyclohexene as the preferred hydrogen donor and one of the most frequently employed organic hydrogen donors because of its reactivity and availability. Also frequently used are tetralin, limonene, terpinolene and $\alpha$-phellandrene. ${ }^{13}$

Moreover, increasing the degree of unsaturation in hydroaromatics leads to a rapid rate of reaction. Therefore, dienes are more reactive than alkenes, while saturated hydrocarbons react more slowly or may not react at all under the TH conditions. Limonene and $\alpha$ phellandrene are considered more reactive donors given their shorter reaction times. ${ }^{13}$ Also, increasing substituent bulk on the organic donors has been found to reduce reaction rates, particularly when using cyclohexene is used as donor molecule. An activating substituent such as phenyl is noted to increase reaction rates due to its electron-rich $\pi$-system. For example, 1- 
phenylcylohexene was found to release hydrogen atoms more quickly than 1-ethylcylohexene and unsubstituted cyclohexene. ${ }^{14}$

Recent studies have shown that the use of alcohols (2-propanol - IPA), formic acid (FA) and triethyl ammonium formate (TEAF) as the hydrogen atom donor and solvent have overtaken the use of hydroaromatics, with significant acceleration in reaction rates. ${ }^{3}$ The hydrogen donor, TEAF in particular, has proven to be a good hydrogen atom donor because of its solubility in many organic solvents. Moreover, dehydrogenation of FA derivatives provides the energetics for $\mathrm{TH}$, since the transfer of hydrogen atom from the formic acid derivative is an irreversible and exothermic process. ${ }^{3,12}$ Thus, TEAF is the usual alternative hydrogen donor for FA, in a system where unfavorable thermodynamic tendencies of transfer hydrogenations may be expected. ${ }^{15}$

\subsection{2: Effect of Solvents}

The effect of a solvent on $\mathrm{TH}$ is largely limited to its ability to effectively solubilize the reacting species, except in a system where the solvent is also the organic donor. ${ }^{4}$ Early investigation did not find any significant effects of solvent on $\mathrm{TH}$, other than varied reaction times depending on the system under study. Transfer hydrogenation, therefore, showed a wide tolerance for a number of common organic solvents in normal or supercritical states, ionic liquids and recently more common aqueous solvents. ${ }^{16}$ The aqueous solvents are becoming increasingly popular because of their green chemistry advantages, good water solubility of commonly employed hydrogen donors, and importantly, in the design and synthesis of efficient water-soluble catalyst complexes. Although, transition metal catalysts tend to be sensitive to 
the $\mathrm{pH}_{\text {conditions }}{ }^{3}$ (requiring slightly basic $\mathrm{pH}$ ), a careful balance of the reaction and solvent conditions can enhance selectivity and reduce possible side reactions. Notwithstanding the necessity of aqueous solvents, pure alcohols still remain the leading organic solvents for effective TH reactions. For example, isopropyl alcohol (IPA), in particular has been widely employed as hydrogen atom donor and solvent especially, in the $\mathrm{TH}$ of carbonyl and imine compounds. ${ }^{17}$ The alcohol, IPA is stable, easy to handle, relatively volatile (bp $82{ }^{0} \mathrm{C}$ ), environmentally friendly (nontoxic), inexpensive and dissolves many organic compounds which facilitates reactivity. Furthermore, IPA generates acetone as a by-product, which can be readily removed and recycled for consumption. ${ }^{17}$

\subsection{3: Effect of Temperature}

The reaction temperature is a critical variable in transfer hydrogenation reactions. Early studies have employed hydrogen atom transfer at higher temperatures (usually $>150{ }^{\circ} \mathrm{C}$ ), particularly, in hydrogen transfer leading to aromatization reactions. For example, the transformation of benzene, $\mathbf{1 . 1 1}$, to cyclohexane, $\mathbf{1 . 1 3}$ in the presence of a heterogeneous

nickel catalyst (Scheme 1.5). ${ }^{18}$ Nevertheless, with the advances in the design and synthesis of efficient homogeneous transition metal catalysts coupled with effective hydrogen atom donors, much lower temperatures have been used for effective $\mathrm{TH}$ of many organic compounds. The work of Chowdhury and Backvall in the 1990s, particularly made TH reactions possible over a mild range of temperatures; including ambient to refluxing temperatures with noted increased rates of reactions. ${ }^{19}$ 


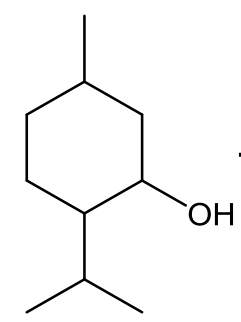

1.10<smiles>c1ccccc1</smiles>

1.11

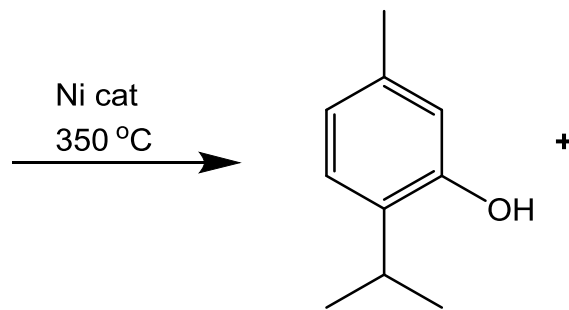

1.12

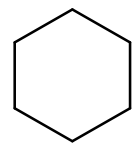

1.13

Scheme 1.5. Aromatization reaction via transfer hydrogenation of cyclohexane and benzene derivatives. $^{18}$

\subsection{4: Effect of Promoters}

Reaction promoters include strong bases such as potassium hydroxide ( $\mathrm{KOH})$, potassium carbonate $\left(\mathrm{K}_{2} \mathrm{CO}_{3}\right)$, potassium t-butoxide $\left(\mathrm{KO}^{t} \mathrm{Bu}\right)$, cesium carbonate $\left(\mathrm{Cs}_{2} \mathrm{CO}_{3}\right)$, sodium hydroxide $(\mathrm{NaOH})$, sodium alkoxides, and several other inorganic bases like potassium hexamethyldisilazane (KHMDS) and potassium phosphate $\left(\mathrm{K}_{3} \mathrm{PO}_{4}\right)$ have all shown to produce beneficial effects on the rates of reaction in $\mathrm{TH}^{3,4,19}$ Their influence in the catalytic efficiencies of homogeneous transition metal catalysts is exerted through their role as catalyst preactivation agents. Their presence in the reaction mixture affords a highly active and reproducible catalyst system for effective transfer of hydrogen atoms. For example, in the reduction of ketones with IPA as hydrogen donor, $\mathrm{KOH}$ is the usual promoter and its addition is essential, as no reaction occurs in its absence or in low concentrations. ${ }^{15 a}$ Nonetheless, TH has recently been shown to occur without the addition of the base in a few cases using iridium and ruthenium based catalysts. $^{20}$ It is suspected that the dissociated ligands in these cases may be acting as the reaction promoters. 


\section{3: Catalysts in Transfer Hydrogenation}

The presence of a catalyst is a key requirement for a successful TH reaction. Prior to the pioneering MPV reduction of carbonyl compounds in 1925, TH reactions have only been effective with heterogeneous palladium and nickel catalysts albeit at high temperatures. Other known catalysts such as platinum and rhodium did not work. ${ }^{4}$

In the advent of homogeneous catalysis and decades after the publication of the MPV process over an aluminum catalyst, direct transfer hydrogenation via the MPV process have been explored. These were found to occur through the concerted formation of the a cyclic sixmembered ring transition state, with other catalysts such as zirconium, lanthanum, cerium, samarium and ytterbium (Scheme 1.6). ${ }^{21}$

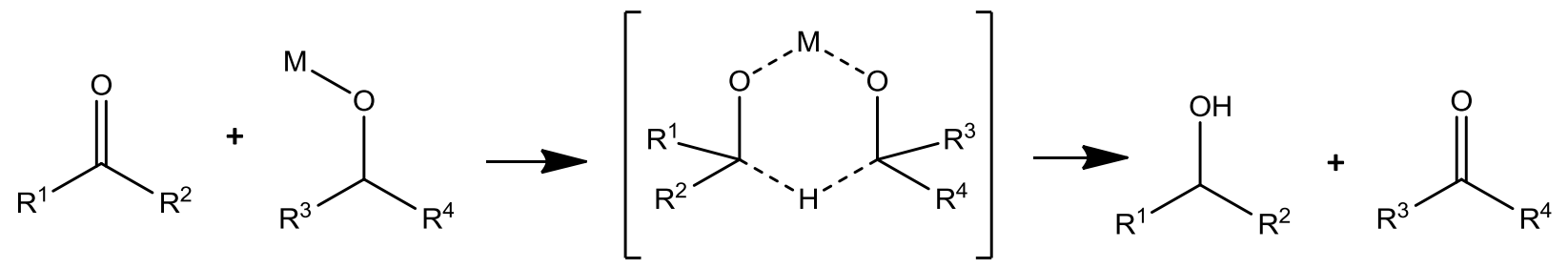

Scheme 1.6. General scheme for the MPV transfer hydrogenation process. ${ }^{21}$

The MPV process has also been reported with the use of heterogeneous Lewis acidic or basic catalysts such as supported aluminum alkoxides, magnesium oxide, hydrotalcites, hydrous zirconia, and supported zirconium complexes, as well as zeolites, and grafted lanthanide alkoxides. Despite its extensive use, this reaction is limited to the ketones and it is not $a$ truly catalytic process given the stoichiometry requirement of the reagents, sensitivity of the aluminum catalyst to air and moisture, and the undesirable side products. However, the MPV 
process is the harbinger of the successful TH reactions of many varieties of organic compounds today.

Transfer hydrogenation, therefore, truly became a viable research endeavor with the discovery of organic solvents, and soluble catalyst complexes of late transitional metals such as $\mathrm{Fe}, \mathrm{Ru}, \mathrm{Os}, \mathrm{Co}, \mathrm{Rh}, \mathrm{Ir}, \mathrm{Ni}, \mathrm{Pd}, \mathrm{Pt}, \mathrm{Cu}, \mathrm{Ag}$, and $\mathrm{Au}$. These homogeneous catalyst complexes, particularly, complexes of iridium, ruthenium and rhodium showed significant efficient capacity in the TH of carbonyl compounds. ${ }^{3}$ In the 1960s, Henbest and co-workers demonstrated the efficiency of iridium-hydride in catalyzing the reductions (transfer hydrogenations) of cyclohexanone and $\alpha, \beta$-unsaturated ketones to their corresponding alcohols, with IPA as hydrogen atom donor and solvent. ${ }^{22}$ Sasson and Blum's contribution in the early 1970 s showed dichlorotris(triphenylphosphine)ruthenium(II) $\left[\mathrm{RuCl}_{2}\left(\mathrm{PPh}_{3}\right)_{3}\right]$ as an active catalyst in the homogeneous transfer hydrogenations of $\alpha, \beta$-unsaturated carbonyl compounds with formyl and IPA donors at high temperatures. ${ }^{23}$ This concept was later improved by the work Chowdhury and Backvall in the 1990s, when the duo discovered a significant acceleration in the rate of transfer hydrogenation reactions upon addition of catalytic amounts of $\mathrm{NaOH}$ as a co-catalyst. ${ }^{19}$ This discovery paved the way for the transfer hydrogenation reaction to be conducted at much lower reaction temperature - room temperature to reflux, leading into the asymmetric transfer hydrogenation (ATH) reaction with chiral ligands. 
<smiles>CC(=O)c1ccccc1</smiles>

1.14

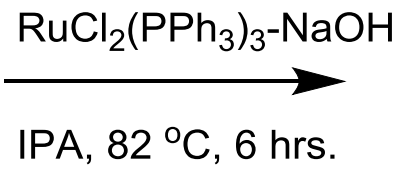

IPA, $82^{\circ} \mathrm{C}, 6$ hrs.

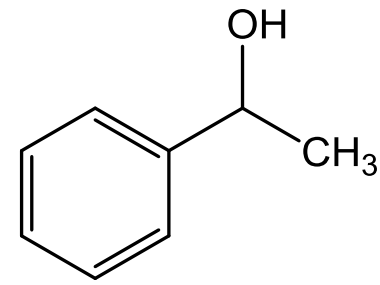

1.15

Scheme 1.7. Transfer hydrogenation of acetophenone. ${ }^{23}$

\section{4: Asymmetric Transfer Hydrogenation (ATH)}

The first example of an ATH reaction was first demonstrated by Doering and Young in 1950 via a partially asymmetric MPV reduction. ${ }^{24 a}$ In the beginning of the 1980 s, Bianchi and co-workers reported the practical viability of ATH in contemporary chemistry with the use of chiral ruthenium complexes. ${ }^{24 b, c}$ Thereon, the ATH reaction became the research focus of several groups and in 1992, Gladiali and co-workers ${ }^{15 a}$ reviewed the advances in ATH reactions catalyzed by homogeneous transition metals catalysts with $C_{2}$-symmetrical chiral ligands. They concluded that ATH reactions rival the classical asymmetric hydrogenation $(\mathrm{AH})$, given the impressive asymmetric induction achieved with chiral iridium, rhodium and ruthenium catalyst complexes in the reduction of carbonyl compounds. ${ }^{15} \mathrm{~A}$ major breakthrough in ATH was reported by Noyori and co-workers in 1995, with the development of ruthenium complexes using chiral diamine ligands (the Noyori-Ikariya catalysts, 1.17-1.19) Figure 1.1. ${ }^{12 a}$ 


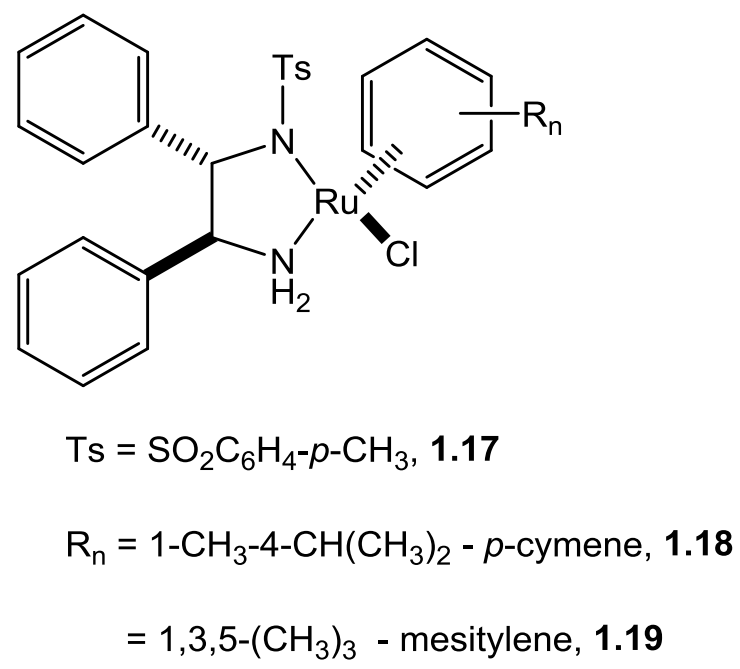

Figure 1.1. Representative structures of Noyori's ATH catalysts, 1.17-1.19. ${ }^{12 a}$

The efficiency of this catalyst and many of its variants made the ATH one of the most powerful methods for asymmetric reduction of carbonyl compounds. The substrate scope was also extended to other unsaturated substrates such as alkenes, imines and heteroarenes, efficiently converting them to their corresponding saturated chiral compounds. Highlights of the ATH reactions with Noyori's class of catalysts are presented in Figure 1.2. Reactions were separately performed using IPA and formic acid as both hydrogen atom donors and solvents. ${ }^{17}$

The success of these catalysts in the reduction of a wide range of unsaturated organic compounds and their applications in the syntheses of important bioactive compounds such as carbonic anhydrase inhibitors and $\mathrm{LTD}_{4}$ antagonists, has not only made the ATH a powerful reaction, but has also elevated the transition metal ruthenium to the level of most classic and popular types of catalysts for highly efficient asymmetric reduction processes. ${ }^{12 c}$ 
<smiles>[R]C(=O)c1ccccc1</smiles>

$\frac{(\mathrm{S}, \mathrm{S}) \text {-catalyst }}{\left(\mathrm{CH}_{3}\right)_{2} \mathrm{CHOH}}$<smiles>[R][C@H](O)c1ccccc1</smiles>

$93-98 \%$ yield

$(\mathrm{S}, \mathrm{S})$-catalyst $=\left[\mathrm{RuCl}_{2}(p \text {-cymene })\right]_{2}-(\mathrm{S}, \mathrm{S})-\mathrm{TsDPEN}-\mathrm{KOH}$ (mole ratio 1:2:5)<smiles>[R]C(O)C1=CCCC=C1</smiles>

$\mathrm{R}=\mathrm{CH}_{3} \quad 97 \%$ ee, $\mathbf{1 . 2 0}$

$\mathrm{R}=\mathrm{C}_{2} \mathrm{H}_{5} \quad 97 \%$ ee, $\mathbf{1 . 2 1}$<smiles>C[C@H](O)c1ccccc1</smiles>

$\mathrm{R}=m-\mathrm{Cl} 98 \%$ ee, $\mathbf{1 . 2 2}$ $\mathrm{R}=p-\mathrm{Cl} 93 \%$ ee, $\mathbf{1 . 2 3}$

$\mathrm{R}=m-\mathrm{OCH}_{3} 96 \%$ ee, 1.25<smiles>C[C@@H](O)c1ccccn1</smiles>

$>97 \%$ yield, $95 \%$ ee, $\mathbf{1 . 2 6}$<smiles>C[C@H](O)c1cccc2ccccc12</smiles>

93\% ee, 1.27<smiles>C[C@H](O)c1ccc2ccccc2c1</smiles>

$98 \%$ ee, 1.28

Scheme 1.8. The ATH reactions of aromatic carbonyl compounds, 1.20 , to their corresponding chiral secondary alcohols, 1.20-1.28 using IPA as hydrogen atom donor. ${ }^{12 c}$ 
<smiles>[R]C(=O)c1ccccc1</smiles>
$\underset{\mathrm{HCOOH} / \mathrm{N}\left(\mathrm{C}_{2} \mathrm{H}_{5}\right)_{3}}{\stackrel{(\mathrm{S}, \mathrm{S}) \text {-catalyst }}{\mathrm{H}}}$ IPA, $28^{\circ} \mathrm{C}$<smiles>[R][C@H](O)c1ccccc1</smiles>

93-99\% yield

$(\mathrm{S}, \mathrm{S})$-catalyst $=\left[\mathrm{RuCl}_{2}(\text { mesitylene })\right]_{2}-(\mathrm{S}, \mathrm{S})-\mathrm{TsDPEN}-\mathrm{KOH}$ (mole ratio 1:2:5)<smiles>C[C@H](O)c1ccccc1</smiles>

1.29 $96 \%$ ee<smiles>C[C@H](O)c1ccccc1</smiles>

$\mathrm{R}=m-\mathrm{Cl} 97 \%$ ee $\mathbf{1 . 3 0}$ $\mathrm{R}=p-\mathrm{Cl} 95 \%$ ee $\mathbf{1 . 3 1}$ $\mathrm{R}=m-\mathrm{OCH}_{3} 98 \%$ ee $\mathbf{1 . 3 2}$ $\mathrm{R}=p-\mathrm{OCH}_{3} \quad 97 \%$ ee $\mathbf{1 . 3 3}$
1.34

$97 \%$ ee<smiles>C[C@H](O)c1cccc2ccccc12</smiles>

1.35 $83 \%$ ee<smiles>C[C@H](O)c1ccc2ccccc2c1</smiles>

1.36

$96 \%$ ee<smiles>[R]C1C[C@H](O)c2ccccc21</smiles>

$\mathrm{R}=\mathrm{CH}_{2} \quad 99 \%$ ee $\mathbf{1 . 3 7}$<smiles>Oc1ccc2ccccc2c1</smiles>

$70 \%$ yield, $83 \%$ ee $\mathbf{1 . 3 9}$

$$
\mathrm{R}=\left(\mathrm{CH}_{2}\right)_{2} \quad 99 \% \text { ee } 1.38
$$<smiles>CC1(C)C[C@@H](O)c2ccccc2O1</smiles>

1.40

$47 \%$ yield, $98 \%$ ee

Scheme 1.9. The ATH reactions of aromatic carbonyl compounds, 1.20 , to their corresponding chiral alcohols, 1.29-1.40 using formic acid as hydrogen atom donor. ${ }^{12 c}$ 


\section{5: Mechanisms of TH and ATH}

Transfer hydrogenation has long been presumed to operate by two discrete mechanisms, depending on the nature of the metal catalyst and the hydrogen source, both of which have been extensively studied. ${ }^{25}$ The first mechanism involves a concerted process with direct hydrogen atom transfer occurring in a six-membered transition state that begins with the MPV reduction of carbonyls (Figure 1.2). In this mechanism, the hydrogen donor and acceptor are concertedly coordinated to a metal center, for example, rhodium or iridium to facilitate hydrogen transfer from the donor to the acceptor.

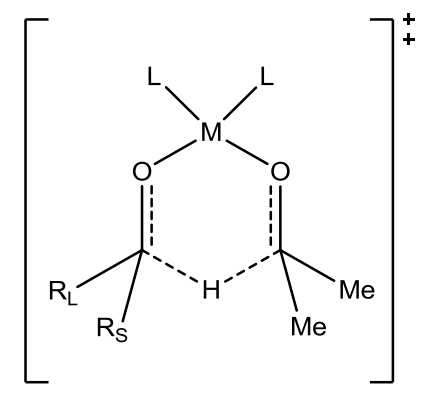

Figure 1.2. Representative concerted transition state mechanism of the MPV reduction process. $^{25}$

The other proposed mechanism involves a stepwise process via the formation of a metal-hydride complex (Scheme 1.10). The hydrogen atom donor (2-propanol or formic acid) first coordinates to the metal catalyst, followed by the elimination of acetone or carbon-dioxide to generate a metal hydride which then coordinates with the substrate to effect hydride transfer. ${ }^{25}$ 


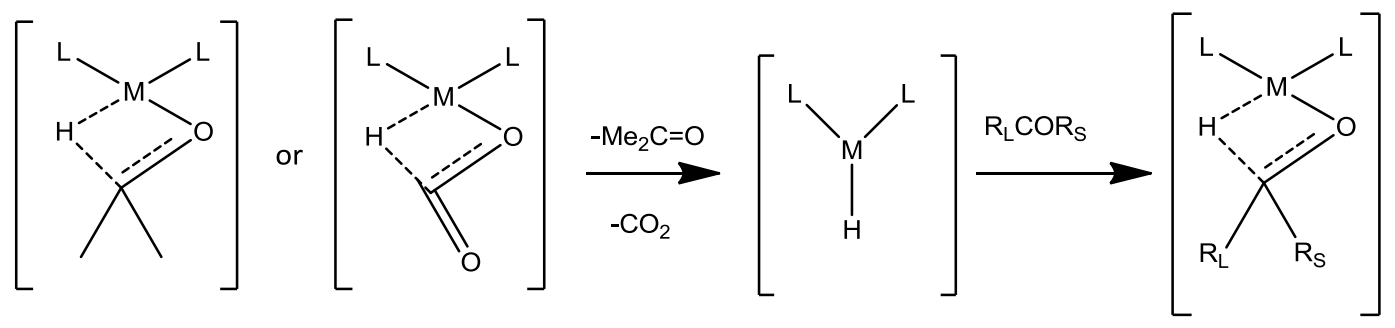

Scheme 1.10. Mechanism of hydride transfer from a donor source to acceptor. ${ }^{25}$

Both pathways are regarded as inner-sphere mechanisms since the donor and acceptor remain coordinated to the metal center at some point of the catalytic cycle. The metal-hydride pathway is considered to be the more conventional mechanism for $\mathrm{TH}$ reactions involving transition metal catalysts. $^{26}$ 


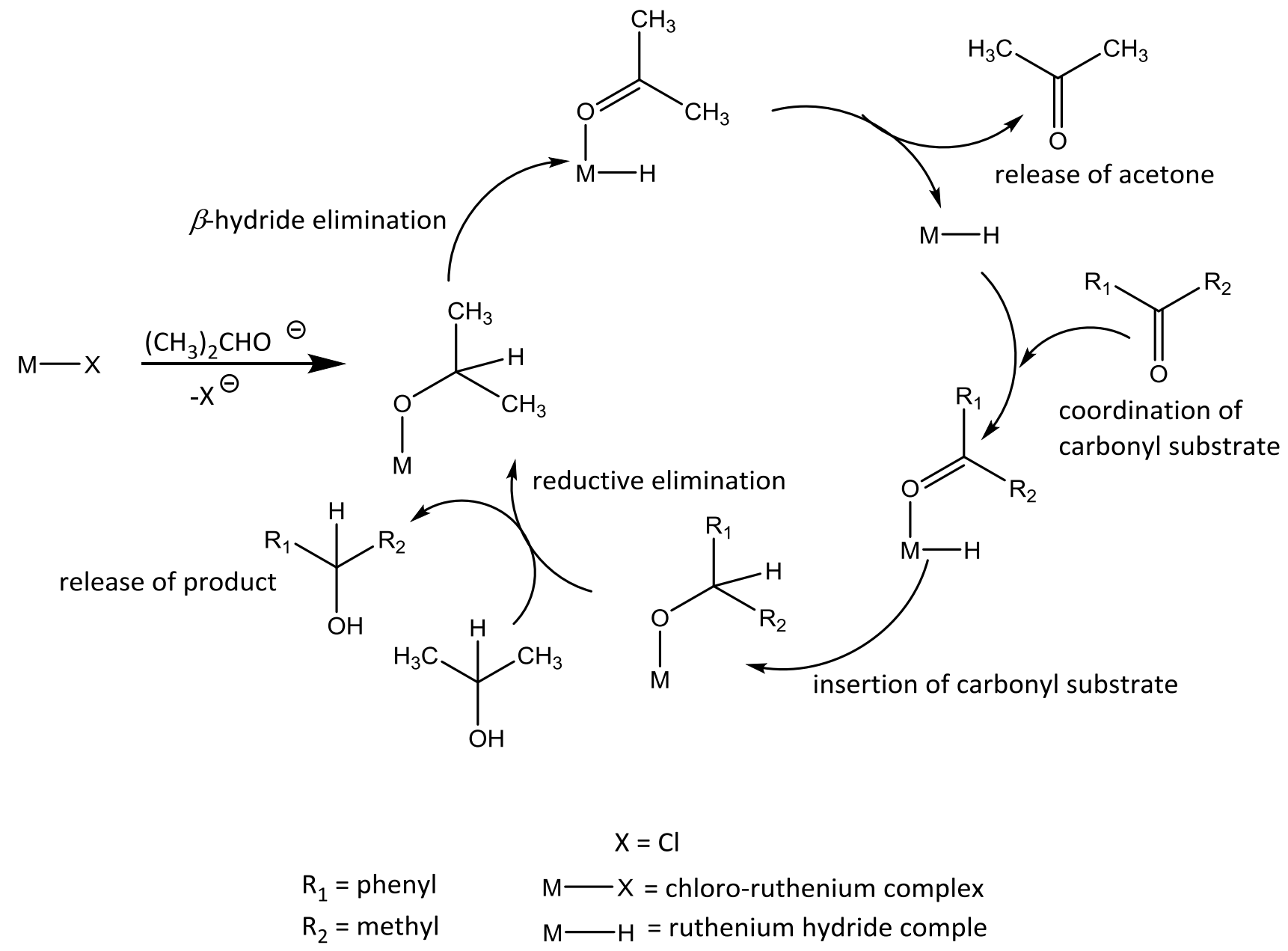

Scheme 1.11. Conventional mechanism of TH with IPA. ${ }^{26}$

The catalytic cycle of the TH reaction with IPA begins with base (KOH) deprotonation of IPA forming the alkoxide intermediate which coordinates with the dechlorinated metal complex, initially a chloro-ruthenium complex. The 6 -hydride elimination reaction of the coordinated complex generates the ruthenium metal hydride species which coordinates to the carbonyl substrate. The carbonyl substrate is then inserted into the metal hydride complex via migratory hydride transfer onto the carbonyl carbon of the substrate forming the metal alkoxide complex. Protonation by the incoming hydrogen source releases the alcohol product and the metal 
complex via reductive elimination. The metal complex re-enters the catalytic cycle and regenerates the active metal hydride to begin another catalytic cycle. This mechanism has been reasonably explained by Noyori and co-workers, through a combination of known stoichiometry reactions where each elementary step has been well established with model compounds. ${ }^{26 a, 29}$

The mechanism involving formic acid as hydrogen donor with or without trimethylamine as a base has not been clearly stated. Many literature reports have shown the success of transfer hydrogenation with this hydrogen donor over a mild range of temperatures ( $\mathrm{rt}$ to $70{ }^{\circ} \mathrm{C}$ ) and using standard operating conditions. ${ }^{27}$ However, only a few reports have described the use of autoclaves, due to the large increases in reaction pressures observed from production of hydrogen gas and carbon dioxide at higher temperatures $\left(>125{ }^{0} \mathrm{C}\right) .{ }^{28}$ This decomposition of formic acid was also noted under catalytic conditions, and is inconsequential to the process, because the gaseous hydrogen generated does not participate in the alcohol formation. ${ }^{15 c}$ The reaction mechanism may be resolved through detailed mechanistic studies by deuterium labeling experiments involving formic acid/triethylamine as the hydrogen donor and solvent.

The excellent performance of Noyori's catalysts introduced a new mechanistic perspective, the outer-sphere mechanism in which the substrate does not interact with the metal center. ${ }^{26 a}$ This mechanism is described as a bifunctional metal-ligand mechanism and has been established for the ATH reactions with nitrogen containing ligands. This mechanism involves the critical participation of the ligand's basic amido group of the chiral rutheniumdiamine complex in the hydrogen atom transfer. ${ }^{29}$ 


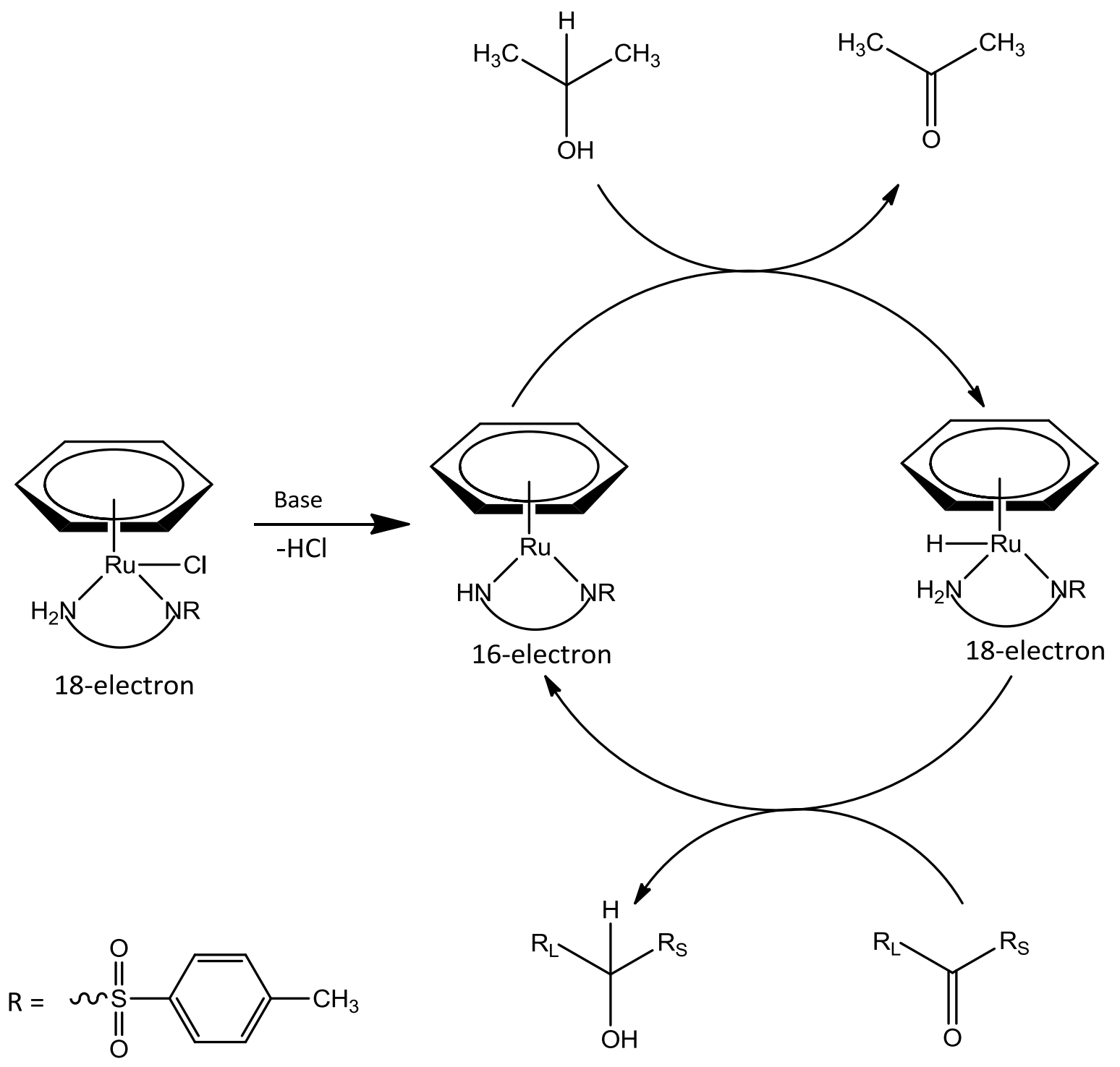

Scheme 1.12. ATH mechanism with chiral ruthenium-diamine catalyst complex. ${ }^{29}$

The critical role of the ligand amido group begins with the base initiated nucleophilic attack of the 18-electron ruthenium-diamine complex generating a 16-electron rutheniumamido complex. This step activates the amido nitrogen which is nucleophilic enough to deprotonate IPA with concomitant hydride transfer to the adjacent ruthenium metal center and reestablishes the 18-electron saturated complex. This reactive complex is activated via a highly ordered cyclic transition state with alternate charge distribution (Figure 1.3), which favors a 
concerted hydride transfer from the complex to the ketone substrate to afford the alcohol product and catalytic turnover. ${ }^{29}$ Moreover, this highly ordered cyclic transition state provides the platform for asymmetric induction. This is due to the chiral ruthenium-diamine complex which serves as the source of both the proton and hydride species, thereby allowing the prochiral ketone substrate to orient itself in its most energy minimal geometry in order to induce chiral recognition.

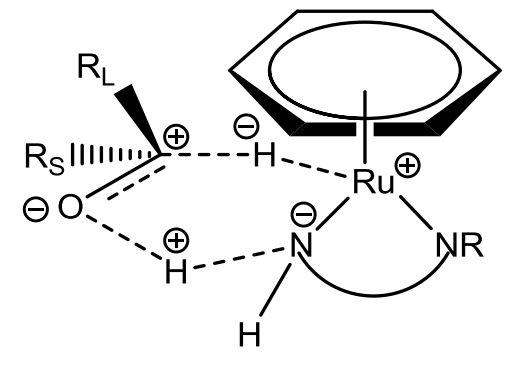

Favored transition state

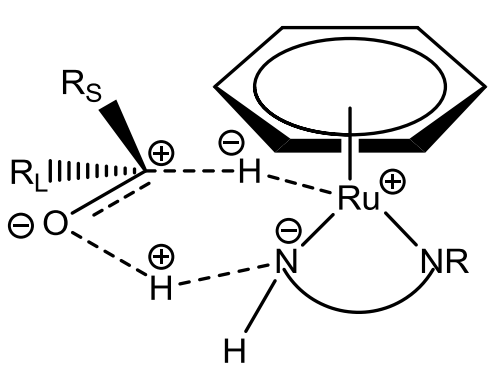

Unfavored transition state

Figure 1.3. Transition states representing chiral recognition in $\mathrm{ATH}^{29}$

\section{6: Ligands for ATH}

Over the years, chiral bidentate ligands with $C_{2}$-symmetry have provided excellent stereoselectivity in asymmetric hydrogenation and asymmetric transfer hydrogenation reactions. $^{30}$ These ligands are regarded as "privileged", because of their structural characteristics, such as, ease of modification and formation of rigid chiral pockets that facilitate the proximity of the substrate's prochiral center to the metal coordination site, thereby ensuring 
a strong metal substrate binding. The symmetry axes of these ligands create chiral fences around the metal center, thereby narrowing the path towards the metal center. This reduces the number of possible diastereomeric transition states, thus, enhancing asymmetric induction (Figure 1.4). Also, the metal-ligand complexes facilitate substrate-catalyst complex studies, thus, simplifying mechanistic and structure reactivity experiments. ${ }^{31}$ Chiral phosphine ligands remain popular in hydrogen atom transfer reactions, particularly $\mathrm{AH}$ involving gaseous hydrogen, with iridium, rhodium and ruthenium metal complexes. ${ }^{15 a}$ Chiral ligands containing nitrogen atoms, not phosphorus, are the most used in the field of ATH. This may be due to the less polarizable nature of the nitrogen atom compared to the phosphorus atom, and the ability of the nitrogen atom to localize electron density that may be involved in catalysis. For example, in the bifunctional metal ligand mechanism proposed by Noyori and co-workers, ${ }^{29}$ the critical role of the amido group can be ascribed to the nucleophilicity of the nitrogen atom through its ability to sustain the electron pair in the 16-electron intermediate complex (Scheme 1.12). This results in high catalytic activity as displayed by the chiral ruthenium-diamine complexes.

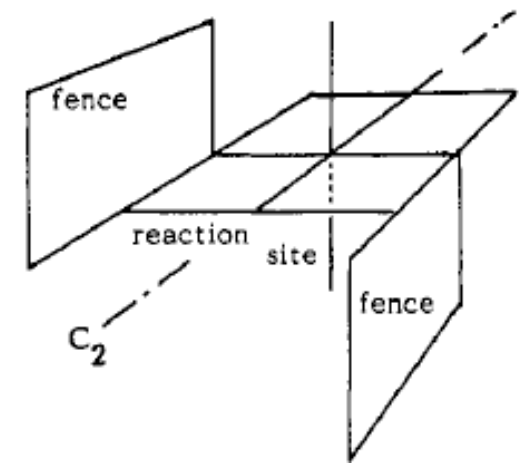

Figure 1.4. $C_{2}$-symmetry representation of privileged ligands. 

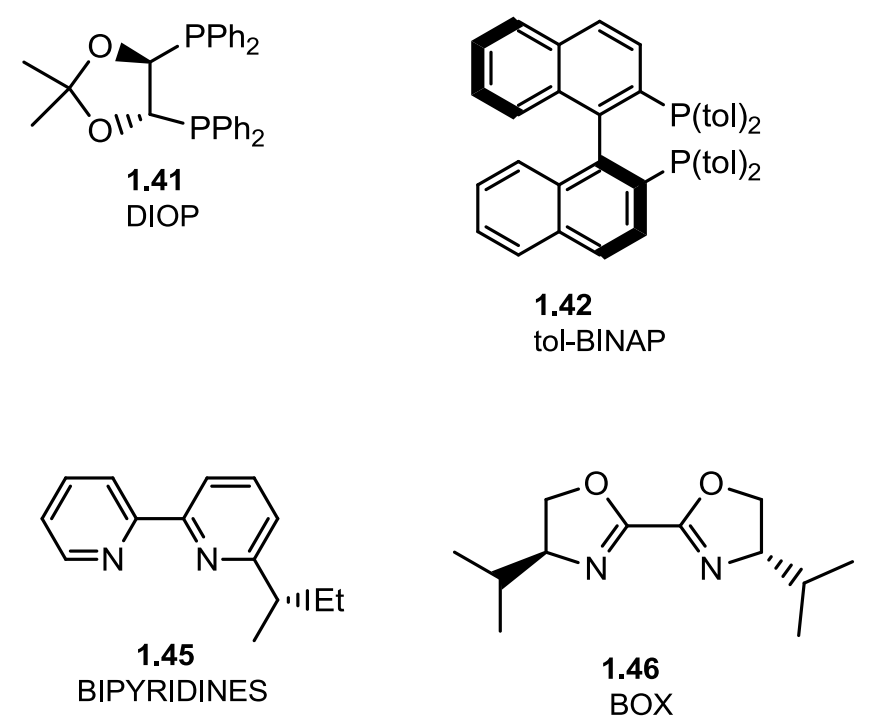
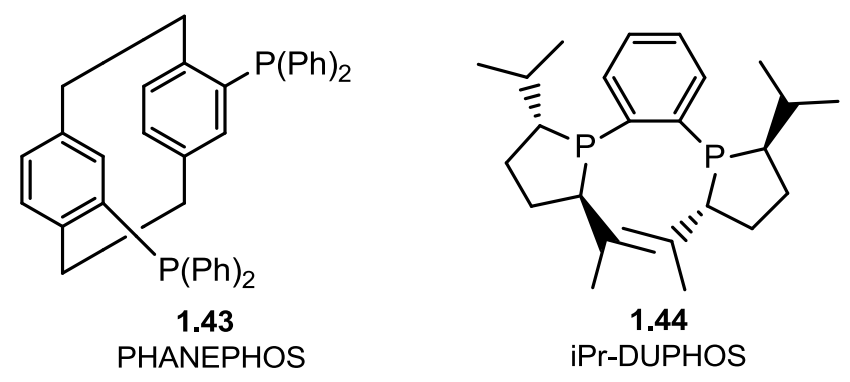

Figure 1.5. Examples of $C_{2}$ symmetrical ligands used for ATH.

\section{7: Catalytic Hydrogenation of Allylic Alcohols}

Hydrogenation of allylic alcohols often promotes formation of carbonyl compounds due to a thermodynamically favorable process that ensures almost exclusive formation of carbonyl compounds as products from allylic alcohols. ${ }^{32}$ This is because, the addition of a metal hydride to an allylic alcohol causes the transposition of the double bond and generates an enol intermediate which tautomerizes to a carbonyl. This process is energetically favored by about $125 \mathrm{~kJ} \mathrm{~mol}^{-1}$ due to the relative strengths of the $\mathrm{C}-\mathrm{C}$, and $\mathrm{C}=\mathrm{O}$ bonds formed in the product compared to the $\mathrm{C}-\mathrm{O}$, and $\mathrm{C}=\mathrm{C}$ bonds of the reactant. ${ }^{33}$ Rhodium, iridium and ruthenium catalysts are suitable DH catalysts for carbonyl compounds, and have been shown to cause 
further reduction of the carbonyl compounds generated from primary allylic alcohols under gaseous hydrogenation reactions. In this way, a straightforward access to saturated alcohols is possible with these catalysts, particularly, ruthenium complexes.

Many investigations reporting the hydrogenation of allylic alcohols have been carried out with cyclic and acyclic allylic systems, particularly, geraniol with various transition metals including rhodium, iridium and ruthenium catalysts. The development of chiral rutheniumBINAP catalysts has made reduction of primary allylic alcohols possible under asymmetric gaseous hydrogenation with high efficiencies (Scheme 1.13). These reactions have led to both applications in the synthesis of fragrances and vitamins. ${ }^{34}$

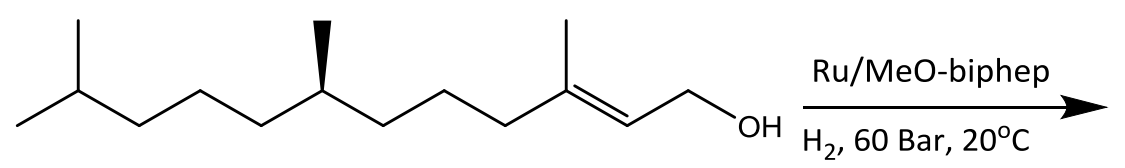

1.48

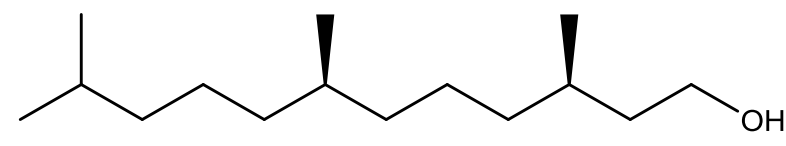

1.49

Precursor to Vitamin E (Tocopherol) side chain

Scheme 1.13. Asymmetric hydrogenation of a chiral allylic alcohol, 1.49. ${ }^{34}$

Preliminary mechanistic studies have suggested a two-point binding of the ruthenium complex to the allylic substrate involving coordination of the hydroxyl oxygen and the alkenyl moiety to the metal complex, leading to high stereoselectivity, with the $\operatorname{Ru}(\mathrm{BINAP})(\mathrm{OAc})_{2}$ catalyst. $^{34 b}$ Complexes of iridium containing P,N ligands have also shown similar selectivity. ${ }^{34 a}$ 


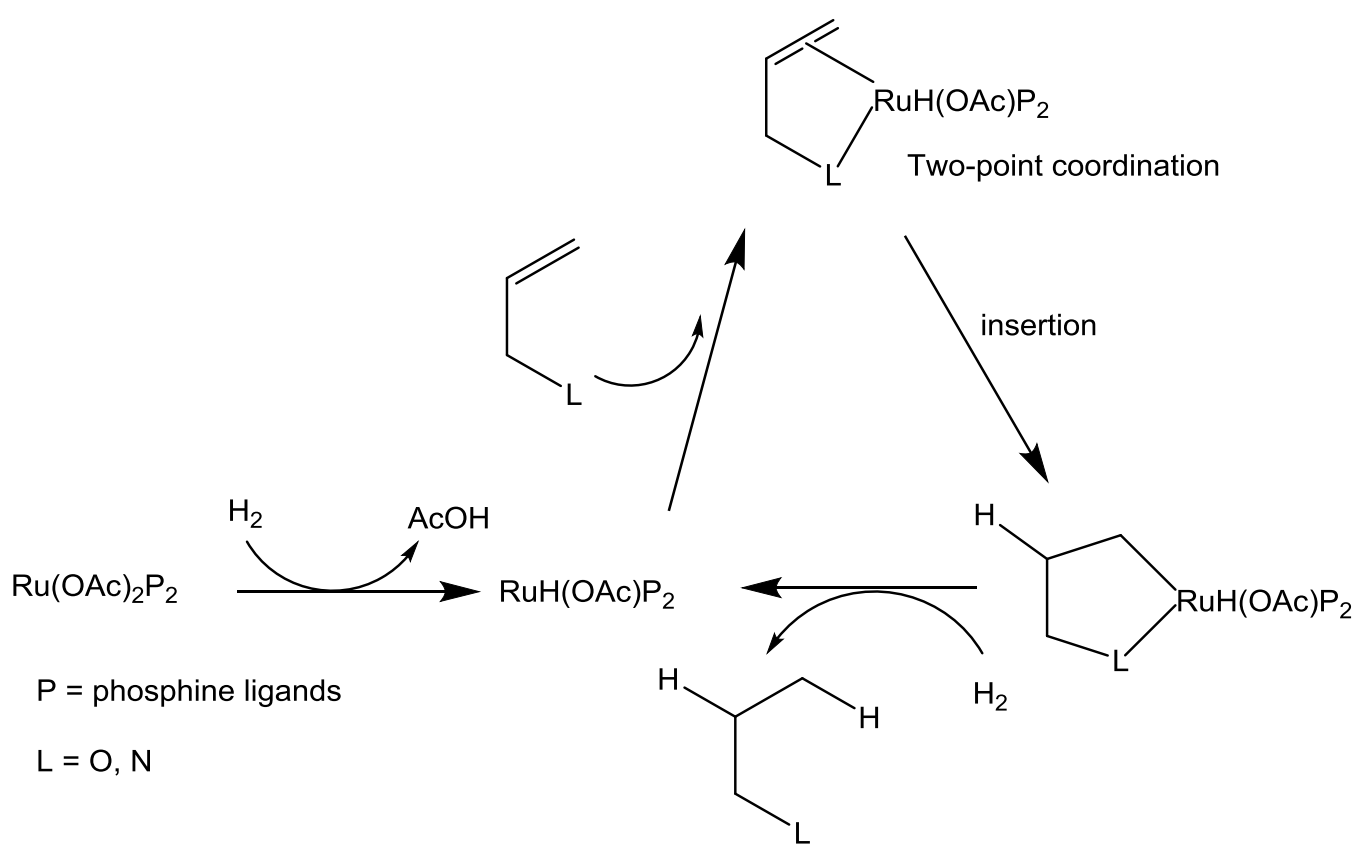

Scheme 1.14. Two-point binding of ruthenium complex to allylic substrate. ${ }^{34 b}$

Geraniol, a primary allylic alcohol, gives (S) or (R)-citronellol in nearly quantitative yields with excellent enantioselectivity (97\%ee) on the reduction of the allylic double bond without affecting the double bond at the $C_{6}$ and $C_{7}$ positions of the substrate. ${ }^{35}$ This reduction requires high hydrogen pressures in order to obtain high enantioselectivities, as low pressure causes racemization of the product.
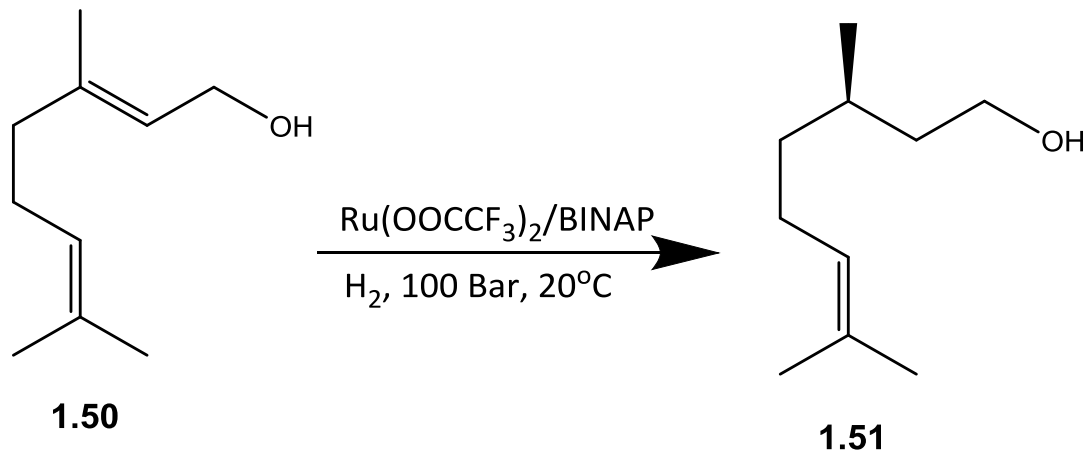

$97 \%$ ee

Scheme 1.15. Asymmetric hydrogenation of geraniol. ${ }^{35}$ 


\section{8: Conclusions}

Hydrogenation of unsaturated organic compounds is an important fundamental reaction in organic chemistry. Of the two strategies used for hydrogenation, TH and ATH have been established as essential classes of reactions in modern synthetic chemistry. This is due to their operational simplicity, safety and green chemistry advantages. With the advances in the design and synthesis of more homogeneous catalysts and controllable reaction variables and conditions, the field of ATH has evolved into a powerful research area and safe alternative to the gaseous AH. The widening scope of ATH and its tolerance of other functional groups in a variety of organic solvents have made it a choice reaction in the asymmetric synthesis of bioactive compounds and functional materials.

\section{References}

1. (a) Rylander, P. N. "Hydrogenation and Dehydrogenation" in Ullmann's Encyclopedia of Industrial Chemistry, Wiley-VCH, Weinheim, 2005. (b) Wisniak, J. Ind. J. Chem. Tech., Vol. 12, 2005, 232-243.

2. (a) Cerveny, L., Ed. Catalytic Hydrogenation; Elsevier: Amsterdam, 1986. (b) de Vries, J. G., Elsevier, C. J., Eds. The Handbook of Homogeneous Hydrogenation; Wiley-VCH: Weinheim, 2007. (c) Andersson, P. G., Munslow, I. J., Eds. Modern Reduction Methods; Wiley-VCH Verlag GmbH \& Co. KGaA: Weinheim, 2008.

3. Wang, D., Astruc, D. Chem. Rev. 2015, 115, 6621-6686.

4. Brieger, G.; Nestrick, T. J. Chem. Rev. 1974, 74, 567-580. 
5. Barrero, A. F., Oltra, J. E., Cuerva, J. M. and Rosales, A. J. Org. Chem., 2002, 67, 2566-2571.

6. (a) Cannizzaro, S. Liebigs Annalen, 1853, 88, 129-130. (b) Tishchenko, V. J. Russ. Phys. Chem. Soc, 1908, 38, 355-402.

7. Palmer, M. J. and Wills, M. Tetrahedron: Asymmetry, 10, 1999, 2045-2061.

8. Knoevenagel, E.; Bergdolt, B. Chem. Ber. 1903, 36, 2857-2860.

9. (a) Wieland, H. Chem. Ber. 1912, 45, 484-493. (b) Verley, A. Bull. Soc. Chim. Fr. 1925, 37, 537 -542. (c) Meerwein, H.; Schmidt, R. Liebigs Ann. Chem. 1925, 444, 221-238. (d) Ponndorf, W. Angew. Chem. 1926, 39, 138.

10. Braude, E. A.; Linstead, R. P. J. Chem. Soc. 1954, 3544-3547.

11. (a) Wang, C.; Wu, X.; Xiao, J. Broader, Chem. Asian. J. 2008, 3, 1750-1770. (b) Gladiali, S.; Alberico, E. Chem. Soc. Rev. 2006, 35, 226-236.

12. (a) Hashiguchi, S.; Fujii, A.; Takehara, J.; Ikariya, T.; and Noyori, R. J. Am. Chem. Soc. 1995, 117, 7562-7563. (b) Everaere, K.; Mortreux, A.; Adv. Synth. Catal. 2003, 345, 67-77. (c) Ikariya, T.; Blacker, A. J. Acc. Chem. Res. 2007, 40, 1300-1308.

13. Kindler, K and Luhrs, K. Liebigs Ann. Chem., 1965, 685, 36.

14. Scribe, P. and Pallaud, R., Chem. Rev. Acad. Sci., 1963, 256, 1120.

15. (a) Zassinovich, G.; Mestroni, G.; Gladiali, S. Chem. Rev. 1992, 92, 1051-1069. (b) Noyori, R.; Hashiguchi, S. Acc. Chem. Res. 1997, 30, 97-102. (C) Fujii, A.; Hashiguchi, S.; Uematsu, N.; Ikariya, T. and Noyori, R. J. Am. Chem. Soc. 1996, 118, 2521-2522.

16. (a) Mao, J.; Wan, B.; Wu, F. and Lu, S. Tetrahedron Letters, 2005, 46, 7341-7344. (b) Li, X.; Wu, X.; Chen, W.; Hancock, F. E.; King, F. and Xiao, J. Org. Lett., 2004, 6, 3321-3324.

17. Noyori, R. and Hashiguchi, S. Acc. Chem. Res. 1997, 30, 97-102.

18. Atkins, H.; Richards, L. M. and Davis, J. W. J. Am. Chem. Soc., 1941, 63, 1320.

19. Chowdhury, R.; Bäckvall, J. J. Chem. Soc., Chem. Commun. 1991, 1063-1064.

20. Carrion, M. C.; Sepulveda, F.; Jalon, F. A. and Manzano, B. R. Organometallics, 2009, 28, 3822-3833.

21. (a) Chuah, G. K.; Jaenicke, S.; Zhu, Y. Z.; Liu, S. H. Curr. Org. Chem. 2006, 10, 1639-1654. (b) de Graauw, C. F.; Peters, J. A.; van Bekkum, H.; Huskens, J. Synthesis, 1994, 10, 1007-1017. (c) 
Evans, D.; Nelson, S.; Gagne, M.; Muci, A. J. Am. Chem. Soc. 1993, 115, 9800. (d) Cohen, R.; Graves, C. R.; Nguyen, S. T.; Martin, J. M. L.; Ratner, M. A. J. Am. Chem. Soc. 2004, 126, 1479614803.

22. (a) Haddad, Y. M. Y.; Henbest, H. B.; Husbands, J.; Mitchell, T. R. Proc. Chem. Soc., 1964, 361 -365. (b) Trochagr, J.; Henbest, H. B. Chem. Commun. 1967, 544-544. (c) McPartli, M.; Mason, R. Chem. Commun. 1967, 545-546.

23. (a) Sasson, Y.; Blum, J. Tetrahedron Lett. 1971, 12, 2167-2170. (b) Blum, J.; Sasson, Y.; Iflah, S. Tetrahedron Lett. 1972, 13, 1015-1018. (c) Sasson, Y.; Blum, J. J. Org. Chem. 1975, 40, 1887 $-1896$.

24. (a) Doering, W. E.; Young, R. W. J. Am. Chem. Soc. 1950, 72, 631-631. (b) Bianchi, M.; Matteol, U.; Menchi, G.; Frediani, P.; Pratesi, U.; Piacenti, F.; Botteghi, C. J. Organomet. Chem. 1980, 198, 73-80. (c) Matteoli, U.; Frediani, P.; Bianchi, M.; Botteghi, C.; Gladiali, S. J. Mol. Catal. 1981, 12, 265-319.

25. Palmer, M. J. and Wills, M. Tetrahedron: Asymmetry, 10, 1999, 2045-2061.

26. (a) Noyori, R.; Yamakawa, M.; Hashiguchi, S. J. Org. Chem., 2001, 66, 7931-7944. (b) Mizushima, E.; Yamaguchi, M.; Yamagishi, T. Chem. Lett., 1997, 237.

27. (a) Murata, K.; Okano, K.; Miyagi, M.; Iwane, H.; Noyori, R.; Ikariya, T. Org. Lett., 1999, 1, 1119. (b) Yamada, I.; Noyori, R. Org. Lett., 2000, 2, 3425.

28. (a) Wagner, K. Angew. Chem. Int. Edit. 1970, 9, 50. (b) Watanabe, Y.; Ohta, T.; Tsuji, Y. Bull. Chem. Soc. Jpn. 1982, 55, 2441.

29. Yamakawa, M.; Ito, H. and Noyori, R. J. Am. Chem. Soc. 2000, 122, 1466-1478.

30. (a) Dang, T. P. and Kagan, H. B. J. Chem. Soc. D, 1971, 481-481. (b) Nishiyama, H.; Sakaguchi, H.; Nakamura, T.; Horihata, M.; Kondo, M. and Itoh, K. Organometallics, 1989, 8, 846-848.

31. (a) Seebach, D.; Beck, A. K.; Heckel, A. Angew. Chem. Int. Ed. 2001, 40, 92-138. (b) Katsuki, T. Synlett, 2003, 281.

32. (a) van der Drift, R. C.; Bouwman, E. and Drent, E. J. Organomet. Chem., 2002, 650, 1-24. (b) Uma, R.; Crevisy, C. and Gree, R. Chem. Rev. 2003, 103, 27-51.

33. Carey, F. A.; Sundberg, R. J.; Advanced Organic Chemistry. Part A: Structure and Mechanisms, Plenum Press, New York, 1991, p. 12. 
34. (a) Akutagawa, S. Top. Catal. 1997, 4, 271. (b) Tsuji, J.; Transition Metal Reagents and Catalysts; Innovations in Organic Synthesis, Wiley, 2002.

35. Takaya, H.; Ohta, T.; Sayo, N.; Kumobayashi, H.; Akutagawa, S.; Inoue, S.; Kasahara, I.; Noyori, R. J. Am. Chem. Soc., 1987, 109, 1596-1597. 


\section{Chapter Two: Accounts of Chemical Research from the Sowa Group on the ATH of Allylic Alcohols}

\section{1: ATH of primary allylic alcohols}

\subsection{1: Introduction}

The ATH reaction has emerged as a strong alternative to the gaseous $\mathrm{AH}$ reaction in the field of asymmetric synthesis. The methodology has been successfully applied to ketones, imines, heteroarenes and activated $\alpha, \beta$-unsaturated carbonyls of olefinic and acetylenic moieties in excellent yields and enantioselectivities. ${ }^{1}$ The advances in the design and synthesis of homogeneous catalyst complexes, particularly with the introduction of the Noyori-lkariya chiral ruthenium-diamine catalysts and many of their analogues have provided an extended repertoire of useful chiral alcohols. Moreover, the practical applications of the ATH reaction on industrial scales have made the methodology a powerful chemical process. ${ }^{2}$ However, the ATH appears to fall short in its applications to unsaturated compounds, such as the allylic alcohols, particularly, the secondary allylic alcohols. This is due to the perceived notion that the allylic bond is inactive towards reduction process involving transfer hydrogenation. ${ }^{4}$

It has been established from extensive studies conducted on catalytic hydrogenation of allylic alcohols with transition metals that the metal hydride species are the active catalytic components in the transformations of allylic alcohols into carbonyl compounds. ${ }^{3}$ This energetically favored transformation allowed the metal hydride to promote internal redox isomerization of the olefinic moiety of the allylic alcohol to form an enol intermediate which upon tautomerization affords the carbonyl compound (Scheme 2.1). This transformative 
process has been very successful with catalyst complexes of iron, rhodium and ruthenium metals. $^{4}$

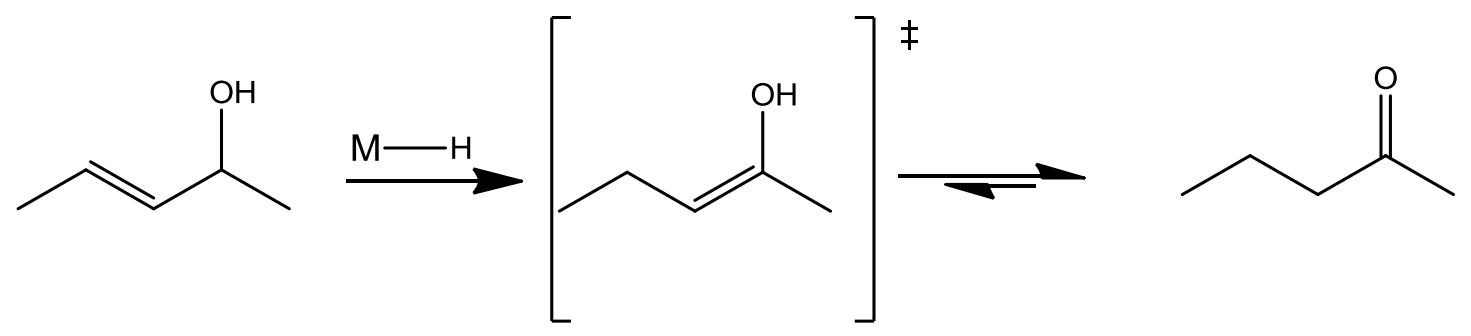

Scheme 2.1: Redox isomerization of allylic alcohol to carbonyl compound. ${ }^{3}$

Similarly, complexes of iridium, rhodium and ruthenium have been shown to reduce carbonyl compounds to their corresponding alcohols via the preformed or in situ generated metal hydrides. This process has been efficiently applied in transfer hydrogenation reactions using IPA as solvent and hydrogen source. ${ }^{3,5}$

Therefore, it is reasonable to hypothesize a one-pot, two-step process in which the catalytic activities of the metal hydride are effectively sustained under suitable reaction conditions. In this manner, effective reduction of the double bond and the carbonyl group occurs via transposition of the olefinic moiety (redox isomerization) and transfer hydrogenation of the carbonyl group, using IPA. This reaction mechanism was proven following the serendipitous discovery of the ATH reaction of allylic alcohols by the Sowa research group while investigating the effect of pressure changes on the $\mathrm{AH}$ of an allylic alcohol - geraniol.

The Sowa research group was able to demonstrate this hypothesis with an asymmetric induction using chiral ruthenium catalyst complexes and IPA. Enantioselection and good product 
yields were observed in the isomerization step of primary allylic alcohols, and in the transfer hydrogenation step of secondary allylic alcohols (Scheme 2.2). The reactions with the secondary allylic alcohols not only showed the possibility of the ATH reaction with allylic alcohols, but also pioneered an emerging methodology to optically active secondary alcohols made directly from racemic secondary allylic alcohols under mild reaction conditions. ${ }^{17}$
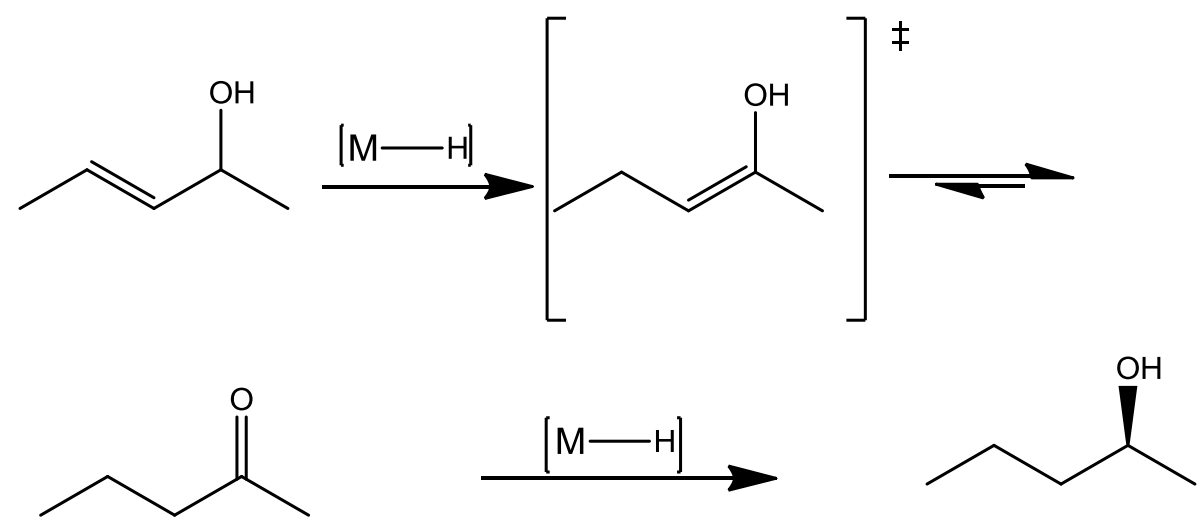

Scheme 2.2: Postulated reaction mechanism for the transformation of secondary allylic alcohols to their corresponding secondary alcohols.

\subsection{2: Isomerization-Hydrogenation mechanism - the discovery of ATH reaction}

\section{of allylic alcohols}

In 1995, the Sowa research group was prompted to understand the rationale for the observed effects of hydrogen gas pressure on the enantioselectivity of the hydrogenation of geraniol. In the studies conducted, a striking inversion of stereochemistry became evident in the formation of the hydrogenated products between the initial and final conversions of geraniol mediated by the (S)-dichlororutheniumtol-BINAP catalyst in methanol. A close monitoring of the 
reaction revealed an isomerization-hydrogenation mechanism (Scheme 2.3). ${ }^{6}$ The initial isomerization step involved an interconversion between the internal olefin in geraniol (2.1) and external olefin in $\gamma$-geraniol (2.2). This step was found to occur during the dissolution of the catalyst in a mixture of geraniol and methanol prior to the addition of hydrogen gas. This observation was rationalized by the confirmed presence of $y$-geraniol in the reaction mixture according to ${ }^{1} \mathrm{H}$ NMR spectrum. ${ }^{6 a}$ These prochiral olefin isomers then underwent hydrogenation reactions upon addition of hydrogen gas resulting in their respective citronellol isomers, 2.3, and, 2.4 (Scheme 2.3). ${ }^{6 a}$

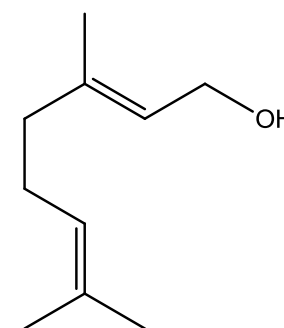

2.1
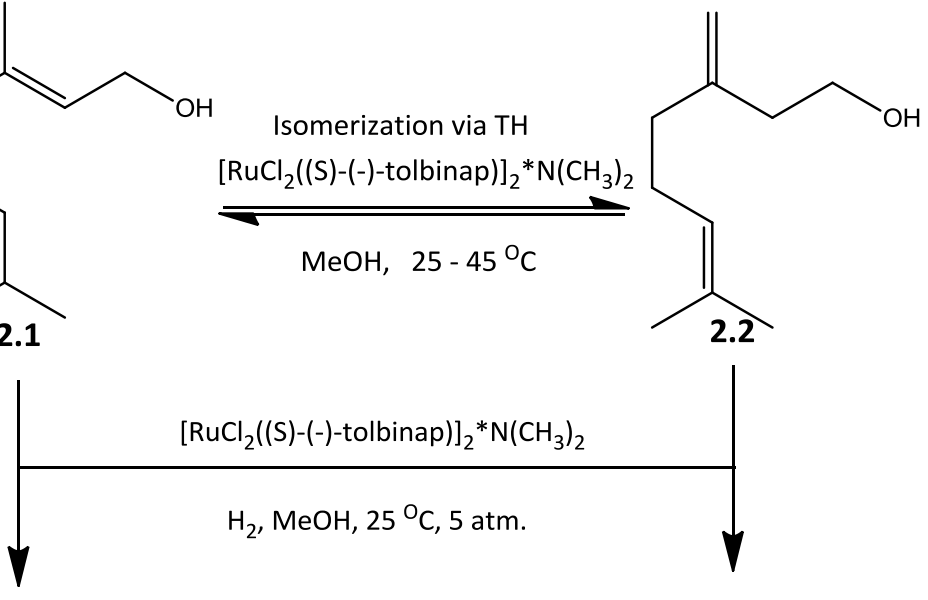

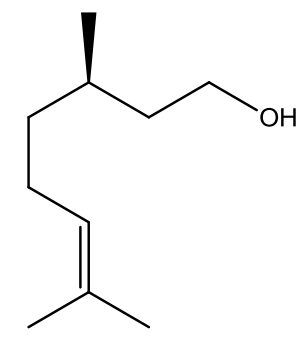

(R)-Citronellol

2.3

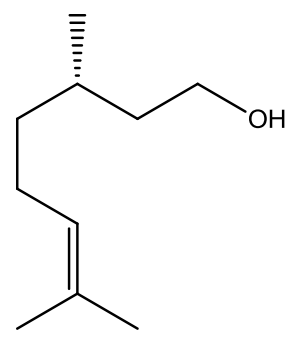

(S)-Citronellol

2.4

Scheme 2.3. Isomerization-hydrogenation mechanism. ${ }^{6 a}$ 
A temperature dependent study indicated an increase in the rate of isomerization reaction in between $25{ }^{\circ} \mathrm{C}$ and $45{ }^{\circ} \mathrm{C}$ with an increase in the concentration of $\mathrm{\gamma}$-geraniol during the isomerization of geraniol. This is consistent with literature reports which suggested that a strongly competitive isomerization reaction is typically unavoidable in this type of procedure. ${ }^{7}$ It has also been suggested that the competitive isomerization may be suppressed by high hydrogen pressures in order to increase enantioselectivity. ${ }^{8}$ The effect of isomerization between 2.1 and 2.2 indicated that the rates of the interconversion and subsequent hydrogenation are key variables in determining the stereochemical outcome of asymmetric hydrogenation of the allylic alcohol substrate - geraniol. ${ }^{6 a}$

Based on these results, the Sowa research group investigated the isomerization (equilibration) process by NMR and chiral HPLC techniques. These experiments were based on the hypothesis that the hydrogen atom was being transferred by an in situ generated ruthenium hydride catalyst dissolved in methanol. This isomerization step also occurred in other oxidizable alcohol solvents such as ethanol and IPA, but failed to occur in $t$-butanol and $t$-butanol/water combination. This indicated that the hydrogen atom alpha to the hydroxyl group was being transferred from the alcohol solvent to the ruthenium metal via thermal oxidation or by an auto-oxidation process, to generate the required ruthenium hydride. This can be rationalized by the proposed mechanism highlighted in Scheme $2.4 .^{6 \mathrm{~b}}$ This presumed mechanism was postulated to begin with thermal or auto-oxidation of ethanol (a), generating the ruthenium hydride which coordinates with geraniol (b) via the hydroxyl allylic olefin moiety. This is followed by migratory insertion of the hydride into the olefin moiety $(\mathbf{c})$. The 6 -elimination of the 
ruthenium metal via external methyl group releases -geraniol and regenerates ruthenium hydride which cycles back into the isomerization process (d).

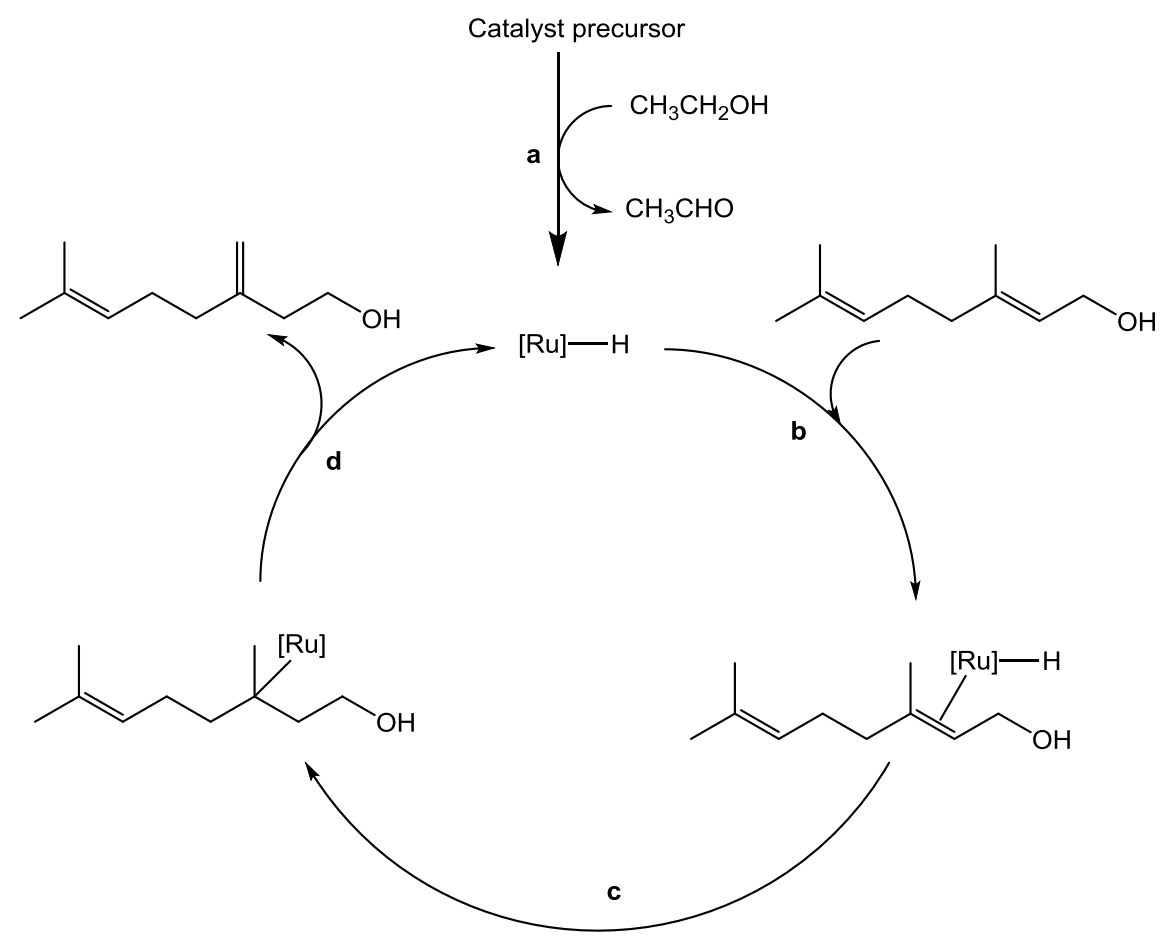

Scheme 2.4: Proposed mechanism for isomerization of geraniol to $\gamma$-geraniol. ${ }^{6 b}$

Moreover, a surprising result was obtained in an attempt to further understand the isomerization process in between geraniol and $\mathrm{\gamma}$-geraniol. (R)-Citronellol was unexpectedly formed in $50 \%$ ee and $27 \%$ yield, among other products, when a mixture of geraniol, alcohol solvent and the catalyst were stirred at $140{ }^{\circ} \mathrm{C}$ for 72 hours. Surprisingly, y-geraniol was not formed during this reaction process. This result ultimately changed the direction of the investigation. The formation of the optically active citronellol from geraniol indicated an 
enantioselective isomerization-transfer hydrogenation process, that is, an ATH reaction of the allylic alcohol - a process that until then had not before been reported in the literature. ${ }^{6 b}$

\subsection{3: The development of ATH reaction of allylic alcohols}

Prior to the discovery of the ATH reaction of allylic alcohols by the Sowa group, allylic alcohols were considered inactive towards reduction reactions involving transfer hydrogenation procedures. ${ }^{4}$ Although some research was attempted with homogeneous and heterogeneous catalysts, ${ }^{9}$ no literature reports described transfer hydrogenation of allylic alcohols at the time. Thus, it became imperative to carefully study the key reaction parameters for the development and optimization of the ATH reaction of allylic alcohols using geraniol as a model substrate.

The notable hydrogen atom donors and solvents in the ATH reactions, such as IPA and formic acid, are cheap and readily available. ${ }^{10}$ Moreover, IPA is a safer, non-toxic and environmentally benign choice, however, it has an unfavorable thermodynamic equilibrium associated with its by product - acetone. This has been shown to effect reactivity and selectivity in the ketone substrates. ${ }^{11}$ Nonetheless, the use of a large excess of solvent (IPA) can be employed to drive the equilibrium towards the desired product. In contrast, formic acid presents a better alternative to overcome the thermodynamic factors hindering the applications of IPA. However, the tendency of formic acid to decompose into hydrogen gas and carbon dioxide at elevated temperature results in elevated pressures which raises safety concerns. ${ }^{12}$ Although, this has been suggested to not be a limiting issue, ${ }^{13}$ IPA was chosen as hydrogen atom donor for the development of ATH reactions of allylic alcohols. 
Other alcohol compounds were examined as hydrogen atom donors and solvents, but IPA furnished better results (Table 2.1, entry 1 ).

Table 2.1. ATH of geraniol in different hydrogen donors/solvents. ${ }^{16}$

\begin{tabular}{|c|c|c|c|c|}
\hline Entry & H-atom Donor/Solvent & Temp. $\left({ }^{\circ} \mathrm{C}\right)$ & \% Conversion & ee $^{\mathrm{c}}(\mathrm{R})$ \\
\hline 1 & IPA & 100 & 100 & 98 \\
2 & 2-Pentanol & 100 & 84 & 77 \\
3 & 2-Pentanol & 120 & 100 & 72 \\
4 & (S)-2-Pentanol & 120 & 100 & 26 \\
5 & (R)-2-Pentanol & 120 & 100 & 72 \\
7 & Cyclohexanol $^{\mathrm{d}}$ & 100 & 74 & 66 \\
\hline
\end{tabular}

${ }^{\mathrm{a}}$ Reaction time was $2 \mathrm{~h}$. ${ }^{\mathrm{b}}$ Conversions measured by GC. ${ }^{\mathrm{C}}$ ee analysis measured with a RT-Beta

DEXsa $30 \mathrm{~m} \times 0.32 \mathrm{~mm}$ ID $\times 0.25 \mu \mathrm{m}$ GC Column. ${ }^{\mathrm{d}}$ Reaction time was $4 \mathrm{~h}$.

The long established efficiencies of the chiral ruthenium complexes in the $\mathrm{AH}$ and the ATH of ketones, along with the concept of bifunctional catalysis made the ruthenium metal well suited for the investigation of the ATH reactions of allylic alcohols. The ruthenium polymer $\left[\mathrm{Ru}(\mathrm{COD}) \mathrm{Cl}_{2}\right]_{\mathrm{n}}$ was chosen as the catalyst precursor and as a source of ruthenium because of its convenient reactivity in the formation of the pre-requisite metal-ligand complexes. Among the chiral bidentate ligands that were evaluated for the ATH of allylic alcohols, (S)-tol-BINAP, (R)BINAP and (S,S)-iPr-DUPHOS showed very high catalyst activity with the ruthenium polymer 
and yielded complete conversion of geraniol and significant enantioselectivities (up to $98 \%$ ee) of the desired product citronellol (Table 2.2, entry 5). The reaction was developed with (S)-tolBINAP, because it offered the best results in substrate conversion and \% ee.

Table 2.2. ATH of geraniol with different chiral ligands. ${ }^{16}$

\begin{tabular}{|c|c|c|c|c|}
\hline Entry & Ligand & Time (h) & $\begin{array}{c}\% \text { Citronellol }^{a} \\
\left(\% \text { Conversion }{ }^{a}\right)\end{array}$ & $\begin{array}{l}\% \text { ee }{ }^{b} \\
\text { (Configuration) }\end{array}$ \\
\hline 1 & $(S, S)-D I O P$ & 20 & $31(38)$ & 0 \\
\hline 2 & (S)-PHANEPHOS & 29 & $20(24)$ & $9, R$ \\
\hline 3 & (S)-Me DUPHOS & 2 & $80(92)$ & $75, \mathrm{R}$ \\
\hline 4 & $(S, S)-E t$ BPE & 2 & $56(80)$ & $31, \mathrm{R}$ \\
\hline 5 & (S)-tol-BINAP & 2 & $98(100)$ & $98, \mathrm{R}(78 \%)^{\mathrm{c}}$ \\
\hline 6 & (R)-BINAP & 2 & $92(100)$ & $87, \mathrm{~S}$ \\
\hline 7 & $(\mathrm{~S}, \mathrm{~S})$-iPr DUPHOS & 2 & $50(100)$ & $84, \mathrm{R}$ \\
\hline $8^{c}$ & $(\mathrm{~S}, \mathrm{~S})$-iPr DUPHOS & 24 & $98^{d}(100)$ & $90, R^{d}$ \\
\hline
\end{tabular}

${ }^{a}$ Conversions and yields measured by GC. ${ }^{b}$ ee analysis measured on the (R)-Mosher ester on a Chiralcel OJ-H column (Daicel, $250 \mathrm{~mm} \times 4.6 \mathrm{~mm}$ ). ${ }^{\mathrm{C}} 78 \%$ isolated yield by column chromatography. ${ }^{d}$ Yield and ee of dihydrocitronellol, \{geraniol-Ru(COD) $\left.\mathrm{Cl}_{2}\right]_{n}-\mathrm{KOH}$-ligand molar ratio $=2 / 1 / 2 / 2\}$

Backvall and Chowdhury had shown the importance of a base $(\mathrm{NaOH}, \mathrm{KOH})$ in increasing the rate of isomerization of allylic alcohols to carbonyl compounds. ${ }^{14}$ Noyori and co-workers also established the requirement of strong inorganic mineral bases as co-catalysts in the various 
ATH reactions of ketones and imines. ${ }^{10}$ The base thus plays a critical role in the pre-activation of the catalyst, therefore, the presence of a base as reaction promoter for the ATH reaction of allylic alcohols was also examined. A two equivalent amount of $\mathrm{KOH}$ per Ru was found to be optimal, and lower amounts compromised reaction conversions and enantioselectivities.

Other reaction parameters that were examined included the reaction temperature, substrate/catalyst ratio and the reaction sensitivity to air and moisture. A temperature of 100 ${ }^{0} \mathrm{C}$ was selected for a $2 \mathrm{~h}$ reaction. Slightly lower temperatures of $83{ }^{\circ} \mathrm{C}$ were later determined to be optimum for the reaction.

The substrate/catalyst (S/C) ratio was optimized at 10/1, which was found to enhance complete conversion of the substrate, while facilitating the purification of the product. This reaction was also found to be very sensitive to air and moisture, which led to the use of freezepump-thaw degassing procedures which protected the reaction from oxygen and water.

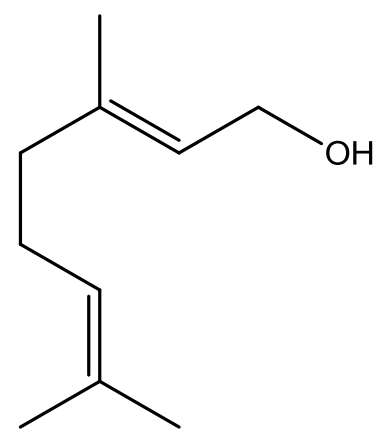

2.1

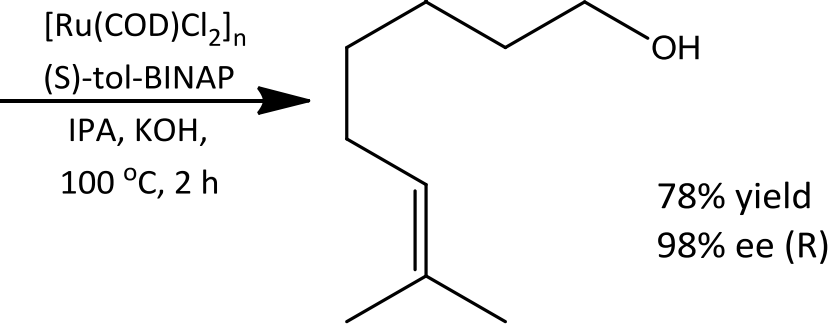

2.3

Scheme 2.5. ATH reaction of geraniol under optimized conditions. ${ }^{6 b}$ 
The ATH reaction of geraniol was later optimized with respect to the cocktail catalytic conditions. In this case, all the reacting species were added together and degassed through cycles of freeze-pump-thaw process before heating at $100{ }^{\circ} \mathrm{C}$ for $2 \mathrm{~h}$ (Scheme 2.5)..$^{6 \mathrm{~b}}$

An extension of this reaction to the Z-isomer of geraniol, nerol, gave $100 \%$ conversion and $70 \%$ yield of the isolated product, $\mathbf{2 . 8},(\mathrm{S})$ - citronellol in $93 \%$ ee.

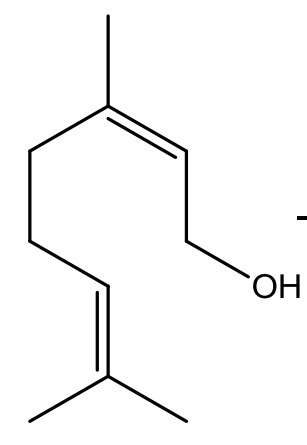

2.5

\section{$\left[\mathrm{Ru}(\mathrm{COD}) \mathrm{Cl}_{2}\right]_{\mathrm{n}}$} (S)-tol-BINAP IPA, $\mathrm{KOH}$, $100^{\circ} \mathrm{C}, 2 \mathrm{~h}$

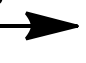

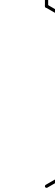

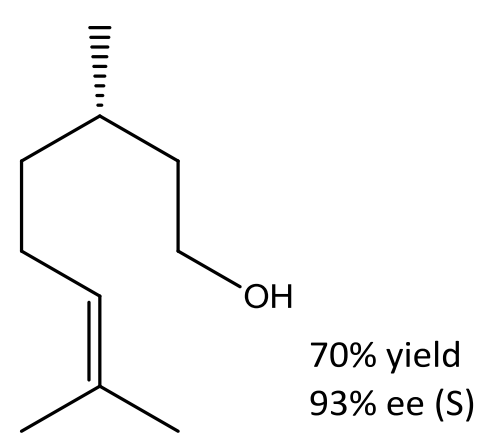

2.6

Scheme 2.6. ATH reaction of nerol under optimized conditions. ${ }^{6 b}$

Similarly, the use of 3-phenyl-2-buten-1-ol under these reaction conditions afforded 99\% yield and $72 \%$ ee of $\mathbf{2 . 8}$, in $12 \mathrm{~h}$.

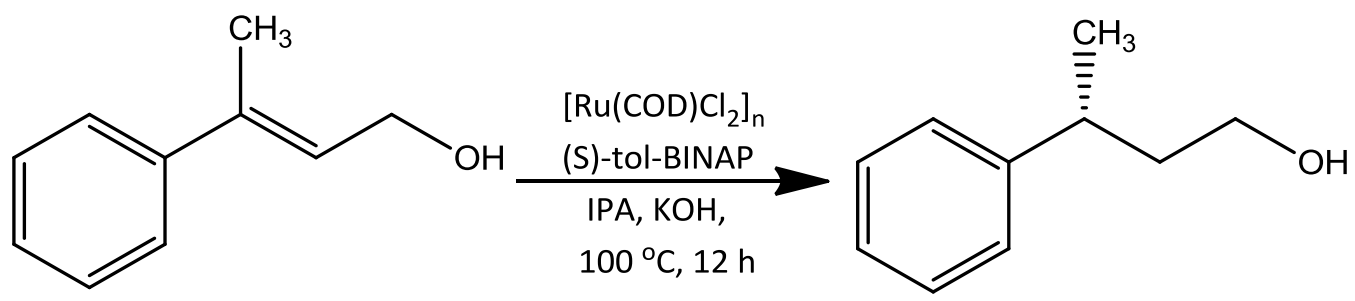

2.7

Scheme 2.7. ATH reaction of 3-phenyl-2-buten-1-ol, 2.9, under optimized conditions. ${ }^{6 b}$ 
Attempts at extending this reaction to $\gamma$-geraniol and $\alpha, \beta$-unsaturated ketones gave very low yields and enantioselectivities, even at higher catalyst or base concentration. ${ }^{6 b, 16}$ In contrast, gaseous hydrogenation of these substrates have afforded better results, ${ }^{15}$ this suggests that the ATH reaction of the allylic alcohols is operating under a specific mechanism which differs from the classical $\mathrm{AH}$. This mechanism was investigated and published by the Sowa group in $2012 .{ }^{16}$ To evaluate the performance of this ATH reaction, studies were also conducted with commercially available pure catalyst - [(S)-tol-BINAP]Ru(II)Cl $\mathrm{Cl}_{2}(\mathrm{p}$-cymene)]. Here, the reaction was efficient at a higher substrate concentration and a lower temperature of $83{ }^{\circ} \mathrm{C}$ affording a high yield and enantioselectivity.

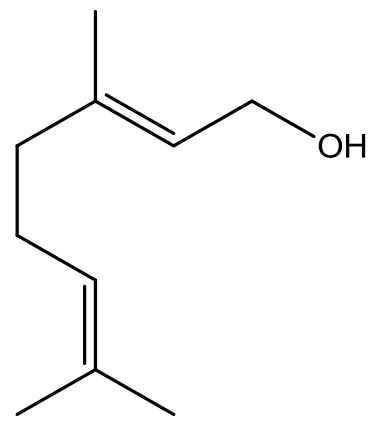

2.1

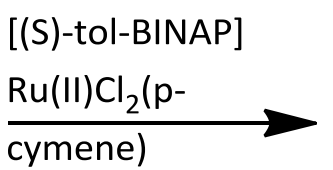

IPA, $\mathrm{KOH}, 83^{\circ} \mathrm{C}$

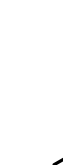

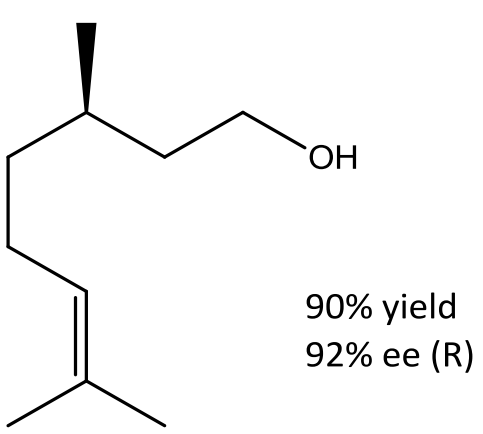

2.3

Scheme 2.8. ATH reaction of geraniol using commercial catalyst complex. ${ }^{16}$

\subsection{4: Mechanistic Studies of ATH of allylic alcohols}

Considering that only a few literature reports of asymmetric isomerization of allylic alcohols exists, ${ }^{4}$ mechanistic studies of the ATH reaction of allylic alcohols were carefully performed by the Sowa group to ascertain the mechanism of reaction. 
In the initial experiment conducted without IPA, the substrate geraniol served as the solvent and the hydrogen atom donor with $47 \%$ conversion, affording the hydrogenated product citronellol (13\%) 2.9, along with citronellal (21\%) 2.10 and citral (13\%) 2.11 . Interestingly, $y$-geraniol was not formed, an indication that equilibration between geraniol and $\gamma$-geraniol did not occur at this elevated temperature. ${ }^{6 b}$ Based on the isolated yields, citronellal was considered a reaction intermediate, as documented in literature reports on the transposition of allylic alcohols to carbonyl compounds. ${ }^{4}$

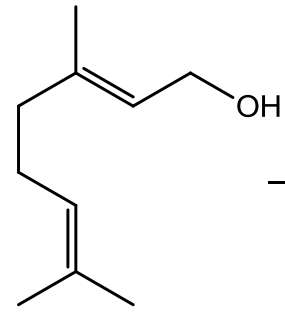

2.1

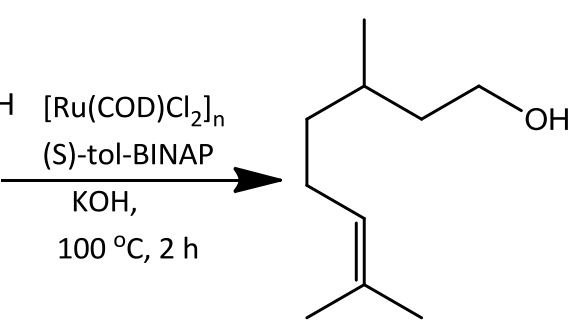

2.9

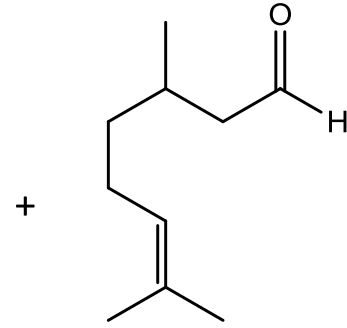

2.10

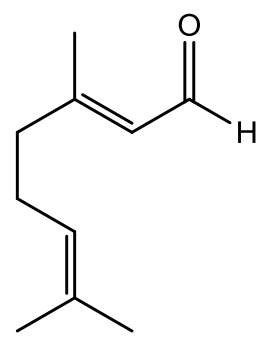

2.11

Scheme 2.9. ATH of geraniol without IPA. ${ }^{16}$

Subsequent deuterium labelling experiments were conducted with $\mathrm{d}_{8}$ IPA and confirmed the formation of $d_{3}$-citronellol as the major product, with $m / z$ of 159 , according to GC/MS. ${ }^{1} \mathrm{H}$ NMR indicated one proton on $\mathrm{C}_{1}$ and two deuterium atoms on $\mathrm{C}_{2}$, which was also confirmed according to ${ }^{13} \mathrm{C}$ NMR and HMQC analyses. This demonstrated that a different reaction mechanism other than the conventional mechanism of direct hydrogenation occurred in the ATH reaction of allylic alcohols. ${ }^{3,4}$ 


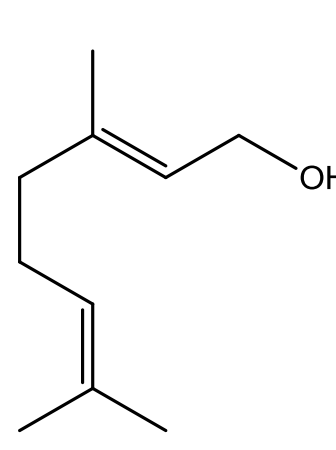

2.1

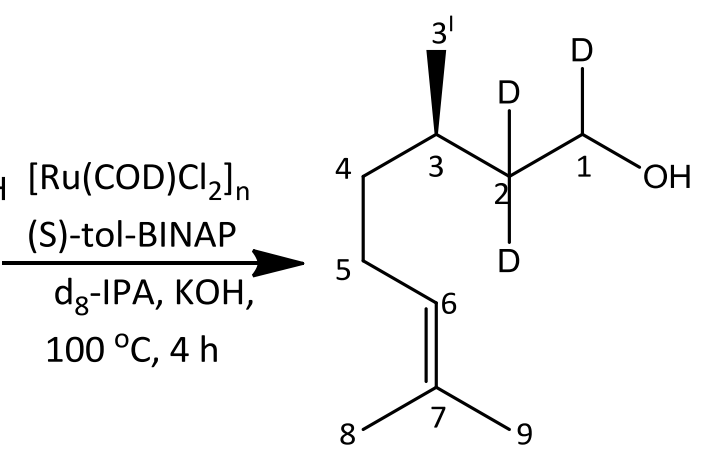

2.12

Scheme 2.10. ATH reaction of geraniol with deuterated IPA. ${ }^{16}$

Further studies with mono deuterated IPA (iPrOD), showed $d_{2}$-citronellol as the major product with $\mathrm{m} / \mathrm{z}$ of $158 .{ }^{1} \mathrm{H} \mathrm{NMR}, \mathrm{COSY}$ and ${ }^{13} \mathrm{C}$ - DEPT 135 experiments also showed no hydrogen atoms on $C_{2}$, with clear coupling between the $C_{2}$ and the deuterium atoms. This indicated that hydrogen atoms were being transferred from IPA to geraniol in the ATH reaction.

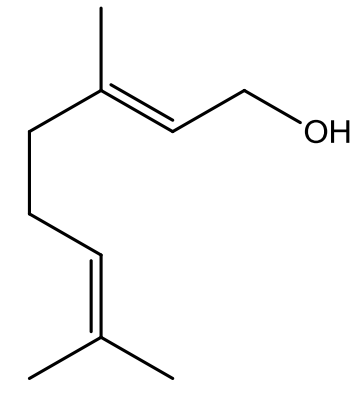

2.1
[(S)-tol-BINAP] $\mathrm{Ru}(\mathrm{II}) \mathrm{Cl}_{2}$ (p-cymene)

iPrOD, $\mathrm{KOH}, 83^{\circ} \mathrm{C}$
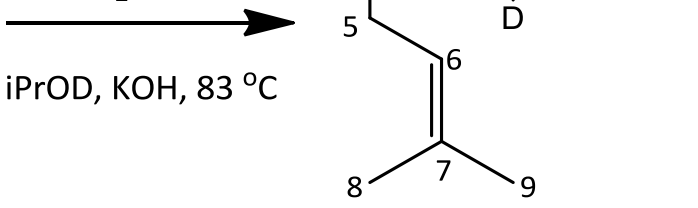

2.13

Scheme 2.11. ATH reaction of geraniol with mono deuterated IPA. ${ }^{16}$

A clearer perspective of the mechanism emerged from the experiment with deuterated geraniol which showed the relocation of deuterium atom from $C_{1}$ to $C_{3}$, in one of the mixed 
deuterated citronellol products. Although, GC/MS analysis showed an $\mathrm{m} / \mathrm{z}$ of 157 for the deuterated citronellol mixture, the identity of the second compound was confirmed by NMR experiments. ${ }^{2} \mathrm{H}$ NMR established the presence of a deuterium atom on $\mathrm{C}_{3}$. This strongly confirmed that a 1,3-hydride shift was occurring in the reaction mechanism.

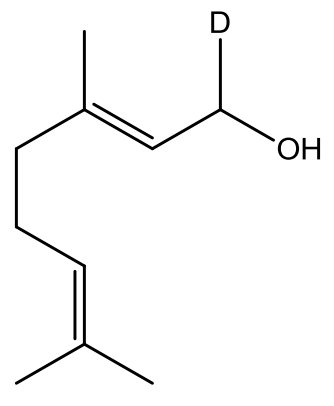

2.14

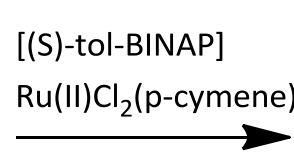

IPA, $\mathrm{KOH}, 83^{\circ} \mathrm{C}$

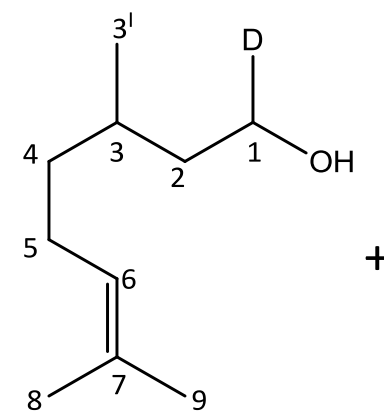

2.15

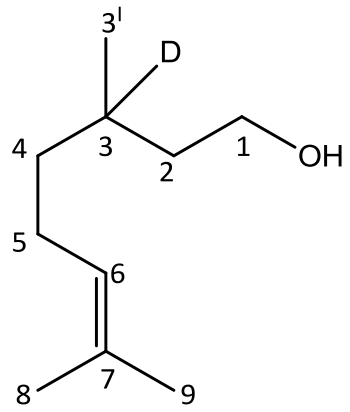

2.16

Scheme 2.12. ATH reaction of deuterated geraniol. ${ }^{16}$

Based on these results, a mechanistic pathway was proposed for the ATH reduction reaction of allylic alcohols as highlighted in Scheme $2.13 .{ }^{16}$ This mechanism begins with base initiated generation of the allylic alkoxide (b) which coordinates to the metal (a-c). This is followed by a 1,3-hydride shift, that generates an enol which tautomerizes to a carbonyl intermediate $(\mathbf{d}-\mathbf{g})$, followed by hydrogen atom transfer to generate the alcohol (h-i). 


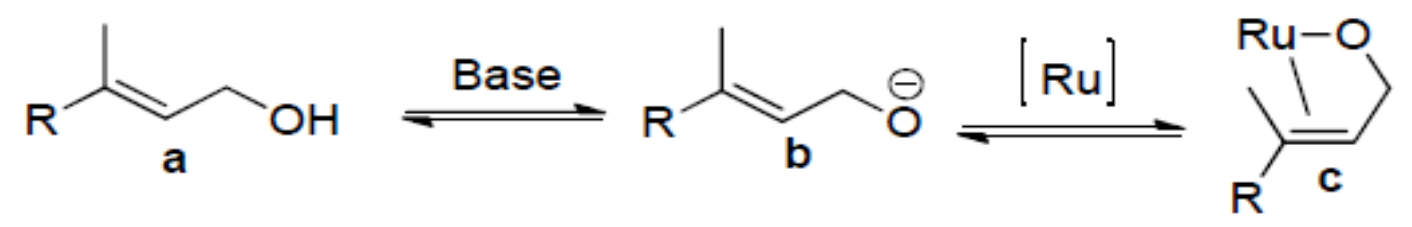

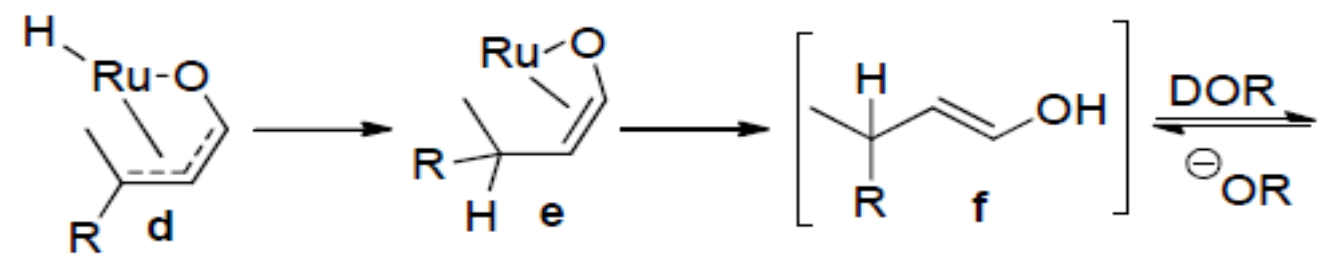

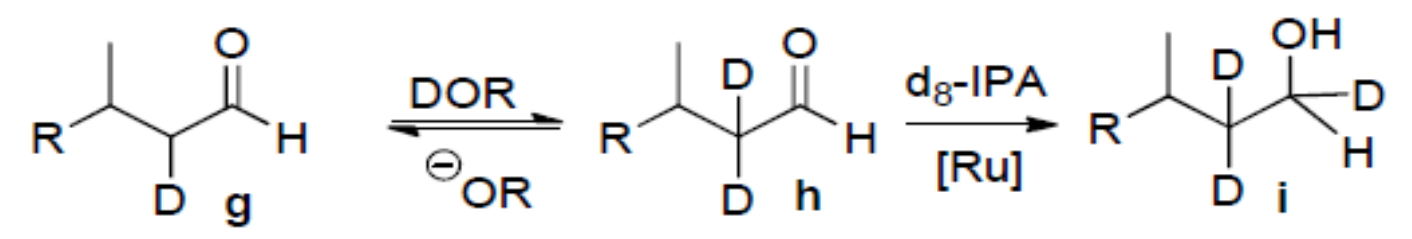

Scheme 2.13. Proposed mechanism of ATH reaction of primary allylic alcohols. ${ }^{16}$

\subsection{5: Summary and Outlook}

The ATH reaction of allylic alcohols and a thorough understanding of its mechanism of reaction using geraniol as model substrate was successfully developed in our laboratory. This reaction method afforded good yields and enantioselectivity, while promising in scope and versatility for a broad range of secondary allylic alcohols. The mechanism of the reaction was carefully investigated and found to involve an initial 1,3-hydride shift, which caused the transposition of the allylic double bond to generate a carbonyl intermediate via enol tautomerization. The carbonyl intermediate reacted further by the active metal hydride (innersphere) to afford the alcohol product. This mechanism is described as an enantioselective isomerization/transfer hydrogenation reaction, which translated into an efficient ATH reaction method. 
Following these successful studies, our research group was prompted to apply the ATH reaction to a broader range of secondary allylic alcohols, including the prochiral benzyl alcohols. Using an $\alpha$-vinyl benzylic alcohol as model substrate, my thesis objectives were based on the development of an efficient and enantioselective ATH reaction for this class of substrates (Scheme 2.14).

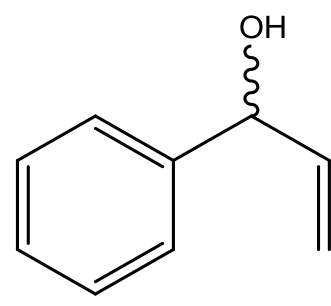

2.17

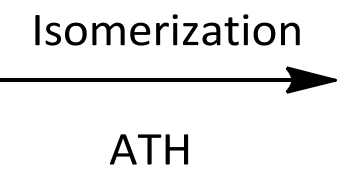

ATH

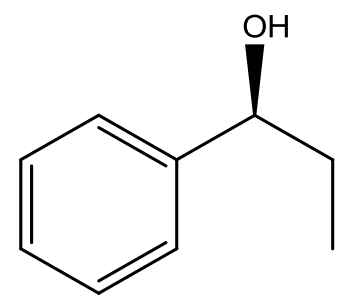

2.18

Scheme 2.14. Proposed model reaction for the ATH reaction of secondary allylic alcohols.

\subsection{Research objectives of ATH reaction of secondary allylic alcohols}

\subsection{1: Research objectives}

The ATH reaction has become an important synthetic tool and an increasingly attractive approach to the enantioselective reduction of unsaturated systems such as ketones, imines, olefins and heterocyclic aromatic compounds. Although, our laboratory has broadened the substrate scope of the ATH reaction with its application to geraniol; a primary allylic alcohol, the extension of this reaction to include another important class of the allylic alcohols; the secondary allylic alcohols is presented in this thesis. In this manner a comprehensive application of its versatility may be achieved, knowing that transition-metal hydrides such as, ruthenium- 
hydride can be generated in situ and actively used to effect the redox-isomerization of the allylic alcohols to prochiral ketones. These can be subsequently reduced to chiral secondary alcohols, in this case, the conversion of $\alpha$-vinyl benzyl alcohol, 2.17, to a chiral benzyl alcohol, 2.18, is proposed as the model reaction (Scheme 2.14).

As noted in sub-section 2.1.5, our laboratory was the first to report the asymmetric transfer hydrogenation of allylic alcohols via a combined enantioselective isomerization /transfer hydrogenation reaction mechanism. The reaction was found to occur, in excellent product yield and \% ee, using primary allylic alcohols such as geraniol and nerol as substrates. ${ }^{16}$ My research objectives related to this dissertation work are to further develop this reaction; to broaden the substrate scope to secondary allylic alcohols and to suggest further applications to the synthesis of useful bioactive compounds.

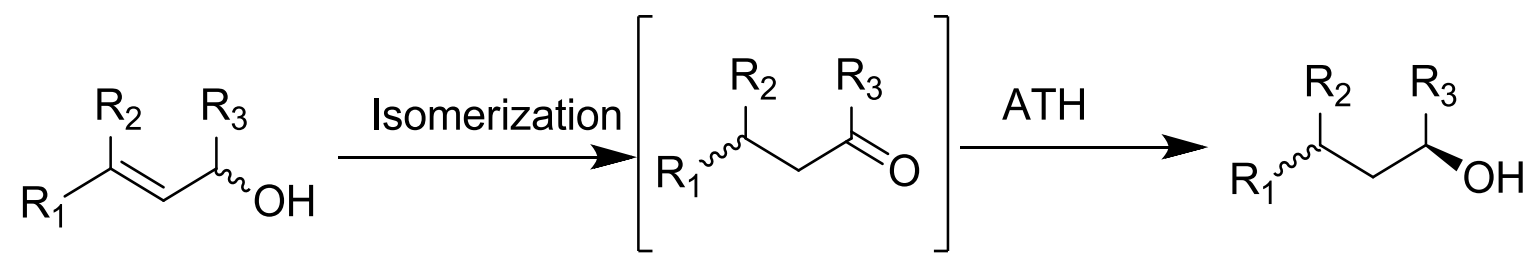

Scheme 2.15. Representative substrate of interest in our investigation.

In this regard, we propose a series of screening reactions, involving the conversion of racemic 1-phenyl-2-propen-1-ol ( $\alpha$-vinyl benzyl alcohol) to a single enantiomer as our model reaction (Figure 2.2). Here we will evaluate different in situ generated catalyst systems, using 
ruthenium based precatalysts such as $d i$ - $\mu$-chlorobis[( $p$-cymene)-chlororuthenium (II)], in combination with "privileged" chiral ligands such as (S)-(-)-2,2'-bis(di-p-tolylphospino)-1-1'binaphtyl [(S)-tol-BINAP], for optimal catalyst activity and selectivity. Through these studies, we will address the problems of low yields and lack of product enantioselectivity that was observed in the applications of the ATH reaction to secondary allylic alcohols studied in our preliminary investigations. Our aim will be to increase the enantioselectivity, propose the reaction mechanism and heuristically investigate the ruthenium-based precatalyst with a variety of chiral ligands.

We will also monitor the reaction \% ee over time by HPLC analysis. Monitoring the reaction over time may help us determine the point of asymmetric induction, product accumulation and possible racemization. Because the reaction is performed in isopropyl alcohol, it is ideally suitable for microwave synthesis. ${ }^{25}$ In fact, it may also be possible to perform this reaction in isopropyl alcohol/water mixture. Thus, we will also carry out this reaction under microwave conditions to determine the potential of microwave technology to perform the ATH reaction.

Furthermore, we will study this reaction with various derivatives of $\alpha$-vinyl benzyl alcohol, to evaluate the electronic effects of both electron withdrawing and electron donating groups on reactivity and enantioselectivity (Scheme 2.16 ). 


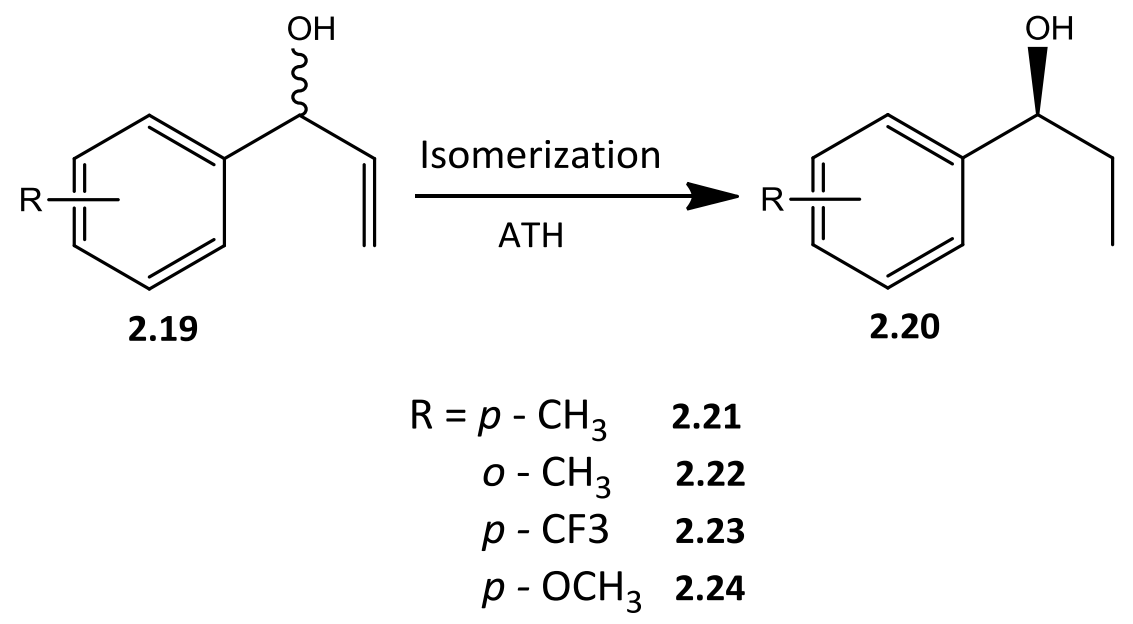

Scheme 2.16. Evaluation of electronic effects in the ATH of $\alpha$-vinyl benzylic alcohols 2.21-2.24.

Moreover, 1,3-diphenyl-2-propen-1-ol (Scheme 2.17), an important core component in the synthesis of $\mathrm{LTD}_{4}$ antagonist Singulair ${ }^{\mathrm{TM}}$ (Merck Inc.) will also be examined in the optimized ATH process.

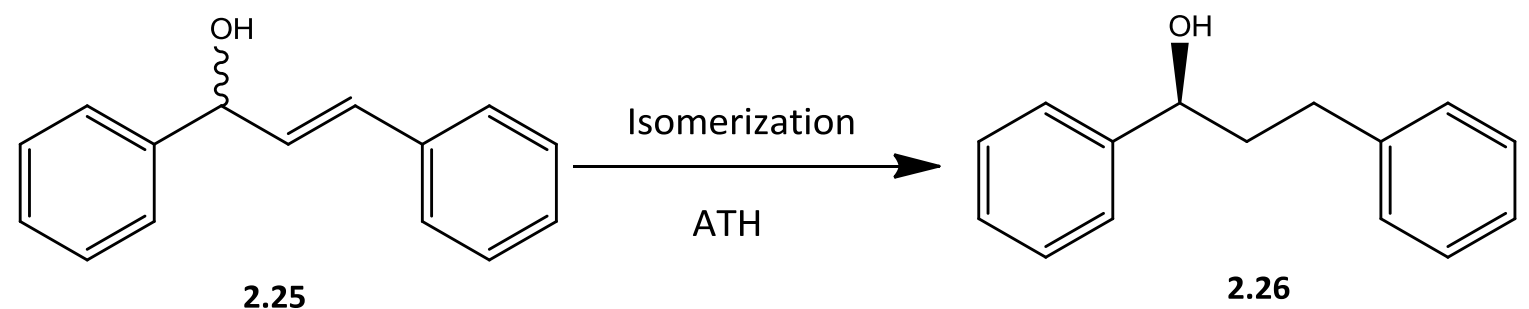

Scheme 2.17. Secondary allylic alcohols of interest to our investigation.

Similarly, we will explore competition reactions of the ATH technique between equimolar amounts of the model substrate and its derivatives to qualitatively determine the rate of tautomerization of the enol intermediate on the overall rate of the reaction. 
We believe the reaction proceeds with a mechanism similar to the one elucidated by our colleagues in the ATH reaction of primary allylic alcohols as enantioselective isomerization/transfer hydrogenation reaction published in $2012 .{ }^{16}$ However, we suspect that the keto-enol intermediate presumed to be involved in the secondary allylic alcohol could be reacting under a different reduction mechanism, possibly through an outer-sphere bifunctional catalysis mechanism in which a highly ordered six-membered ring transition state is formed to afford the alcohol product. In this regard, this hypothesis may be studied in future applications by deuterium labeling experiments using GC/MS and NMR. These techniques in addition to computational density functional theory (DFT) and molecular orbital (MO) calculations may be used to determine the origin of the hydrogen atom transfer and to rationalize the orientation of the ketone intermediate during the reduction step.

\section{3: Conclusions}

The objective of this thesis as described above applies the ATH reaction developed in our laboratory to secondary allylic alcohols. This includes making necessary modifications towards addressing the problems of low yields and limited enantionselectivity under the optimized cocktail conditions developed for the primary allylic alcohols. We believe we can achieve higher yields and enantiomeric excesses through well-studied and optimized reaction conditions; catalyst, ligands, base and temperature. As presented in this thesis, a better understanding of the ATH reaction and its mechanism is applied to secondary allylic alcohols. 


\section{References}

1. (a) Samec, J. S.; Backvall, J. E.; Andersson, P. G.; Brandt, P. Chem. Soc. Rev. 2006, 35, 237 248; (b) Krische, M. J.; Sun, Y.-K. Acc. Chem. Res. 2007, 40, 1237 - 1419. (c) Ikariya, T.; Blacker, A. J. Acc. Chem. Res. 2007, 40, 1300 - 1308.

2. (a) Noyori, R.; Hashiguchi, S. Acc. Chem. Res. 1997, 30, 97 - 102. (b) Noyori, R. Asymmetric Catalysis in Organic Synthesis, John Wiley, NewYork, 1994. (c) Noyori, R. Angew. Chem. Int. Ed. 2002, 41, $2008-2022$.

3. (a) Clapman, S. E.; Hadzovic, A.; Morris, R. H. Coord. Chem. Rev. 2004, 248, 2201. (c) Gladiali, S.; Alberico, E. Chem. Soc. Rev. 2006, 35, 226-236.

4. (a) Uma, R.; Crevisy, C.; Gree, R. Chem. Rev. 2003, 103, 27-51. (b) van der Drift, R. C.; Bouwman, E.; Drent, E. J. Organomet. Chem., 2002, 650, 1-24. (c) Shabatai, J.; Lazar, R.; Biron, E. J. Mol. Catalysis 1984, 27, 35.

5. Baratta, W.; Chelucci, G.; Gladiali, S.; Siega, K.; Toniutti, M.; Zanette, M.; Zangrando, E; Rigo. R. Angew. Chemie. Int. Ed., 2005, 44, 6214

6. Sun, Y.; LeBlond, C.; Wang, J.; Blackmond, D. G.; Laquidara, J.; Sowa, Jr., J. R. J. Am. Chem. Soc., 1995, 117, 12647-12648. (b) Laquidara, J. Asymmetric Transfer Hydrogenation of Allylic Alcohols, Ph.D. Thesis, 2003.

7. (a) Takaya, H.; Ohta, T.; Inoue, S.-I.; Tokunaga, M.; Kitamura, M.; Noyori, R. Org. Synth. 1993, 72, 74. (b) Saburi, M.; Tsukahara, T.; Ishii, Y.; Ikariya, T., Takahashi, T.; Uchida, Y. J. Organomet. Chem. 1992, 428, 155.

8. (a) Brown, J. M.; Naik, R. G. J. Chem Soc., Chem. Commum. 1982, 348. (b) Evans, D. A. Morrissey, M. M. J. Am. Chem. Soc. 1984, 106, 3866.

9. (a) Shabatai, J.; Lazar, R.; Biron, E. J. Mol. Catalysis 1984, 27, 35. (b) Aramendia, M. A.; Borau, V.; Jimenez, C.; Marinas, J. M.; Ruiz, J. R.; Urbano, F. J. Applied Catalysis A: General 2001, 206, 95.

10. Ikariya, T.; Blacker, A. J. Acc. Chem. Res. 2007, 40, 1300-1308.

11. Hashiguchi, S.; Fujii, A.; Haack, K.-J.; Matsumura, K.; Ikariya, T.; Noyori, R. Angew. Chem., Int. Ed. Engl. 1997, 36, 288-290. 
12. (a) Wagner, K. Angew. Chem. Int. Edit. 1970, 9, 50. (b) Watanabe, Y.; Ohta, T.; Tsuji, Y. Bull. Chem. Soc. Jpn. 1982, 55, 2441.

13. Fujii, A.; Hashiguchi, S.; Uematsu, N.; Ikariya, T.; Noyori, R. J. Am. Chem. Soc. 1996, 118, 2521-2522.

14. Chowdhury, R.; Bäckvall, J. J. Chem. Soc., Chem. Commun. 1991, 1063-1064.

15. (a) Kitamura, M.; Kasahara, I.; Manabe, K.; Noyori, R.; Takaya, H. J. Org. Chem. 1988, 53, 710 - 712. (b) Noyori, R. Angew. Chem. Int. Ed. 2002, 41, 2008 -2022;

16. Wu, R.; Beauchamps, M. G.; Laquidara, J. M.; Sowa, Jr. J. R. Angew. Chem. Int. Ed., 2012, 51, 1-6.

17. Shoola, C. O.; DelMastro, T.; Wu, R.; Sowa, Jr., J. R. Eur. J. Org. Chem., 2015, 1670-1673.

18. (a) Fürstner, A.; Hannen, P. Chem. Eur. J., 2006, 12, 3006-3019. (b) Hett, R.; Fang, Q. K.; Gao, Y.; Hong, Y.; Butler, H. T.; Nie, X.; Wald, S. Tetrahedron Lett., 1997, 38, 1125-1128.

19. (a) Yang, Z.-H. ; Zeng, R.; Yang, G.; Wang, Y.; Li, L-Z.; Lv, Z-S.; Yao, M.; Lai, B. J. Ind. Micro. and Biotech. 2002, 35, 1047-1051.

20. Ohkuma, T.; Ooka, H.; Hashiguchi, S.; Ikariya, T.; Noyori, R. J. Am. Chem. Soc. 1995, 117, 2675. (b) Ohkuma, T.; Ooka, H.; Yamakawa, M.; Ikariya, T.; Noyori, R. J. Org. Chem., 1996, 61, 4872

21. (a) Hartwig, J. F. Organotransition Metal Chemistry: From Bonding to Catalysis, 1st ed., 2009. (b) Crabtree, R. H. The Organometallic Chemistry of the Transition Metals, Wiley; 5th ed., 2009.

22. (a) Jones, J.B. Tetrahedron, 1986, 42, 3351-3403. (b) Schoffers, E.; Goleblowski, A.; Johnson, C.R. Tetrahedron, 1996, 52, 3769-3826.

23. (a) M. T. Reetz, X. Li, J. Am. Chem. Soc. 2006, 128, 1044-1045. (b) R. Kadyrov, T. H. Riermeier, U. Dingerdissen, V. Tararov, A. Borner, J. Org. Chem. 2003, 68, 4067-4070. (c) Tripathi, R. P.; Verma, S. S.; Pandey, J.; Tiwari, V. K. Curr. Org. Chem. 2008, 12, 1093-1115. (d) Zhou, S.; Fleischer, S.; Junge, K., Das, S.; Addis, D.; Beller, M. Angew. Chem. Int. Ed. 2010, 49, 8121-8125. (e) Nguyen, T. B.; Bousserouel, H.; Wang, Q.; Guéritte, F. Org. Lett., 2010, 12,47054707.

24. (a) N. J. A. Martin, L. Ozores, B. List, J. Am. Chem. Soc. 2007, 129, 8976-8977. (b) D. Xue, Y.C. Chen, X. Cui, Q.-W. Wang, J. Zhu, J.G. Deng, J. Org. Chem. 2005, 70, 3584-3591; (c) N. J. A. 
Martin, B. List, J. Am. Chem. Soc. 2006, 128, 13368-13369 (d) Yang, J. W.; Fonseca, M. T. H.; Vignola, N.; List, B. Angew. Chem. Int. Ed., 2005, 44, $108-110$.

25. Gordon, E. M.; Gaba, D. C.; Jebber, K. A.; Zacharias, D. M. Organometallics, 1993, 12, 50205022. 


\section{Chapter Three: Development and Optimization of the ATH Reaction of Secondary Allylic Alcohols}

\section{1: Development of the ATH reaction of secondary allylic alcohols}

The investigation into the isomerization and ATH reaction of secondary allylic alcohols was initiated by adapting the reaction conditions optimized in the case of the primary allylic alcohol; geraniol, (Scheme 3.1). ${ }^{1}$ These reaction conditions included (S)-tol-BINAP and ruthenium (II) $p$-cymene dissolved together in a mixture of IPA and the base $\mathrm{KOH}$, and heated at $83^{\circ} \mathrm{C}$ for $18 \mathrm{~h}$.

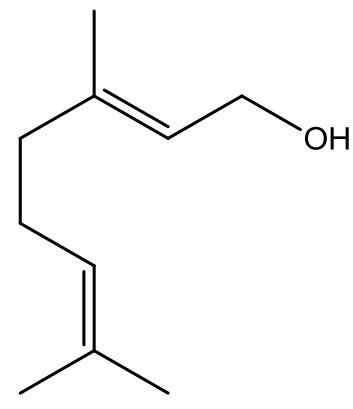

3.1
[(S)-tol-BINAP]

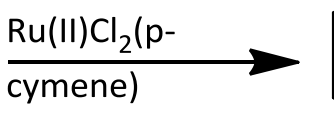

IPA, $\mathrm{KOH}, 83^{\circ} \mathrm{C}$

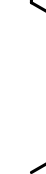

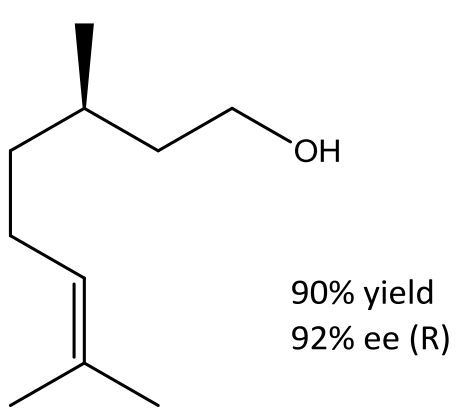

3.2

Scheme 3.1. Optimized reaction conditions for the primary allylic alcohol, geraniol, 3.1. ${ }^{1}$

In my approach, a slight modification in the addition sequence of the reacting components was accomplished. In this manner, a stepwise addition of the reagents as opposed to a cocktail approach was adopted in order to generate the active catalyst first. Additionally, the base was changed from $\mathrm{KOH}$ to $\mathrm{K}_{2} \mathrm{CO}_{3}$, on the assumption that the $\mathrm{OH}$ group from $\mathrm{KOH}$ may lead to the generation of water which may poison catalyst reactivity. Thus, the initial reaction commenced with the degassing of the solvent and reducing agent (IPA) from room temperature 
to $83{ }^{\circ} \mathrm{C}$, followed by addition of the pre-catalyst, di- $\mu$-chlorobis[(p-cymene)chlororuthenium(II)]

3.9, (Figure 3.2) and the ligand, (S)-tol-BINAP, and then the substrate, - $\alpha$-vinyl benzyl alcohol and $\mathrm{K}_{2} \mathrm{CO}_{3}$ as the base dissolved in isopropyl alcohol, respectively. The substrate/pre-catalyst /ligand /base mole ratio was 10:1:1:2. The reaction proceeded for $18 \mathrm{~h}$ and cleanly afforded good product conversion ( $>80 \%$ ) and the product was isolated in yield of $75 \%$ via silica gel column chromatography (Scheme 3.2$)$. However, low enantioselectivity ( $21 \%$ ee) for the Renantiomer, 3.4, was observed upon analysis by reverse phase chiral HPLC, using a Daicel Chiralcel OD-RH HPLC column and a 50/50 (v/v) mixture of methanol/water as mobile phase at $20{ }^{\circ} \mathrm{C}$ with $220 \mathrm{~nm}$ UV detection. The \% ee was determined by peak area integration, and enantiomers were identified by retention times, as validated by reverse phase chiral HPLC analysis of the commercially available racemic mixture of the desired product; ( \pm )-1-phenyl-1propanol, under similar conditions. ${ }^{1}$ (Figure 3.1). Nonetheless, these results were promising, because under similar conditions when the reacting components were added at the same time, the cocktail approach, no enantioselectivity was observed.

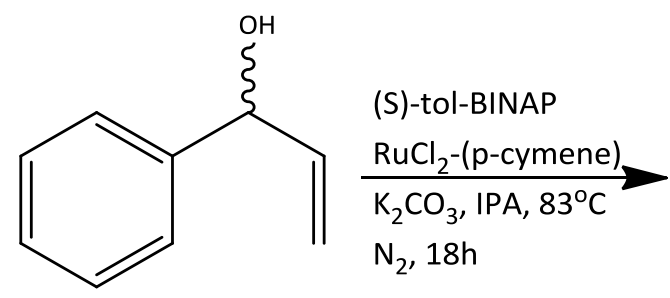

3.3

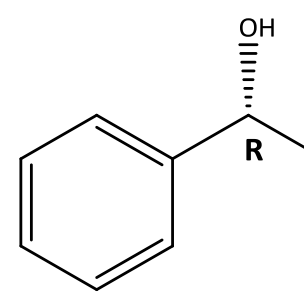

3.4

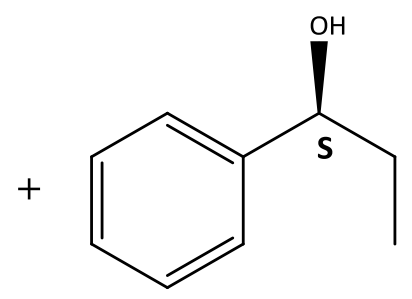

3.5

$80 \%$ yield, $\mathbf{2 1 \%}$ ee $(\mathrm{R})$ - enantiomer

Scheme 3.2. First attempted ATH reaction of secondary allylic alcohols. 


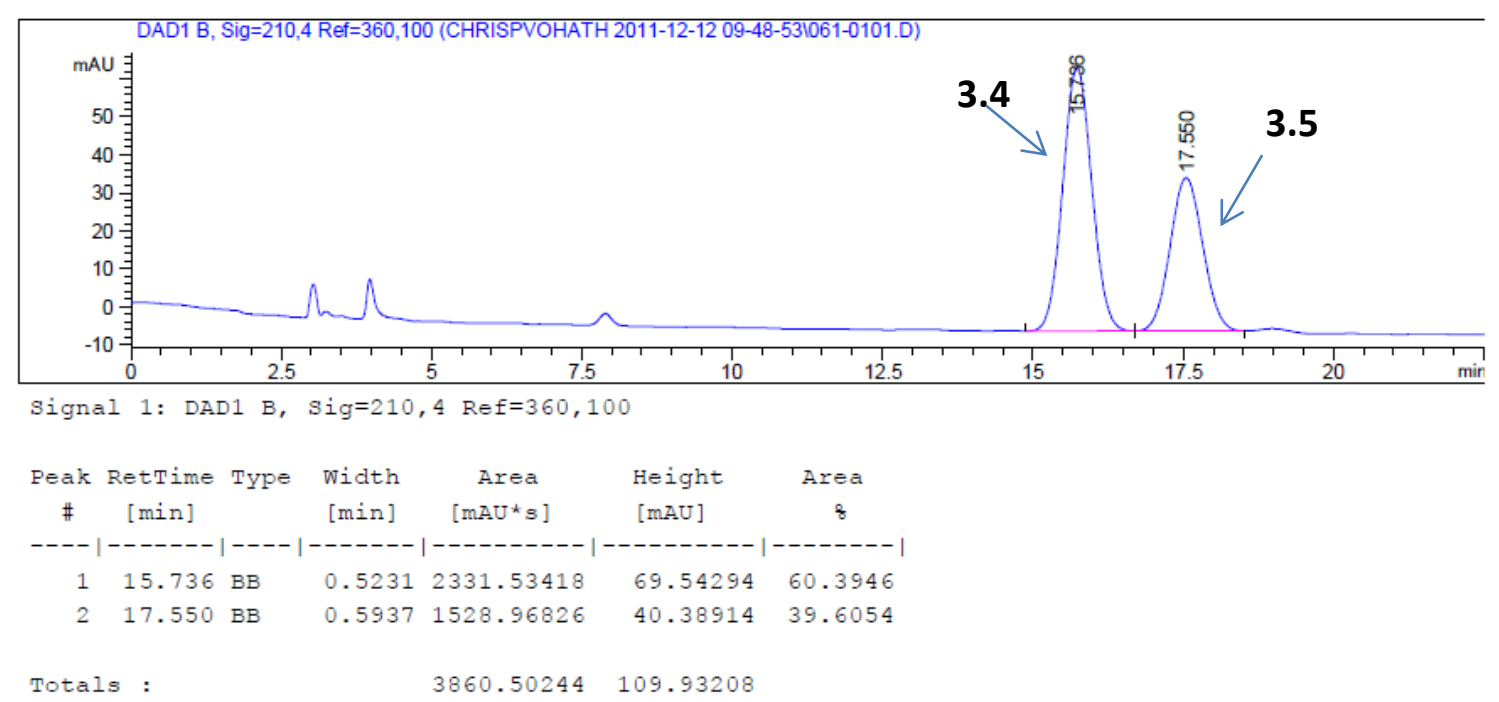

Figure 3.1. Chiral separation of the first attempted ATH reaction of secondary allylic alcohol.

In an attempt to improve the enantioselectivity of the reaction, a review of the proposed reaction mechanism for the primary allylic alcohol under these conditions revealed that asymmetric induction occurred during the isomerization step, and also, the transfer hydrogenation step was achiral (Scheme 3.3). However, in the case of the secondary allylic alcohols, the isomerization step is considered to be achiral, whereas, the transfer hydrogenation step produces chirality (Scheme 3.4). The proposed reaction mechanisms are based on those published by our laboratory for the primary allylic alcohol, geraniol ${ }^{1}$ and the isomerization reactions of allylic alcohols. ${ }^{2}$

This observation became an important point to consider in the subsequent optimization studies. 

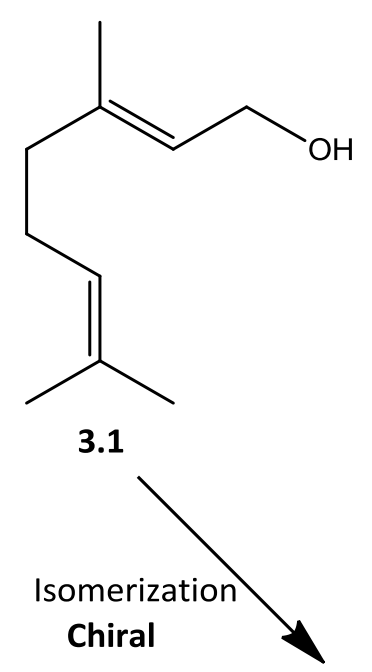

(S)-tol-BINAP $\underset{\mathrm{KOH}, \mathrm{IPA}, 83^{\circ} \mathrm{C}}{\mathrm{RuCl}}$

$\mathrm{N}_{2}$,

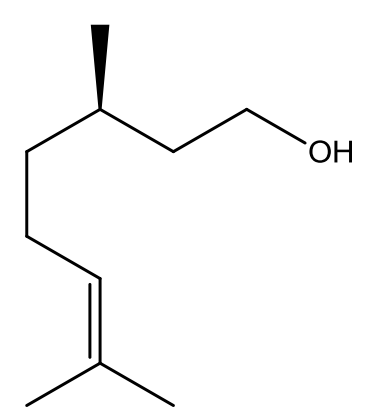

3.2
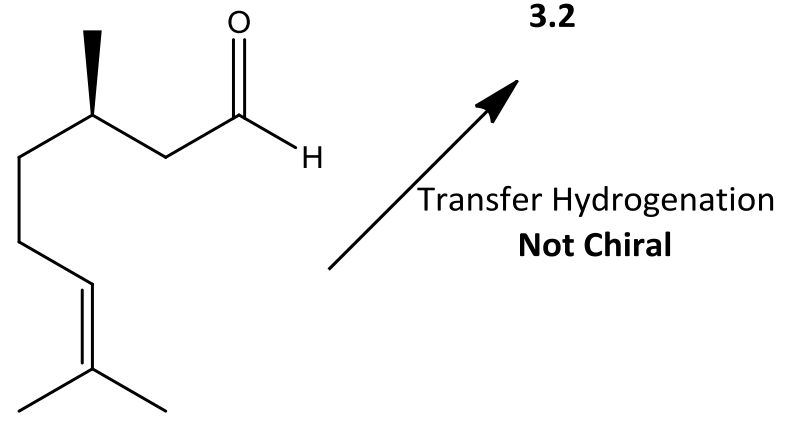

3.6

Scheme 3.3. Enantioselective isomerization/transfer hydrogenation mechanism of geraniol,

\section{1. ${ }^{1}$}<smiles>C=CC(O)c1ccccc1</smiles>

3.3 $\underset{\text { Not Chiral }}{\stackrel{\text { Isomerization }}{2}}$

Not Chiral

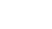<smiles>C/C=C(/O)c1ccccc1</smiles>

3.7

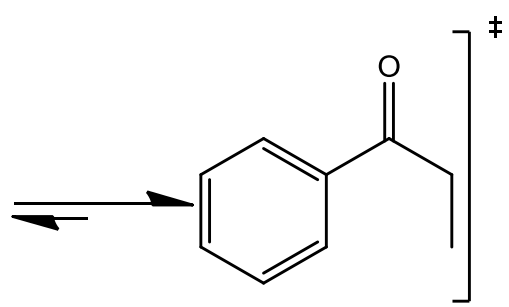

3.8

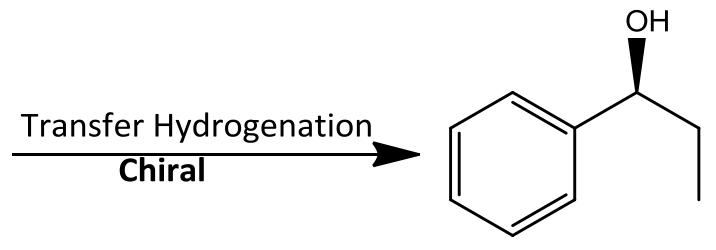

3.5

Scheme 3.4. Isomerization/ATH of secondary allylic alcohol, $\alpha$-vinyl benzyl alcohol, 3.3. ${ }^{2}$

Given that the tautomerization step following the isomerization of the secondary allylic alcohol produces a ketone intermediate, it was envisaged that a catalyst system known for 
effective transfer hydrogenation of ketones might be able to form the isomer of the allylic alcohol substrate and also reduce the ketone intermediate to the corresponding alcohol. ${ }^{3}$ This has shown to be the case in the following examples, the reduction of acetophenone and unsymmetrically substituted 1,2-diketones to their corresponding optically active secondary alochols. $^{3 a}$

Based on the literature conditions for effective transfer hydrogenations of ketones, the following factors were explored in an attempt to optimize the enantioselcetivity of the ATH reaction of secondary allylic alcohols.

\section{A. Ligand effect}

B. Metal - ligand mole ratio

D. Change in reaction temperature

E. Solvent and base effects

Consultation of the literature on the ATH reactions of ketones and imines led to the choice of the diamine ligand; (S,S)-TsDPEN, which showed enhanced selectivity in the screening reactions. ${ }^{3 a, 4}$ The combination of this diamine ligand, $(S, S)$-para-toluene sulfonyldiphenyl ethylenediamine $[(\mathrm{S}, \mathrm{S})-\mathrm{TSDPEN}]$ 3.10, proved to be the most efficient with \% ee ranging from $68-83 \%$ (Table 3.1, entries 1-2). A series of screening reactions were conducted with other ligands in combination with the pre-catalyst 3.9. ${ }^{4}$ These screening reactions afforded significant 
conversions of the substrate in over $80 \%$ yields, but the selectivity was poor in each case, with less than $40 \%$ ee (Table 3.1, entries 3-7).

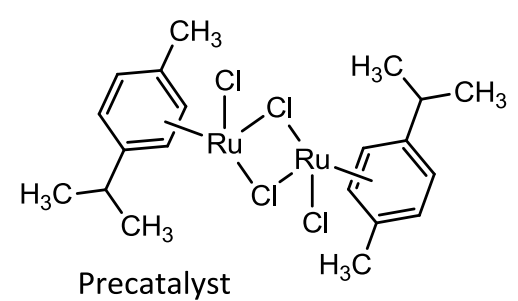

$\mathrm{RuCl}_{2}$ (p-Cymene) dimer

3.9

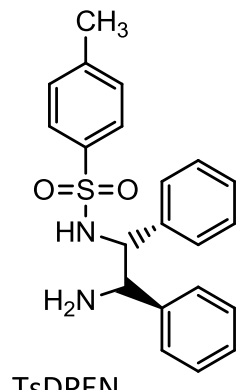

TsDPEN

$N$-(p-toluenesulfonyl) diphenylethylene diamine

$\mathbf{3 . 1 0}$

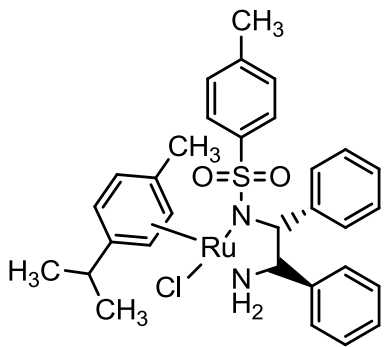

18 - electron complex Coordinated Ru - Ligand Complex

3.11

Figure 3.2. Structures of pre-catalyst, ligand, and presumed metal-ligand catalyst complex.

It is not so surprising that the combination of the Ru-pre-catalyst and TsDPEN; presumably forming the Ru-TSDPEN complex 3.11, led to higher \%ee values (Table 3.1, entries 1-2). This combination is the well-known Noyori-lkariya catalyst, which has afforded excellent enantioselectivities and product yields in the ATH of prochiral ketones and imines. ${ }^{5}$ Nonetheless, the efficiency of this catalyst system to effect the transposition of the double bond at low temperature (rt) was concerning, because it was noted during the screening experiments that isomerization of secondary allylic alcohol is enhanced at temperatures higher than $40{ }^{\circ} \mathrm{C}$. Thus, a temperature dependent study was developed. This was achieved by initially mixing the pre-catalyst and the ligand at $80{ }^{\circ} \mathrm{C}$ for half-hour; and then lowering the temperature to around $50-60{ }^{\circ} \mathrm{C}$, and adding the solutions of the base and the substrate, respectively. The reaction mixture was allowed to stir for about $2 \mathrm{~h}$, and finally the temperature was lowered to $25{ }^{\circ} \mathrm{C}$ the reaction allowed to stir for $16 \mathrm{~h}$. An appreciable increase in the \% ee 
(from 68 to $83 \%$ ) was achieved through this approach, which was further optimized for the ATH reaction of secondary allylic alcohols.

Variation of metal-ligand mole ratios from 1:1 to $1: 2$ was attempted during the screening experiments, but no significant difference was observed in the reaction outcome.

The ATH reaction was also attempted under microwave conditions (MW, $120{ }^{\circ} \mathrm{C}, 20$ bar, 25 min.). Furthermore, a 40/60 percentage of water/IPA mixture as solvent and source of hydrogen atom was also attempted. In both cases, no enantioselectivity was observed.

Table 3.1. Study of catalytic activity and selectivity.

\begin{tabular}{|c|c|c|c|c|}
\hline Entry & Pre-Catalyst $^{\mathrm{a}}$ & Ligand $^{b}$ & Base $^{c}$ & ee $(\%)^{d}$ \\
\hline 1 & $\begin{array}{l}\text { di- } \mu \text {-chlorobis }[(p \text {-cymene }) \\
\text { chlororuthenium(II)] }\end{array}$ & $(\mathrm{S}, \mathrm{S})-\mathrm{TsDPEN}$ & $\mathrm{K}_{2} \mathrm{CO}_{3}$ & 83 \\
\hline 2 & $\begin{array}{l}\text { di- } \mu \text {-chlorobis }[(p \text {-cymene }) \\
\text { chlororuthenium }(I I)]\end{array}$ & $(S, S)-T s D P E N$ & $\mathrm{~K}_{2} \mathrm{CO}_{3}$ & 68 \\
\hline 3 & $\begin{array}{l}\text { di- } \mu \text {-chlorobis }[(p \text {-cymene }) \\
\text { chlororuthenium(II)] }\end{array}$ & (S)-PHANEPHOS & $\mathrm{K}_{2} \mathrm{CO}_{3}$ & 36 \\
\hline 4 & $\begin{array}{l}\text { di- } \mu \text {-chlorobis }[(p \text {-cymene }) \\
\text { chlororuthenium(II)] }\end{array}$ & $(S, S)-i-P r-D U P H O S$ & $\mathrm{~K}_{2} \mathrm{CO}_{3}$ & 30 \\
\hline 5 & $\begin{array}{l}\text { di- } \mu \text {-chlorobis }[(p \text {-cymene }) \\
\text { chlororuthenium(II)] }\end{array}$ & (S)-Tol-BINAP & $\mathrm{K}_{2} \mathrm{CO}_{3}$ & 21 \\
\hline 6 & $\begin{array}{l}\text { di- } \mu \text {-chlorobis }[(p \text {-cymene }) \\
\text { chlororuthenium(II)] }\end{array}$ & (R)-Tol-BINAP & $\mathrm{K}_{2} \mathrm{CO}_{3}$ & 11 \\
\hline $\mathrm{e}_{7}$ & $\begin{array}{l}\text { di- } \mu \text {-chlorobis }[(p \text {-cymene }) \\
\text { chlororuthenium }(I I)]\end{array}$ & (S)-PHANEPHOS & $\mathrm{K}_{2} \mathrm{CO}_{3}$ & $<1$ \\
\hline
\end{tabular}

${ }^{\text {a }}$ Pre-catalyst/ligand mixed in IPA at $80^{\circ} \mathrm{C}$ for $20 \mathrm{~min}$., substrate/base added at $60^{\circ} \mathrm{C}$. Reaction held at different temperatures between 60 and $25^{\circ} \mathrm{C}$. ${ }^{\mathrm{e}}$ Microwave conditions (MW, $120^{\circ} \mathrm{C}, 20$ bar, $25 \mathrm{~min}$.) 


\section{2: Optimization of the ATH reaction of secondary allylic alcohols}

Following the preliminary results obtained from the combination of $\mathbf{3 . 9}$ and $\mathbf{3 . 1 0}$ (Figure 3.1), it became desirable to further optimize the reaction conditions for improving the enantioselectivity of the ATH reaction. Based on the chosen metal-ligand catalyst complex (Table 3.1, entry 1), the ATH reaction of secondary allylic alcohols was studied over a temperature range $\left(15-80^{\circ} \mathrm{C}\right)$ in order to examine the influence of temperature on enantioselectivity. In asymmetric catalysis, the diastereomeric energy difference $\left(\Delta \Delta \mathrm{G}^{\ddagger}\right)$ of possible transition states of the substrate-catalyst adduct can seriously impact enantioselectivity. In fact, about $2 \mathrm{kcal} / \mathrm{mol}$ of diastereomeric transition states energy difference is known to cause $95 \%$ ee (equation 3.1 and 3.2). ${ }^{6}$

Therefore, the selectivity of the ATH reaction recorded at each temperature was then correlated to the difference in energy of the diastereomeric transition states of the substratecatalyst adduct of the reaction using the following equations:

$$
\begin{aligned}
& \text { Enantiomeric ratio }=\frac{\text { Major enantiomer }}{\text { Minor enantiomer }}=e^{-(\Delta \Delta G \ddagger / R T)} \\
& -\Delta \Delta \mathrm{G}^{\ddagger}=\ln \left(\frac{\text { Major enantiomer }}{\text { Minor enantiomer }}\right) R T
\end{aligned}
$$

where $-\Delta \Delta G^{\ddagger}$ is the diastereomeric energy difference, $R$ is the gas constant and $T$ is the temperature.

In my investigation, an average of $90 \%$ ee was obtained in several attempted reactions at $25{ }^{\circ} \mathrm{C}$. According to experimentally obtained data shown in Figure 3.3 , this translates to an average diastereomeric energy difference of $1.24 \mathrm{kcal} / \mathrm{mol}$, as deduced from the plot of 
enantioselectivity versus diastereomeric transition states energy difference obtained over the range of temperatures. This value is consistent with literature reports and advanced publications in the field of asymmetric catalysis. $^{6}$

\section{Plot of Enantioselectivity vs Difference in Energy of Diastereomeric Transition States}

$\begin{array}{ccc}\text { Reaction Temperature }\left({ }^{\circ} \mathrm{C}\right) & \text { ee }(\%) & \Delta \Delta \mathrm{G}++(\mathrm{kcal} / \mathrm{mol}) \\ 0 & 92 & 1.39 \\ 15 & 89 & 1.24 \\ 25 & 83 & 0.97 \\ 35 & 68 & 0.48 \\ 45 & & \end{array}$

$\Delta \Delta \mathrm{G}++$ was calculated from the following equation

Enantiomeric ratio $=$ major enatiomer $/$ minor enantiomer $=\mathrm{e}^{-(\Delta \Delta \mathrm{G}++/ \mathrm{RT})}$

$-\Delta \Delta \mathrm{G}^{++}=\ln$ (major enantiomer/minor enantiomer) RT

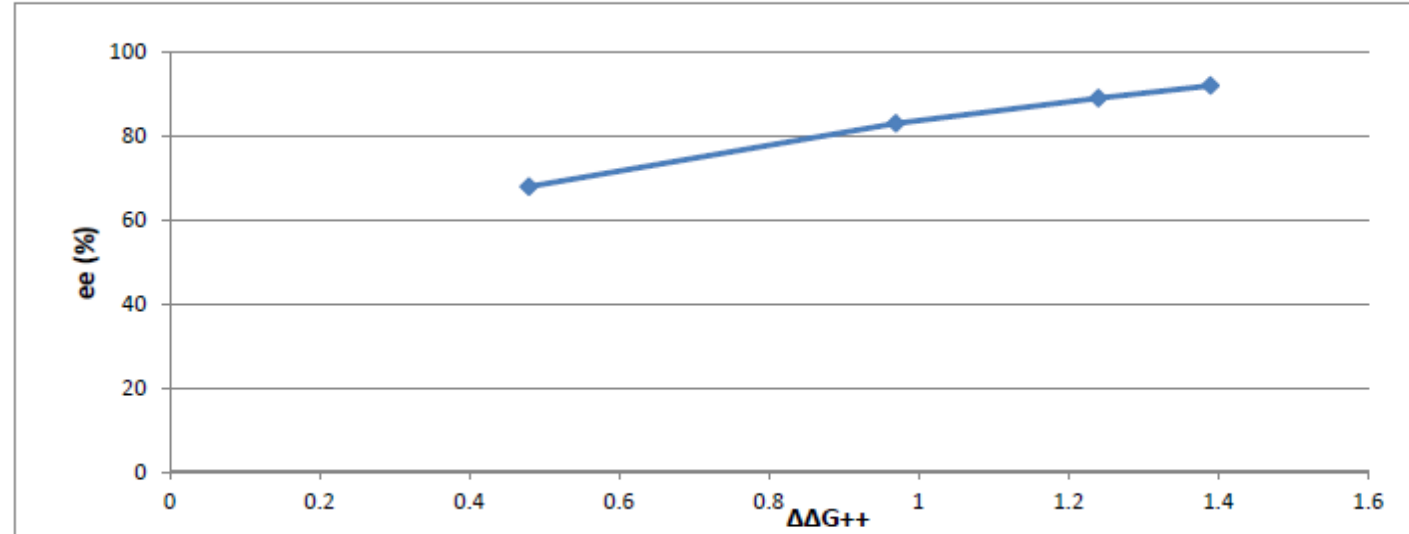

Figure 3.3. Plot of enantioselectivity vs. energy difference of the diastereomeric transition states.

The choice of potassium hydroxide $(\mathrm{KOH})$ in the optimized conditions was selected because of its solubility in IPA. A stoichiometric ratio of (1-2:1, ligand:pre-catalyast) was used in the reaction. 
With these conditions, a solution of IPA was degassed from $r$ to $80{ }^{\circ} \mathrm{C}$, with nitrogen. At $80{ }^{\circ} \mathrm{C}$ the pre-catalyst and ligand were added and allowed to mix for 25 minutes to generate the active catalyst complex, $\mathbf{3 . 1 1}$, in situ. The reaction temperature was then lowered to $55{ }^{0} \mathrm{C}$, at which point a solution of $\mathrm{KOH}$ in IPA was added. The substrate, $\alpha$-vinyl benzyl alcohol, was dissolved in IPA and was then added to initiate the reaction. The mixture was stirred for about 2 $\mathrm{h}$, after which the reaction temperature was further lowered to $25{ }^{\circ} \mathrm{C}$, and allowed to stir for an additional $16 \mathrm{~h}$. The reaction mixture was sampled for \% ee analysis by reverse phase chiral HPLC. Purification and isolation of the product via flash chromatography on silica gel afforded (S)-1-phenyl-1-propanol in 90\% ee and 97\% yield (Scheme 3.5$).^{7}$ The product was characterized by FT-IR, NMR and GC/MS.

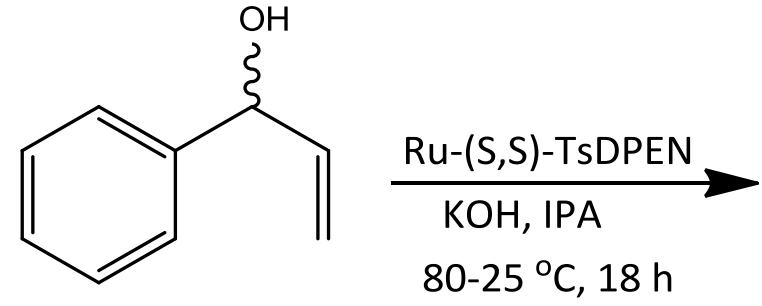

3.3

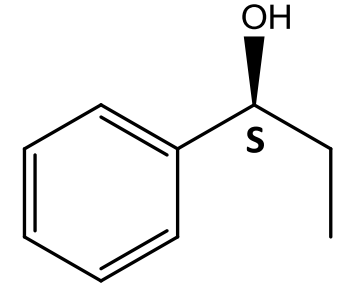

3.5

97\% yield, $\mathbf{9 0 \%}$ ee (S)-enantiomer

Scheme 3.5. Optimized conditions for isomerization/ATH reaction of secondary allylic alcohol,

\section{3.}

The preference for the formation of the S-enantiomer observed with the chiral TsDPEN ligand can be rationalized by the ligand participation in the reduction step. In this case, the substrate-catalyst adduct is a transient planar bicyclic species $\mathbf{3 . 1 9}$ (Scheme 3.6) in which rotation of the substrate is impossible, whereas with the tol-BINAP ligand the substrate-catalyst adduct is formed through a direct coordination between the substrate and the metal center; an 
arrangement that permits rotation of the substrate in order to overcome possible steric hindrance around the metal center.

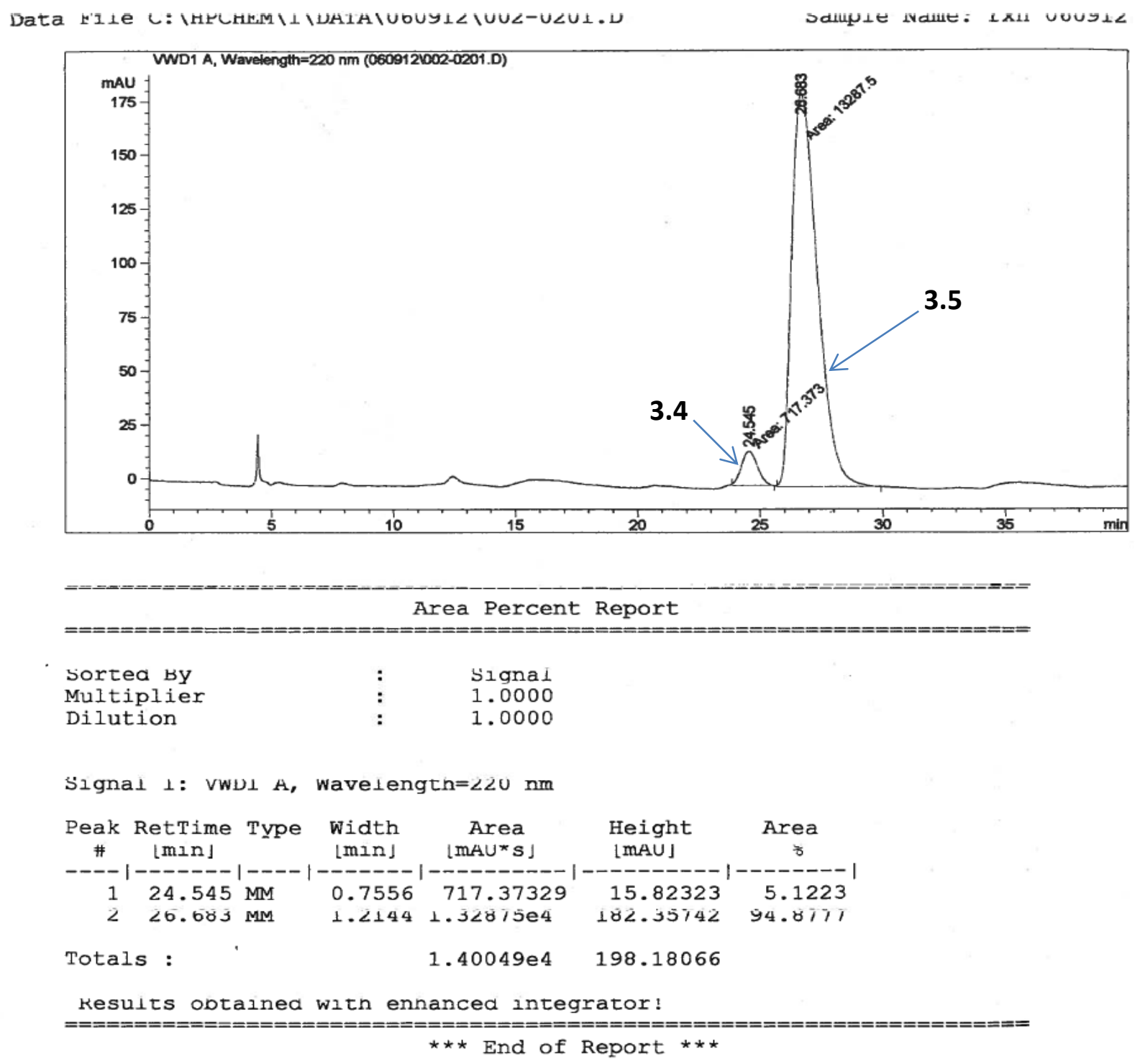

Instrument $19 / 29 / 12$ 4:23:52 PM chris $\quad$ Page 3 of 3

Figure 3.4. Chiral separation of products of isomerization/ATH reaction of secondary allylic alcohol. 


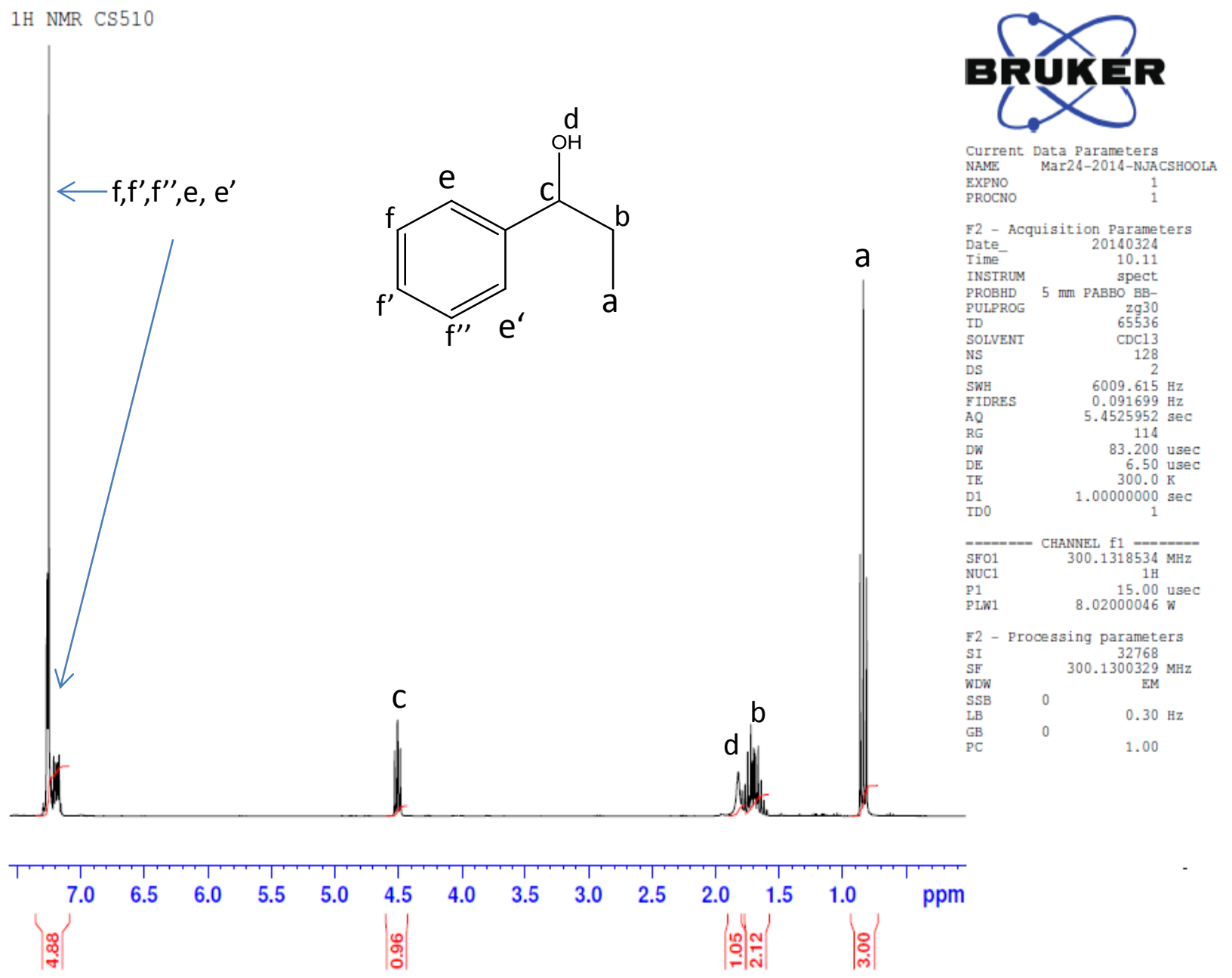

Figure 3.5. ${ }^{1} \mathrm{H}$ NMR spectrum of 1-phenyl-1-propanol,3.5. 


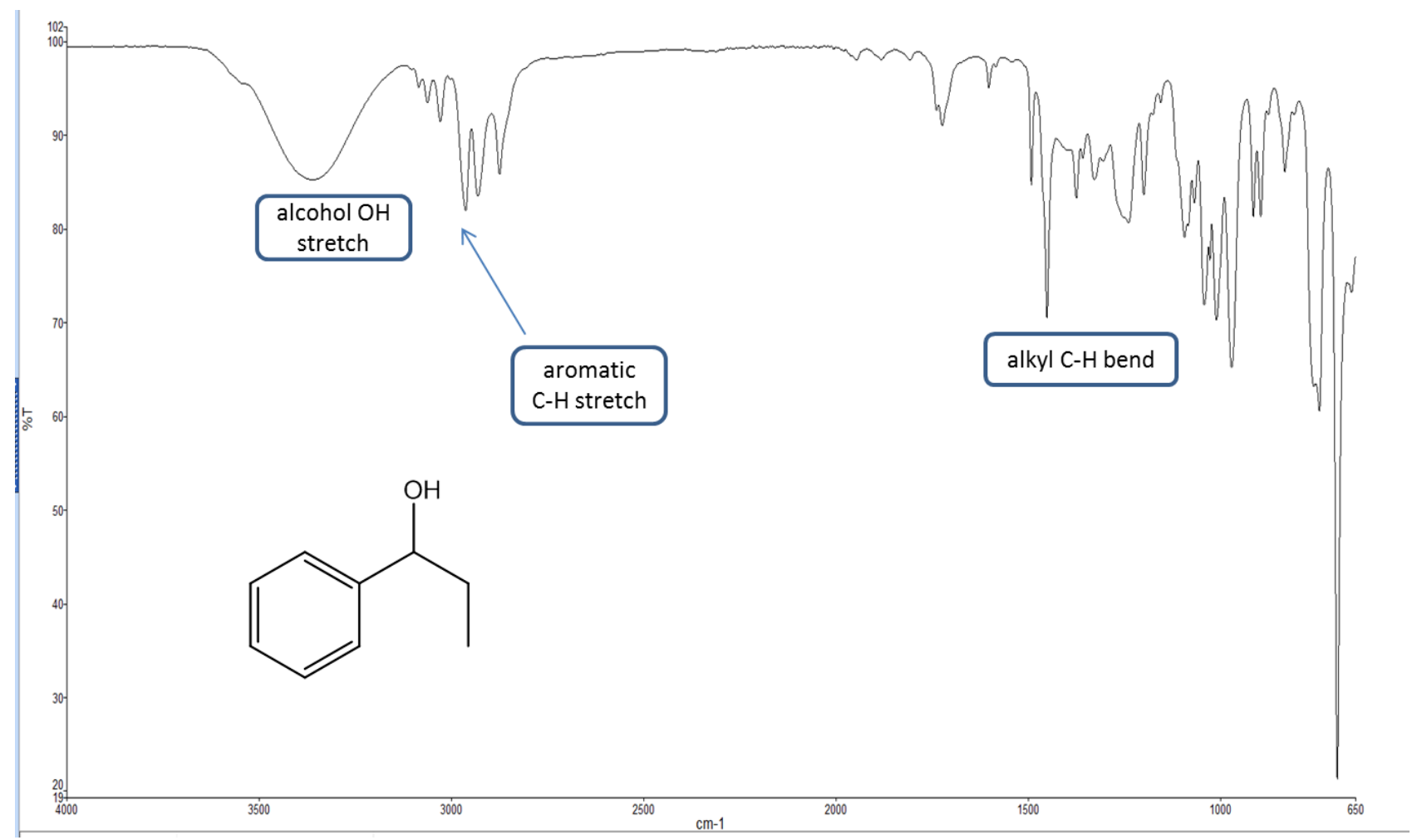

Figure 3.6. FT-IR spectrum of 1-phenyl-1-propanol, 3.5.

\section{3: Postulated mechanism of ATH reaction of secondary allylic alcohols}

The previous work of our laboratory in deducing the mechanism for enantioselective isomerization and transfer hydrogenation reaction of geraniol, ${ }^{1}$ and the excellent work of Noyori and Ikariya, on the mechanism of metal-ligand bifunctional catalysis, ${ }^{8,9}$ provided the rationale for the suggested mechanism of the ATH reaction of the secondary allylic alcohol; $\alpha$ vinyl benzyl alcohol. This mechanism may be described as a synergy of the inner-sphere and 
outer-sphere pathways. In this manner, the inner-sphere pathway involves initial direct interaction of the substrate with the metal center up to the formation of the ketone intermediate. This ketone intermediate then reacts through bifunctional metal-ligand catalysis in an outer-sphere pathway to afford the corresponding chiral alcohol.

The proposed mechanism begins with the base deprotonation of the allylic alcohol 3.12, to generate the allylic alkoxide $\mathbf{3 . 1 3}$, which quickly coordinates to the chiral [Ru]-complex. A 1, 3-hydride shift from the benzylic position in $\mathbf{3 . 1 4}$ via the metal hydride complex $\mathbf{3 . 1 5}$, onto terminal vinyl carbon generates the metal oxy-allyl species 3.16. Upon dissociation of the metal the enol intermediate $\mathbf{3 . 1 7}$ tautomerizes to the ketone intermediate $\mathbf{3 . 1 8}$.

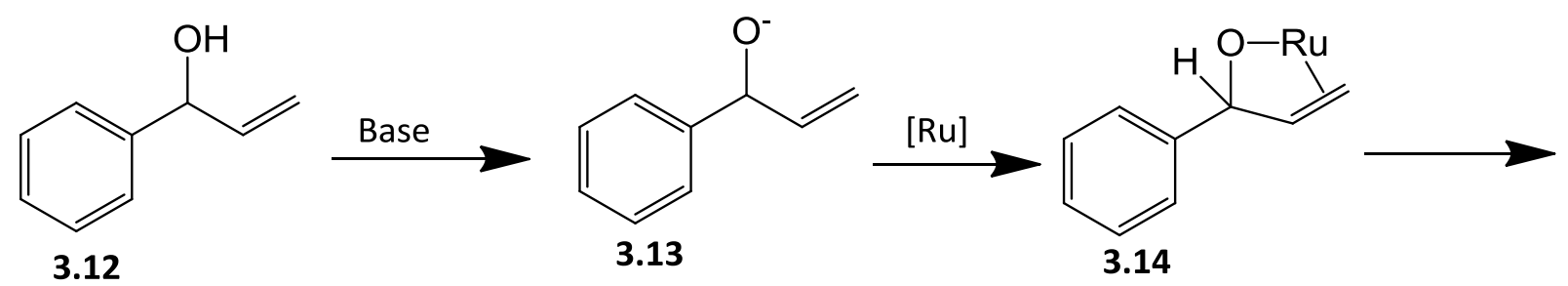<smiles>[R14]OC(=CC)c1cc(CC)cc(C(CC)c2ccc(C(O)=CC)cc2)c1</smiles><smiles>CC[C@H](O)c1ccc(C(C)C)cc1</smiles>

Scheme 3.6. Proposed mechanism for isomerization/ATH reaction of secondary allylic alcohol. 
This ketone intermediate then reacts further with the active chiral Ru-catalyst in an outersphere metal-ligand bifunctional mechanism which dictates chiral induction. The formation of the six-membered ring transition state, $\mathbf{3 . 1 9}$, with alternate charge distribution ${ }^{8}$ via hydrogen bonding (Scheme 3.7), affords the optically active alcohol product, 3.20. The chirality leading to 3.20 originates from the existing five-membered ring structure of the catalyst system which was dictated by the amino end group of the chiral ligand and the metal center. This ring structure locks the catalyst system in a planar position thereby forcing the ketone intermediate to orient its large group away from the catalyst system. This favors transfer of hydrogen on the si-face of the prochiral ketone intermediate.

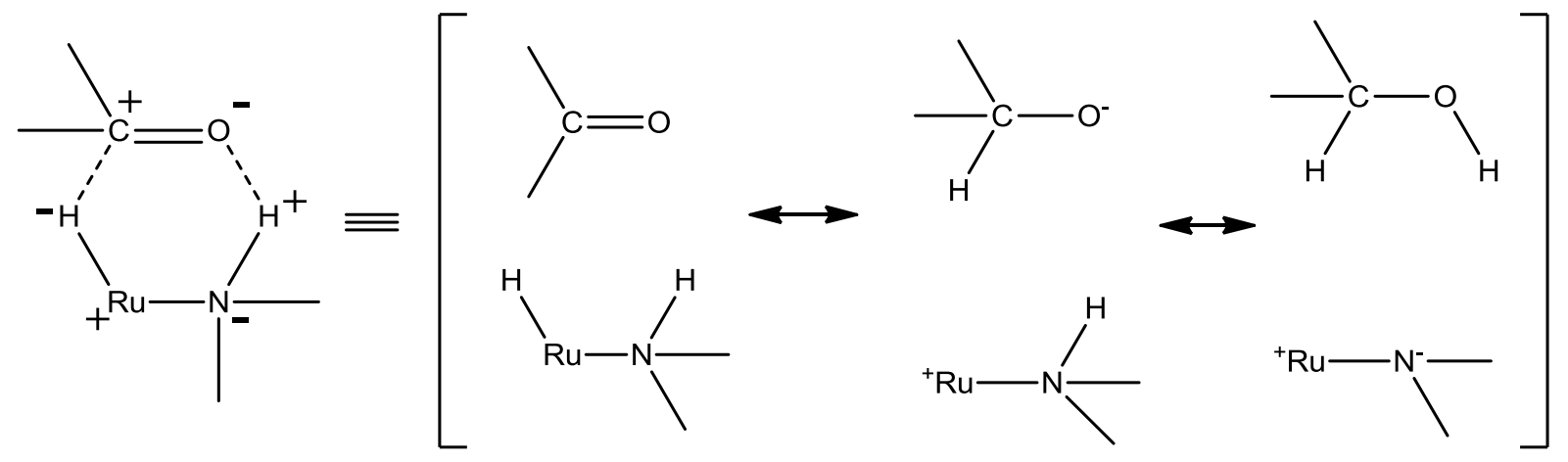

Scheme 3.7. Charge distribution in the transition state via H-bonding. ${ }^{8}$

\section{4: ATH reaction of derivatives of $\alpha$-vinyl benzyl alcohol}

Derivatives of the model substrate $\alpha$-vinyl benzyl alcohol were not commercially available. They were therefore synthesized in the laboratory from their corresponding benzaldehydes via the Grignard reaction, using the modified method of Wagner and coworkers $^{10}$ (Scheme 3.8). Reactions were conducted in dry THF at $0{ }^{0} \mathrm{C}$, with solutions of the 
corresponding aldehyde and slow addition of vinyl magnesium bromide. The mixture was stirred for two hours, and quenched with diethyl ether and aqueous ammonium chloride, after a TLC check showed no presence of the aldehyde. Products were purified and isolated via flash chromatography on silica gel giving an average isolated yield of over $80 \%$. The secondary $\alpha$-vinyl benzyl alcohols were characterized by FT-IR, NMR and GC/MS techniques (Table 3.2)

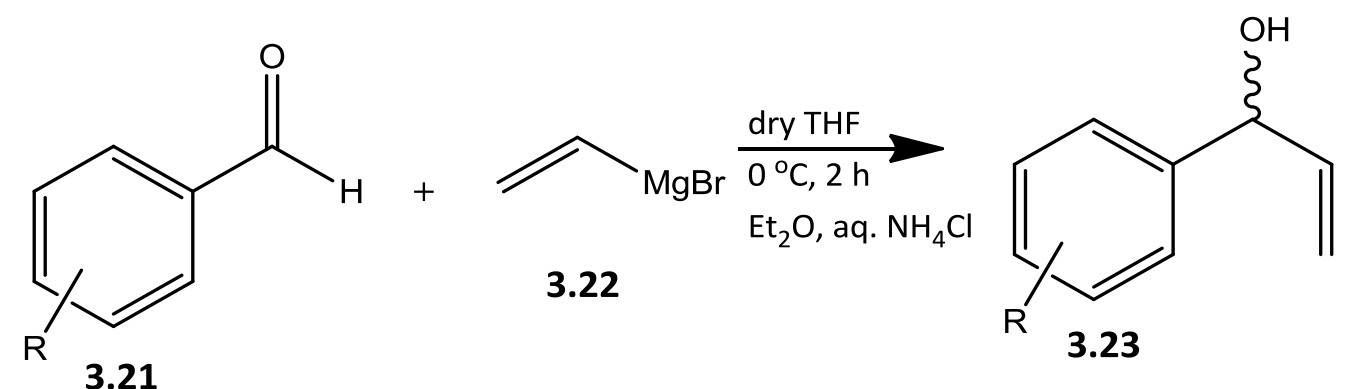

$$
\mathrm{R}=p-\mathrm{CH}_{3}-\mathbf{3 . 2 4} \quad o-\mathrm{CH}_{3}-\mathbf{3 . 2 5} \quad p-\mathrm{OCH}_{3}-3.26 \quad p-\mathrm{CF}_{3}-\mathbf{3 . 2 7}
$$

Scheme 3.8. Synthesis of derivatives 3.15-3.18 of $\alpha$-vinyl benzyl alcohol. ${ }^{10}$

Table 3.2. Derivatives of $\alpha$-vinyl benzyl alcohols.

\begin{tabular}{|l|l|l|l|}
\hline Entry & Substrate & Product & \%Yield $^{\mathrm{a}}$ \\
\hline
\end{tabular}

1.<smiles>Cc1ccc(C=O)cc1</smiles><smiles>C=CC(O)c1ccc(C)cc1</smiles>

2.<smiles>COc1ccc(C=O)cc1</smiles><smiles>C=CC(O)c1ccc(OC)cc1</smiles> 
3.<smiles>O=Cc1ccc(C(F)(F)F)cc1</smiles>

4.<smiles>Cc1ccccc1C=O</smiles><smiles>C=CC(O)c1ccc(C(F)(F)F)cc1</smiles><smiles>C=CC(O)c1ccccc1C</smiles>

${ }^{\mathrm{a}}$ isolated yield

The compound trans-1,3-diphenyl-2-propen-1-ol was purchased from Sigma-Aldrich and used without further purification (Figure 3.5).<smiles>OC(/C=C/c1ccccc1)c1ccccc1</smiles>

Figure 3.7. trans-1,3-diphenyl-2-propen-1-ol.

The isomerization and ATH reactions of these secondary allylic alcohols were conducted using the optimized conditions for the model substrate, 3.3. Under these conditions, overall yields ranged from $77-92 \%$, and $30-93 \%$ ee (Table 3.3). The anisole derivative (entry 3 ) gave the best $\%$ ee, 93\%. The lowest enantioselectivity was obtained with the sterically hindered o-tolyl substrate (entry 5,30\%) and the $\alpha, 6$-unsaturated trans-1,3-diphenyl-2-propen-1-ol derivative (entry 6, 40\%). 
Table 3.3. Isomerization/ATH of substrates under the optimized conditions.

\begin{tabular}{|l|l|l|l|l|}
\hline Entry & Racemic compound & Product & Yield\% $^{\mathrm{a}}$ & \%ee $^{\mathrm{b}}$ \\
\hline
\end{tabular}

1<smiles>C=CC(O)c1ccccc1</smiles>

2<smiles>C=CC(O)c1ccc(C)cc1</smiles>

3<smiles>C=CC(O)c1ccc(OC)cc1</smiles>

4<smiles>C=CC(O)c1ccc(C(F)(F)F)cc1</smiles>

5<smiles>C=CC(O)c1ccccc1C</smiles><smiles>CC[C@H](O)c1ccccc1</smiles><smiles>CC[C@H](O)c1ccc(OC)cc1</smiles><smiles>CC[C@H](O)c1ccc(C(F)(F)F)cc1</smiles><smiles>CC[C@@H](O)c1ccc(C)cc1</smiles>

97 90

86 71

82

93

92 69

6<smiles>OC(/C=C/c1ccccc1)c1ccccc1</smiles><smiles>O[C@H](CCc1ccccc1)c1ccccc1</smiles>

77

40

a. Determined by GC-MS analysis (Column: ZB5-MS , $60 \mathrm{~m}, 0.25 \mathrm{~mm} \mathrm{ID,} 0.25 \mu \mathrm{m}$, Flow rate: $1.2 \mathrm{~mL} / \mathrm{min}$., FID @ $280{ }^{\circ} \mathrm{C}$ ). ${ }^{\text {b. }}$ Determined by chiral HPLC analysis (Chiralpak AS-3R column- $100 \times 4.6 \mathrm{~mm}, 3 \mu$ with $35 / 65 \%$ acetonitrile/water, Flow rate, $1 \mathrm{~mL} / \mathrm{min} . \lambda_{\max } 220 \mathrm{~nm}$ ) 


\section{5: Evaluation of the Electronic Effects}

It has been experimentally established in physical organic chemistry that the presence of a substituent on an aromatic ring system can result in the polarization of electron density around the ring through the $\pi$ system in both the reactant and the product. ${ }^{11}$ This also affects the position of equilibrium and the relative rates of reaction in the reactants and the transition states. One way to study this is through resonance, charge distribution and bond dipoles effects with electron withdrawing groups (EWG) and electron donating groups (EDG). Thus, a series of competition experiments between the model substrate (I) and its derivatives (R) were conducted (Scheme 3.9).

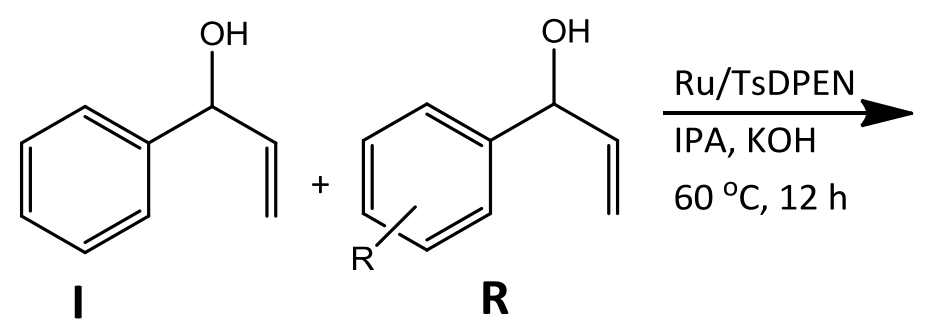<smiles>CCC(O)c1ccccc1</smiles><smiles></smiles>

$$
\begin{array}{lc}
\mathbf{R}= & \mathbf{P}-\mathbf{I} / \mathbf{P}-\mathbf{R} \\
\hline \mathrm{CF}_{3}: & 0.75 \pm 0.2 \\
\mathrm{CH}_{3}: & 1.2 \pm 0.2 \\
\mathrm{OCH}_{3}: & 1.4 \pm 0.5
\end{array}
$$

Scheme 3.9. Evaluation of electronic effects using competition experiments.

Each reaction in Scheme 3.9 was run in triplicate, the relative product ratio of I vs. the substituted derivative $\mathbf{R}$ was determined by GC-MS with relative rate expressed as [P-I]/[P-R].

The trend indicated that the reaction favors $P-R$, when $R$ is the EWG substituent $\mathrm{CF}_{3}$. As noted in previous work from our laboratory, the isomerization step is likely the rate 
determining step in this type of ATH reaction. The electronic effects observed in this reaction can be rationalized by the field effects of the $-\mathrm{CF}_{3}$ group, which favors hydride abstraction (Scheme 3.6, steps 4-5) to form the enolate intermediate. Conversely, electron donating resonance $\left(-\mathrm{OCH}_{3}\right)$ and inductive $\left(-\mathrm{CH}_{3}\right)$ effects destabilize the enolate intermediate, thus slowing its formation. Therefore, on the average, and within experimental error, the trend shows the relative rate of reactivity as, $\mathbf{3 . 3}>\mathbf{3 . 2 4}$ and $\mathbf{3 . 2 6}$, but $<\mathbf{3 . 2 7}$ (Figure 3.5).<smiles>C=CC(O)c1ccc(OC)cc1</smiles>

3.26

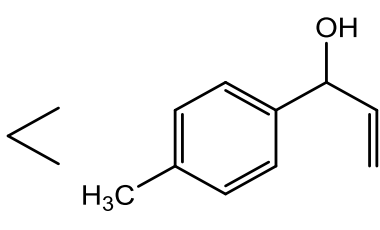

3.24<smiles>C=CC(O)c1ccccc1</smiles>

3.3<smiles>C=CC(O)c1ccc(C(F)(F)F)cc1</smiles>

3.27

Figure 3.7. Comparative trend of relative rates of ATH reaction of secondary allylic alcohols, 3.3,

\section{$3.24,3.26,3.27$.}

\section{6: Conclusions}

In this thesis a new methodology for the transformation of racemic secondary allylic alcohols was developed and optimized for $\alpha$-vinyl benzyl alcohol and a small set of its derivatives. This process featured a ruthenium catalyzed isomerization and asymmetric transfer hydrogenation reaction. The reaction method was optimized via a substrate/catalyst/ligand /base mole ratio of $10 / 1 / 1 / 2$ and a temperature programmed strategy to improve selectivity. Evaluation of electronic effects revealed the sensitivity of the reaction method to both EWG and EDG, as demonstrated by the competition experiments. 


\section{7: Experimental Section}

\subsection{1: General Information}

Reactions were conducted using oven-dried glassware, and under nitrogen atmosphere for all ATH reaction procedures. The catalyst system was generated in situ using Noyori's method. Derivatives of the model allylic alcohol substrate, $\alpha$-vinyl benzyl alcohol, were synthesized using modified method of Wagner and co-workers. ${ }^{10}$

Reagents were purchased from commercial vendors and used as such. The FT-IR spectra were measured with Perkin-Elmer Spectrum 100 FT-IR spectrometer. The NMR spectra were obtained with Bruker $300 \mathrm{MHz}$. Chemical shifts $(\delta)$ are reported in ppm, using the residual undeuterated protio-solvent peak $\left(\mathrm{CDCl}_{3}: \delta \mathrm{H} 7.26\right.$ and $\left.\delta \mathrm{C} 77.16\right)$ as internal standard and TMS $(\delta \mathrm{H} 0.00$ and $\delta C 0.00)$ as reference peak. Coupling constants $(J)$ are given in $\mathrm{Hz}$.

Enantiomeric excess was determined with Agilent HP1090 HPLC, using chiral column OD $\mathrm{RH}$, with 50/50 methanol/water as mobile phase. The flow rate was $0.5 \mathrm{~mL} / \mathrm{min}$. Or, a Chiralpak AS-3R column with $35 / 65 \%$ acetonitrile/water, $1 \mathrm{~mL} / \mathrm{min} . \lambda_{\max } 220 \mathrm{~nm}$

\section{$\underline{\text { GC/MS Parameters }}{ }^{\mathrm{a}}$}

Column

Phenomenex ZB5-MS , $60 \mathrm{~m}, 0.25 \mathrm{~mm} \mathrm{ID}, 0.25 \mu \mathrm{m}$

Injection 


\begin{tabular}{|c|c|}
\hline Injection Volume & $1 \mu \mathrm{L}$ split (150:1) \\
\hline Liner & $4 \mathrm{~mm}$ ID straight inlet liner S/SL w/wool \\
\hline Injection Temperature & $250{ }^{\circ} \mathrm{C}$ \\
\hline Split Vent Flow Rate & $178.5 \mathrm{~mL} / \mathrm{min}$ \\
\hline Oven & \\
\hline Oven Temperature & $100{ }^{\circ} \mathrm{C}$ (hold $7 \mathrm{~min}$ ) to $300{ }^{\circ} \mathrm{C}$ at $10{ }^{\circ} \mathrm{C} / \mathrm{min}$ (hold $15 \mathrm{~min}$ ) \\
\hline Carrier Gas & He, constant flow \\
\hline Flow Rate & $1.2 \mathrm{~mL} / \mathrm{min}$ \\
\hline Detector & FID @ $280{ }^{\circ} \mathrm{C}$ \\
\hline Make-Up Gas Flow Rate & $45.0 \mathrm{~mL} / \mathrm{min}$ \\
\hline Make-Up Gas Type & $\mathrm{He}$ \\
\hline Data Rate & $20 \mathrm{~Hz}$ \\
\hline Detector & MS \\
\hline Mode & Scan \\
\hline Transfer Line Temperature & $280{ }^{\circ} \mathrm{C}$ \\
\hline Analyzer Type & Quadrupole \\
\hline Source Temperature & $230{ }^{\circ} \mathrm{C}$ \\
\hline
\end{tabular}


Electron Energy

Solvent Delay Time

Tune Type

Ionization Mode

Scan Range

Scan Rate

Instrument

${ }^{a}$ Provided by Tom Del Mastro
$70 \mathrm{eV}$

$0.55 \mathrm{~min}$.

PFTBA

Electron Impact (EI)

35-400 amu

3.89 scans/sec

Agilent 5973 Inert Mass Selective Detector (MSD)

\subsection{2: Procedure for Isomerization/Asymmetric Transfer Hydrogenation of}

Model Substrate

To a degassed solution of IPA (40 mL) in a three-neck round bottomed flask, was added the pre-catalyst $\left[\mathrm{RuCl}_{2}\left(\eta^{6}-p \text {-cymene }\right)\right]_{2}(61 \mathrm{mg}, 0.1 \mathrm{mmol})$ and $(1 \mathrm{~S}, 2 \mathrm{~S})-\mathrm{N}-(p$-toluenesulfonyl)-1,2diphenylethylenediamine [(S,S)-TsDPEN] ligand (36 mg, $0.1 \mathrm{mmol}$ ), (Ru atom: TsDPEN mole ratio $=1: 1)$, under an inert atmosphere, and stirred for $25 \mathrm{~min}$ at $80{ }^{\circ} \mathrm{C}$, to give an orange solution, which was then cooled to $45{ }^{\circ} \mathrm{C}$. A pre-mixed solution of the base $\mathrm{KOH}(11 \mathrm{mg}, 0.2$ mmol) and substrate- $\alpha$-vinyl benzyl alcohol (134 mg, $1.0 \mathrm{mmol})$ in IPA was added, and allowed to mix for $2 \mathrm{~h}$. The reaction mixture was then cooled to $25^{\circ} \mathrm{C}$, and stirred for $16 \mathrm{~h}$. The yield was determined by GC-MS and the ee \% value was determined by HPLC with a Daicel chiral OJ-RH 
column with $50 / 50(\mathrm{v} / \mathrm{v})$ methanol/water as mobile phase at $20{ }^{\circ} \mathrm{C}$ at $220 \mathrm{~nm}$. The product was characterized by GC-MS, NMR, FT-IR and chiral HPLC techniques and was isolated by evaporation of the solvent under vacuum and purification by chromatography on silica gel with hexane/ethyl acetate as the eluent.

\subsection{3: Procedure for Synthesis of Allylic Alcohol Derivatives}

Corresponding aldehyde $p$-tolualdehyde $(1.80 \mathrm{~g}, 14.99 \mathrm{mmol})$ was dissolved in a solution of THF (60 mL) contained in a $100 \mathrm{~mL}$ two-neck round bottomed flask fitted with a drying tube and an addition funnel, at $0{ }^{\circ} \mathrm{C}$ and stirred for $5 \mathrm{~min}$. Then $18 \mathrm{~mL}$ of vinyl magnesium bromide (1.0 $\mathrm{M}$ in THF) was added slowly to the mixture and stirred at $0{ }^{\circ} \mathrm{C}$ for an additional 2 hours. The TLC was checked after this period and indicated no presence of the aldehyde. The reaction mixture was diluted with diethyl ether $(10 \mathrm{~mL})$, quenched with ammonium chloride $(10 \mathrm{~mL})$ and allowed to warm up to room temperature. The reaction mixture was transferred into a separatory funnel and extracted with diethyl ether three times. The combined organic layer was washed with brine, dried over $\mathrm{MgSO}_{4}$, and concentrated under vacuum. The crude product was purified and isolated by column chromatography using silica gel with dichloromethane/ethyl acetate (10/1) as eluent. 


\section{8: Experimental Data}

\subsection{1: ATH Product of Model Substrate $-\alpha$-vinylbenzyl alcohol}

(S)-1-phenyl-1-propanol (3.5)

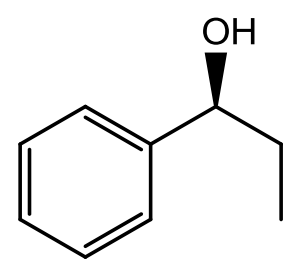

Compound 3.5 was prepared according to the procedure described in section 3.7.2. and afforded a pale yellow oil as the product in $97 \%$ yield and $90 \%$ ee.

${ }^{1} \mathrm{H}$ NMR $\left(300 \mathrm{~Hz}, \mathrm{CDCl}_{3}\right): \delta=7.17-7.02(\mathrm{~m}, 5 \mathrm{H}), 4.74-4.48(\mathrm{t}, 1 \mathrm{H}, J=6.65 \mathrm{~Hz}), 1.79-1.55(\mathrm{~m}, 2 \mathrm{H})$, $0.65-0.60(\mathrm{t}, 3 \mathrm{H}, \mathrm{J}=7.35 \mathrm{~Hz}), 1.92-1.75(\mathrm{brs}, 1 \mathrm{H})$

${ }^{13} \mathrm{C} \mathrm{NMR}\left(300 \mathrm{~Hz}, \mathrm{CDCl}_{3}\right): \delta=144.65,128.40,127.71,127.49,125.98,76.02,31.89,10.13$.

IR (neat, $\left.v_{\max } / \mathrm{cm}^{-1}\right): 3357,3029,1452,1375$

Enantiomeric excess was determined by chiral HPLC analysis (Daicel chiral OJ-RH column with $50 / 50(\mathrm{v} / \mathrm{v})$ methanol/water, $\left.0.5 \mathrm{~mL} / \mathrm{min} . \lambda_{\max } 220 \mathrm{~nm}\right) . \mathrm{R}_{\mathrm{t}}=24.545 \mathrm{~min}(\mathrm{R})$-enantiomer, $\mathrm{R}_{\mathrm{t}}=$ $26.683 \mathrm{~min}(\mathrm{~S})$-enantiomer, $90 \%$ ee.

$\mathrm{GC} / \mathrm{MS}-m / z=136.1$ 


\subsection{2: Synthesis of Intermediates - Derivatives of the model substrate}

\section{1-(4-methylphenyl)-2-propen-1-ol (3.24) ${ }^{12}$}<smiles>C=CC(O)c1ccc(C)cc1</smiles>

p-Tolualdehyde $(1.80 \mathrm{~g} 14.99 \mathrm{mmol})$ was dissolved in a solution of THF $(60 \mathrm{~mL})$, to synthesize compound $\mathbf{3 . 2 4}$ in accordance with the procedure described in section 3.7.3. A yellow oil was obtained as the product in $85 \%$ yield, and was charaterized with NMR, IR and GC/MS.

${ }^{1} \mathrm{H}$ NMR $\left(300 \mathrm{MHz}, \mathrm{CDCl}_{3}\right): \delta=7.35-7.15(\mathrm{~m}, 4 \mathrm{H}), 6.23-5.93(\mathrm{~m}, 1 \mathrm{H}), 5.48-5.33(\mathrm{~m}, 1 \mathrm{H}), 5.25-5.10$ (m, 2H), $2.4(\mathrm{~s}, 3 \mathrm{H}), 2.15-1.95$ (brs, $1 \mathrm{H})$.

${ }^{13} \mathrm{C} \mathrm{NMR}\left(75 \mathrm{MHz}, \mathrm{CDCl}_{3}\right): \delta=140.41,139.77,129.58,127.11,126.57,114.82,75.16,60.42$, 21.11, 14.19 .

IR (neat, $v_{\max } / \mathrm{cm}^{-1}$ ): 3365, 2922, 1512, 1420

$\mathrm{GC} / \mathrm{MS}-m / z=148.1$

\section{1-(2-methylphenyl)-2-propen-1-ol (3.25)}<smiles>C=CC(O)c1ccccc1C</smiles>

o-Tolualdehyde $(2.25 \mathrm{~g}, 18.72 \mathrm{mmol})$ was dissolved in a solution of THF $(50 \mathrm{~mL})$, to synthesize compound $\mathbf{3 . 2 5}$ in accordance with the procedure described in section 3.7.3. A yellow oil was obtained as the product in $80 \%$ yield, and was charaterized with NMR, IR and GC/MS. 
${ }^{1} \mathrm{H}$ NMR $\left(300 \mathrm{MHz}, \mathrm{CDCl}_{3}\right): \delta=7.55-7.10(\mathrm{~m}, 4 \mathrm{H}), 6.0-5.75(\mathrm{~m}, 1 \mathrm{H})$, 5.80-5.65 $(\mathrm{m}, 1 \mathrm{H})$, 5.30-5.00 (m, 2H), $2.25(\mathrm{~s}, 3 \mathrm{H}), 2.0-1.85(\mathrm{brs}, 1 \mathrm{H})$.

IR (neat, $\left.v_{\max } / \mathrm{cm}^{-1}\right): 3364,2977,1694,1487$.

$\mathrm{GC} / \mathrm{MS}-m / z=148.1$

1-(4-methoxylphenyl)-2-propen-1-ol $(3.26)^{12}$<smiles>C=CC(O)c1ccc(OC)cc1</smiles>

p-Methoxybenzaldehyde $(2.37 \mathrm{~g}, 17.43 \mathrm{mmol})$ was was dissolved in a solution of THF (50 $\mathrm{mL})$, to synthesize compound $\mathbf{3 . 2 6}$ in accordance with the procedure described in section 3.7.3. A yellow oil was obtained as product in $95 \%$ yield, and was charaterized with NMR, IR and GC/MS.

${ }^{1} \mathrm{H}$ NMR $\left(300 \mathrm{MHz}, \mathrm{CDCl}_{3}\right): \delta=7.40-7.25(\mathrm{~m}, 2 \mathrm{H}), 6.95-6.85(\mathrm{~m}, 2 \mathrm{H}), 6.15-5.95(\mathrm{~m}, 1 \mathrm{H}), 5.45-$ $5.30(\mathrm{~m}, 1 \mathrm{H}), 5.22-5.08(\mathrm{~m}, 2 \mathrm{H}), 3.84(\mathrm{~s}, 3 \mathrm{H}), 2.32-2.15(\mathrm{brs}, 1 \mathrm{H})$.

${ }^{13} \mathrm{C}$ NMR $\left(75 \mathrm{MHz}, \mathrm{CDCl}_{3}\right): \delta=159.20,140.41,134.90,127.68,126.88,114.73,113.95,71.19$, $67.93,55.29,25.58$.

IR (neat, $\left.\mathrm{v}_{\max } / \mathrm{cm}^{-1}\right): 3410,2836,1608,1509$

$\mathrm{GC} / \mathrm{MS}-m / z=164.1$ 
1-(4-trifluoromethylphenyl)-2-propen-1-ol (3.27)<smiles>C=CC(O)c1ccc(C(F)(F)F)cc1</smiles>

p-Trifluoromethylbenzaldehyde $(2.25 \mathrm{~g}, 13.10 \mathrm{mmol})$ was was dissolved in a solution of THF (50 mL), to synthesize compound $\mathbf{3 . 2 7}$ in accordance with the procedure described in section 3.7.3. An orange oil was obtained as the product in $80 \%$ yield, and was charaterized with NMR, IR and GC/MS.

${ }^{1} \mathrm{H}$ NMR $\left(300 \mathrm{MHz}, \mathrm{CDCl}_{3}\right): \delta=7.65-7.55(\mathrm{~m}, 2 \mathrm{H}), 7.45-7.30(\mathrm{~m}, 2 \mathrm{H}), 6.10-5.60(\mathrm{~m}, 1 \mathrm{H}), 5.38-$ $5.30(\mathrm{~m}, 1 \mathrm{H}), 5.25-5.10(\mathrm{~m}, 2 \mathrm{H}), 2.25-1.59$ (brs, $1 \mathrm{H})$.

${ }^{13} \mathrm{C} \mathrm{NMR}\left(75 \mathrm{MHz}, \mathrm{CDCl}_{3}\right): \delta=146.5,139.6,128.9,126.2,116.7,77.5,76.4,74.9$.

IR (neat, $\left.\mathrm{v}_{\max } / \mathrm{cm}^{-1}\right): 3347,1619,1417,1322$.

$\mathrm{GC} / \mathrm{MS}-m / z=202.1$

trans-1,3-diphenyl-2-propen-1-ol (3.28)<smiles>OC(/C=C/c1ccccc1)c1ccccc1</smiles>

Purchased from Sigma-Aldrich and used without further purification.

\subsection{3: Isomerization/Asymmetric Transfer Hydrogenation Products}

Derivatives of the model substrate - $\alpha$-vinyl benzyl alcohol were subjected to the optimized conditions for isomerization/ATH reaction to afford saturated optically active alcohol 
products, ranging between $77-86 \%$ in yield and $30-93 \%$ ee. Each product was characterized by NMR, IR and GC/MS and chiral HPLC techniques.

(S)- 1-(4-methylphenyl)propan-1-ol (3.29) ${ }^{12}$<smiles>CC[C@H](O)c1ccc(C)cc1</smiles>

In accordance with the procedure described in section 3.7.2. The Isomerization/ATH reaction of $\mathbf{3 . 2 4}$ afforded $\mathbf{3 . 2 9}$ as yellow oil in $86 \%$ yield and $71 \%$ ee.

${ }^{1} \mathrm{H}$ NMR $\left(300 \mathrm{MHz}, \mathrm{CDCl}_{3}\right): \delta=7.25-6.59(\mathrm{~m}, 4 \mathrm{H}), 4.55-4.40(\mathrm{t}, 1 \mathrm{H}, J=6.63 \mathrm{~Hz}), 2.25(\mathrm{~s}, 3 \mathrm{H}), 1.75-$ $1.53(\mathrm{~m}, 2 \mathrm{H}), 1.80$ (brs, $1 \mathrm{H}), 0.90-0.70(\mathrm{t}, 3 \mathrm{H}, \mathrm{J}=7.61)$

${ }^{13} \mathrm{CNMR}\left(75 \mathrm{MHz}, \mathrm{CDCl}_{3}\right): \delta=141.67,137.13,129.08,125.94,75.89,31.94,29.67,22.70,14.12$ 10.18.

IR (neat, $\mathrm{v}_{\max } / \mathrm{cm}^{-1}$ ): 3389, 2927, 1513, 1455.

Chiral HPLC : (Chiralpak AS-3R column- $100 \times 4.6 \mathrm{~mm}, 3 \mu \mathrm{m}$ with 35/65\% acetonitrile/water, 1 $\left.\mathrm{mL} / \mathrm{min} . \lambda_{\max } 220 \mathrm{~nm}\right) . \mathrm{R}_{\mathrm{t}}=4.43 \mathrm{~min}(\mathrm{R})$-enantiomer, $\mathrm{R}_{\mathrm{t}}=4.92 \min (\mathrm{S})$-enantiomer, $71 \%$ ee.

$\mathrm{GC} / \mathrm{MS}-m / z=150.10$ 


\section{(S)-1-(2-methylphenyl)-2-propen-1-ol (3.30)}

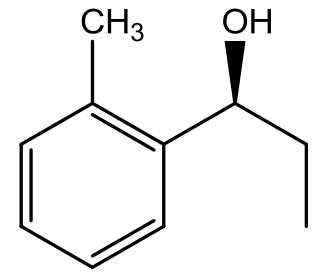

In accordance with the procedure described in section 3.7.2. The isomerization/ATH reaction of $\mathbf{3 . 2 5}$ afforded $\mathbf{3 . 3 0}$ as yellow oil in $86 \%$ yield and $30 \%$ ee.

${ }^{1} \mathrm{H} \mathrm{NMR}\left(300 \mathrm{MHz}, \mathrm{CDCl}_{3}\right): \delta=7.40-7.0(\mathrm{~m}, 4 \mathrm{H}), 4.85-4.70(\mathrm{t}, 1 \mathrm{H}, J=6.70 \mathrm{~Hz}), 2.35(\mathrm{~s}, 3 \mathrm{H}), 1.75-$ $1.65(\mathrm{~m}, 2 \mathrm{H}), 1.55(\mathrm{brs}, 1 \mathrm{H}), 0.95-0.80(\mathrm{t}, 3 \mathrm{H}, \mathrm{J}=7.55)$

IR (neat, $\left.\mathrm{v}_{\max } / \mathrm{cm}^{-1}\right): 3408,2928,1688,1572$.

Chiral HPLC : (Chiralpak AS-3R column- $100 \times 4.6 \mathrm{~mm}, 3 \mu$ with $35 \%$ acetonitrile/65\% water, 1 $\mathrm{mL} / \min . \lambda_{\max } 220 \mathrm{~nm}$ ). $R_{t}=5.64 \min (\mathrm{R})$-enantiomer, $\mathrm{R}_{\mathrm{t}}=5.99 \min (\mathrm{S})$-enantiomer, $30 \%$ ee.

$\mathrm{GC} / \mathrm{MS}-m / z=150.10$

(S)-1-(4-methoxylphenyl)propan-1-ol (3.31)<smiles>CC[C@H](O)c1ccc(OC)cc1</smiles>

In accordance with the procedure described in section 3.7.2. The isomerization/ATH reaction of $\mathbf{3 . 2 6}$ afforded $\mathbf{3 . 3 1}$ as yellow oil in $82 \%$ yield and $93 \%$ ee.

${ }^{1} \mathrm{H}$ NMR $\left(300 \mathrm{MHz}, \mathrm{CDCl}_{3}\right): \delta=7.30-7.15(\mathrm{~m}, 2 \mathrm{H}), 6.95-6.80(\mathrm{~m}, 2 \mathrm{H}), 4.60-4.40(\mathrm{t}, 1 \mathrm{H} J=6.73 \mathrm{~Hz})$, $3.75(\mathrm{~s}, 3 \mathrm{H}), 1.85-1.60(\mathrm{~m}, 2 \mathrm{H}), 1.30-1.20(\mathrm{brs}, 1 \mathrm{H})$ 0.90-0.75 (t, 3H J = $7.45 \mathrm{~Hz})$.

${ }^{13} \mathrm{CNMR}\left(75 \mathrm{MHz}, \mathrm{CDCl}_{3}\right): \delta=159.02,136.77,127.20,113.79,75.66,64.43,55.27,31.78,10.19$.

IR (neat, $\left.v_{\max } / \mathrm{cm}^{-1}\right): 3410,2836,1445,1350$. 
Chiral HPLC : (Chiralpak AS-3R column- $100 \times 4.6 \mathrm{~mm}, 3 \mu$ with 35/65\% acetonitrile/water, 1 $\left.\mathrm{mL} / \mathrm{min} . \lambda_{\max } 220 \mathrm{~nm}\right) . \mathrm{R}_{\mathrm{t}}=5.31 \mathrm{~min}(\mathrm{R})$-enantiomer, $\mathrm{R}_{\mathrm{t}}=5.61 \mathrm{~min}(\mathrm{~S})$-enantiomer, $93 \%$ ee.

$\mathrm{GC} / \mathrm{MS}-m / z=166.10$

(S)-1-(4-trifluoromethyl)propan-1-ol (3.32)

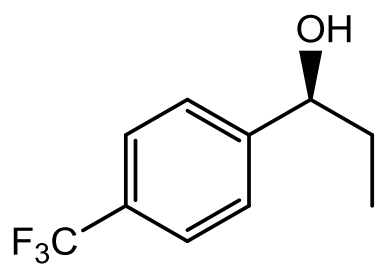

In accordance with the procedure described in section 3.7.2. The isomerization/ATH reaction of $\mathbf{3 . 2 7}$ afforded $\mathbf{3 . 3 2}$ as yellow oil in $92 \%$ yield and $69 \%$ ee.

${ }^{1} \mathrm{H}$ NMR $\left(300 \mathrm{MHz}, \mathrm{CDCl}_{3}\right): \delta=7.65-7.30(\mathrm{~m}, 4 \mathrm{H}), 4.70-4.55(\mathrm{t}, 1 \mathrm{H}, J=5.86 \mathrm{~Hz}), 2.0-1.85$ (brs, $1 \mathrm{H}), 1.80-1.55(\mathrm{~m}, 2 \mathrm{H}), 0.94-0.82(\mathrm{t}, 3 \mathrm{H}, J=7.62 \mathrm{~Hz})$.

${ }^{13} \mathrm{C} \mathrm{NMR}\left(75 \mathrm{MHz}, \mathrm{CDCl}_{3}\right): \delta=142.5,136.8,129.8,126.5,76.1,32.5,29.8,21.0,14.2,10.0$.

IR (neat, $\left.v_{\max } / \mathrm{cm}^{-1}\right): 3395,2959,1464,1376$.

Chiral HPLC : (Chiralpak AS-3R column- $100 \times 4.6 \mathrm{~mm}, 3 \mu$ with 35\% acetonitrile with $0.1 \%$ formic acid/ $65 \%$ water with $0.1 \%$ formic acid, $1 \mathrm{~mL} / \mathrm{min}$. $\lambda_{\max } 220 \mathrm{~nm}$ ). $R_{t}=6.15 \mathrm{~min}(\mathrm{R})$ enantiomer, $\mathrm{R}_{\mathrm{t}}=6.56 \mathrm{~min}(\mathrm{~S})$-enantiomer, $69 \%$ ee.

$\mathrm{GC} / \mathrm{MS}-m / z=204.08$ 
(S)-1,3-diphenylpropan-1-ol (3.33) ${ }^{13}$<smiles>O[C@H](CCc1ccccc1)c1ccccc1</smiles>

Racemic 1,3-diphenyl-2-propen-1-ol (3.28) the precursor to compound 3.33 was purchased from Sigma-Aldrich and used without further purification. Thus, in accordance with the procedure described in section 3.7.2. The isomerization/ATH reaction of this precursor afforded $\mathbf{3 . 3 3}$ as yellow oil in $77 \%$ yield and $40 \%$ ee.

${ }^{1} \mathrm{H}$ NMR $\left(300 \mathrm{MHz}, \mathrm{CDCl}_{3}\right): \delta=7.45-7.15(\mathrm{~m}, 10 \mathrm{H}), 4.75-4.60(\mathrm{t}, 1 \mathrm{H}, J=6.11 \mathrm{~Hz}), 2.85-2.55(\mathrm{~m}$, $2 \mathrm{H}), 2.25-2.00(\mathrm{~m}, 2 \mathrm{H}), 1.95-1.85$ (brs, $1 \mathrm{H})$.

${ }^{13} \mathrm{C} \mathrm{NMR}\left(75 \mathrm{MHzCDCl}_{3}\right): \delta=144.58,141.78,128.97,128.51,128.44,128.38,128.05,127.63$, $125.92,125.85,73.88,60.40,40.46,32.05,31.79,29.66,21.02,14.19$.

IR (neat, $\left.v_{\max } / \mathrm{cm}^{-1}\right): 3395,2859,1602,1494$.

Chiral HPLC : (Chiralpak AS-3R column- $100 \times 4.6 \mathrm{~mm}, 3 \mu$ with 35\% acetonitrile with 0.1\% formic acid/ $65 \%$ water with $0.1 \%$ formic acid, $1 \mathrm{~mL} / \mathrm{min} . \lambda_{\max } 220 \mathrm{~nm}$ ). $\mathrm{R}_{\mathrm{t}}=8.28 \mathrm{~min}(\mathrm{R})$ enantiomer, $R_{t}=8.61 \min (S)$-enantiomer, $40 \%$ ee.

$\mathrm{GC} / \mathrm{MS}-m / z=212.10$ 


\section{References}

1. Wu, R.; Beauchamps, M. G.; Laquidara, J. M.; Sowa, Jr. J. R. Angew. Chem. Int. Ed., 2012, 51, 1-6.

2. (a) van der Drift, R. C.; Bouwman, E. and Drent, E. J. of Organomet. Chem., 2002, 650, 1-24. (b) Uma, R.; Crevisy, C. and Gree, R. Chem. Rev. 2003, 103, 27-51.

3.(a) Noyori, R.; Hashiguchi, S. Acc. Chem. Res. 1997, 30, 97-102. (b) Noyori, R. Asymmetric Catalysis in Organic Synthesis, John Wiley, NewYork, 1994. (c) Noyori, R. Angew. Chem. Int. Ed. 2002, 41, $2008-2022$.

4. Palmer, M. J. and Wills, M. Tetrahedron: Asymmetry, 1999, 10, 2045-2061.

5. (a) Hashiguchi, S.; Fujii, A.; Takehara, J.; Ikariya, T.; Noyori, R. J. Am. Chem. Soc. 1995, 117, 7562-7563. (b) Noyori, R.; Hashiguchi, S. Acc. Chem. Res. 1997, 30, 97-102.

6. (a) Knowles, W. S.; Acc. Chem. Res., 1983, 16, 106-112. (b) Gawley, R. E. J. Org. Chem. 2006, 71, 2411-2416. (c) Hartwig, J. F. Organotransition Metal Chemistry: From Bonding to Catalysis, 1st ed., 2009 (d) Walsh, P. J.; Kozlowski, M. C. Fundamentals of Asymmetric Catalysis, University Science Books, 2009 (e) Gawley, R. E.; Aube, J. Tetrahedron Org. Chem. Series, Vol. 14: Principles of Asymmetric Synthesis, 2006.

7. Shoola, C. O.; DelMastro, T.; Wu, R. and Sowa, Jr., J. R. Eur. J. Org. Chem., 2015, 1670-1673.

8. (a) Yamakawa, M.; Ito, H.; and Noyori, R. J. Am. Chem. Soc. 2000, 122, 1466-1478. (b) Ikariya, T. and Blacker, A. J. Acc. Chem. Res. 2007, 40, 1300-1308.

9. Noyori, R.; Yamakawa, M.; Hashiguchi, S. J. Org. Chem., 2001, 66, 7931-7944.

10. Briot, A.; Baeher, C.; Brouillard, R.; Wagner, A.; Mioskowski, C. J. Org. Chem., 2004, 69, 1374-1377.

11. (a) Hammett, L. P. Some Relations Between Reaction Rates and Equilibrium Constants, 1935. Hammett, L. P. The Effect of Structure upon the Reactions of Organic Compounds. Benzene Derivatives, 1937. (C) Carey, F. A. and Sundberg, R. J. Advanced Organic Chemistry, Part A, Second Edition, Plenum Press ISBN 0-306-41198-9. (d) Anslyn, E. V. and Dougherty, D. A. Modern Physical Organic Chemistry, University Science Books ISBN 1-891389-31-9.

12. T. Slagbrand, H. Lundberg, H. Adolfsson, Chem. Eur. J. 2014, 20, 16102-16106.

13. C. Qin, H. Wu, J. Cheng, X. a. Chen, M. Liu, W. Zhang, W. Su and J. Ding, J. Org. Chem., 2007, 72, 4102-4107 


\section{Chapter Four: Conclusions and Future Work}

\section{1: General Conclusion}

Isomerization and asymmetric transfer hydrogenation reactions of secondary allylic alcohols were carefully studied and developed in our laboratory. This was accomplished following the success with the enantioselective isomerization and transfer hydrogenation reactions of the primary allylic alcohol, geraniol.

In this thesis work, the isomerization and ATH reaction technique has been validated and optimized as a new methodology for the transformation of racemic secondary allylic alcohols into optically active secondary alcohols. This efficient reaction method is catalyzed by a combination of a ruthenium metal complex with TSDPEN as chiral ligand, which is believed to form the active catalyst that effectively reduces both the carbon-to-carbon double bond and the carbonyl group in a one pot process.

The reaction is clean and environmentally friendly, simple to operate and gives good to excellent (70-97\%) yields, with high (90-93\%) enantioselectivity for a small set of substituted $\alpha$ vinyl benzyl alcohols. The reaction rate was found to be sensitive to EWG and EDG; the EWG is postulated to remove electron density from the benzylic carbon via field effects and speeds the rate of reaction through enhanced rate of tautomerization (Scheme 4.1a). Meanwhile the EDG is hypothesized to push electron density towards the reactive site via resonance and inductive effects (Scheme 4.1b). This slows down the rate of tautomerization and the overall reaction rate. The selectivity of the reaction is comparatively consistent with literature reports on the 
isomerization/ATH of secondary allylic alcohols using protected amino acid hydroxyamide chiral ligand. ${ }^{1}$ It appears to be much more affected by sterics in the ortho-substituted derivatives and the disubstituted olefin substrates. However, a more carefully optimized procedure targeted at overcoming steric hindrance may enhance the reactivity and selectivity in these difficult substrates.<smiles>C/C=C(\[O-])c1ccc(C(F)(F)F)cc1</smiles>

4.1

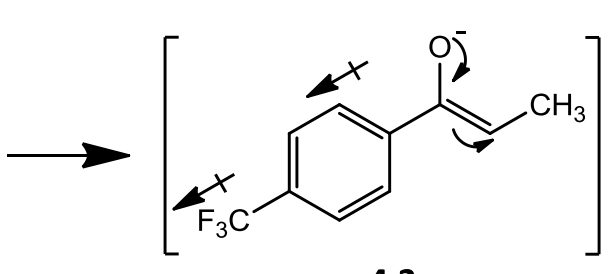

4.2

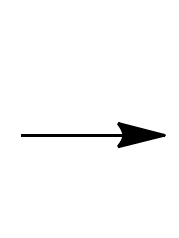

(a) EWG effect<smiles>CCC(=O)c1ccc(C(F)(F)F)cc1</smiles>

4.3<smiles>C/C=C(\[O-])c1ccc(OC)cc1</smiles>

(b) EDG effect

Scheme 4.1. Substituent (a) EWG and (b) EDG effects on the rate of reaction for the ATH of substituted $\alpha$-vinyl benzyl alcohols.

\section{2: Mechanistic Rationale}

The proposed mechanism of this reaction is believed to follow in part; the published mechanism of the ATH reaction for the primary allylic alcohol, geraniol. ${ }^{2}$ The mechanistic steps outlined in the proposed mechanism (Scheme 4.2) are in agreement with the established 
mechanisms of the isomerization of primary allylic alcohol leading to the formation of a carbonyl compound, in this case a ketone intermediate.

The ketone intermediate $\mathbf{4 . 1 3}$ generated from the transposition of the secondary allylic alcohol olefinic moiety $\mathbf{4 . 7}$ is believed to undergo reduction through an outer-sphere enantiofacial transfer of the hydrogen atom via a six-membered ring transition state 4.14. This is stabilized and activated towards the reduction step by hydrogen - bonding promoted alternate charge distribution.

This mechanistic reasoning has been demonstrated by extensive experimental studies on the ATH reactions of prochiral ketones conducted by Noyori and co-workers, and established that the reduction of the ketone substrate occurred through a metal-ligand bifunctional mechanism. In this case, the ligand participated in tandem with the metal to effect hydrogen transfer and formation of the optically active alcohol. ${ }^{3}$

Similarly, the enantiofacial discrimination in the reduction of the ketone intermediate 4.13 from the secondary allylic alcohol 4.7 is facilitated by the participation the amino end group of the ligand TSDPEN, which formed a five membered ring structure with the ruthenium metal center and locks the catalyst system in a planar orientation. This promotes hydrogen transfer more favorably on one face of the prochiral ketone intermediate 4.13. In this way, the ketone intermediate is oriented in a position that places the larger group away from the catalyst system, thereby favoring the S-enantiomer chiral alcohol product 4.15. 


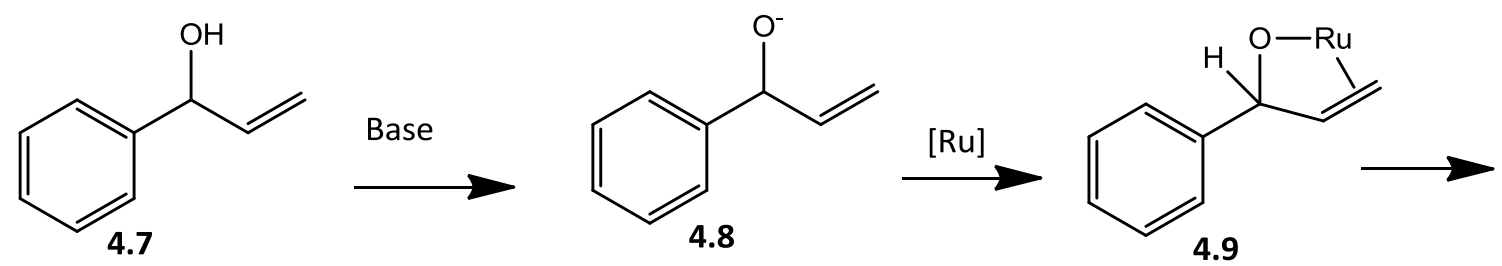<smiles>[R14]c1ccc(C(C)C)cc1/C(O)=C/C</smiles>

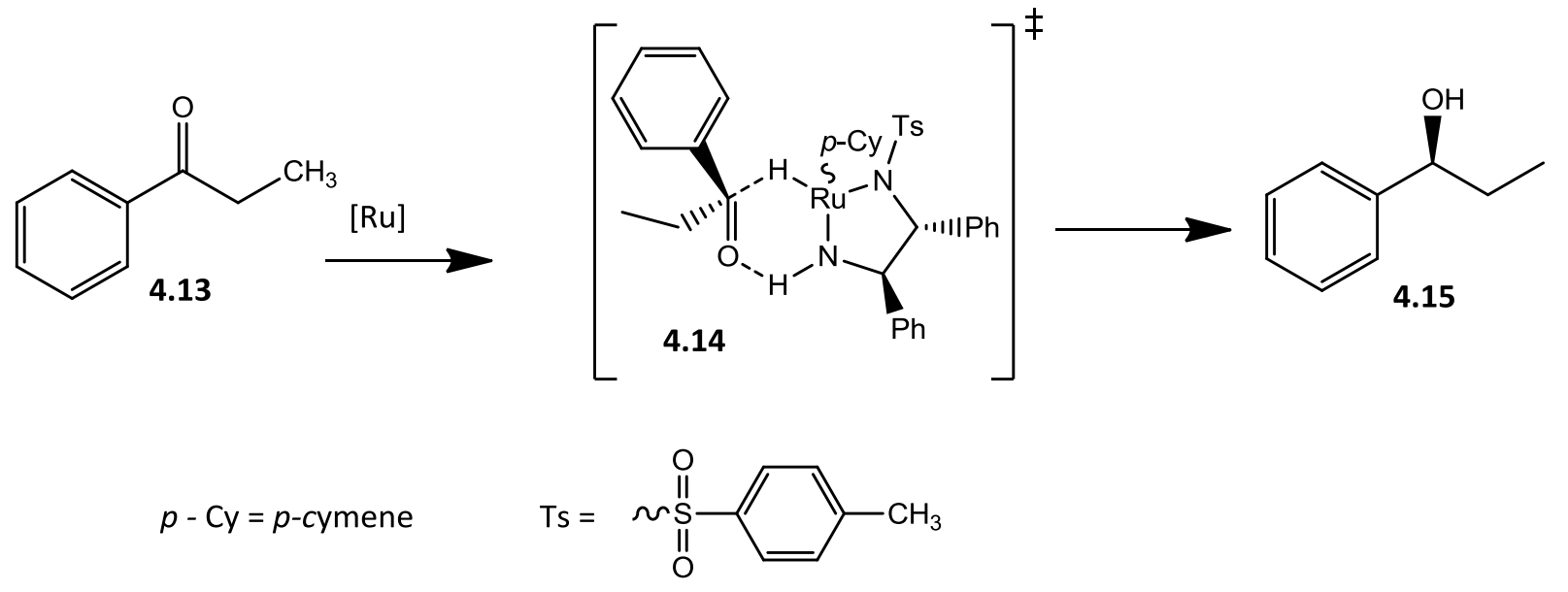

Scheme 4.2. Proposed mechanism of the chiral ATH of $\alpha$-vinyl benzyl alcohols.

\section{3: Future Work}

The synthetic applications of the ATH reaction are proposed in the synthetic designs of two bioactive compounds: ibuprofen and the $\mathrm{LTD}_{4}$ antagonist; Singulair.

Ibuprofen is a common over the counter non-steroidal anti-inflammatory drug (NSAID), ${ }^{4}$ currently synthesized in a four step process both in the industry and academia. ${ }^{5}$ Employing the isomerization/ATH reaction, its synthesis can be conveniently accomplished in two reaction 
steps starting from the commercially available 2-(4-isobutylphenyl)-propen-1-ol (Scheme 4.1). The first step features the optimized conditions for the isomerization/ATH reaction to generate the important precursor 4.17, to ibuprofen, followed by TEMPO oxidation to afford the biologically active S-enantiomer product $\mathbf{4 . 1 8}$. The final product may be characterized using traditional analytical techniques such as, NMR, GC-MS, FT-IR and chiral HPLC. Additionally, biological studies may be conducted to validate the pharmacological activity of the product. ${ }^{6}$

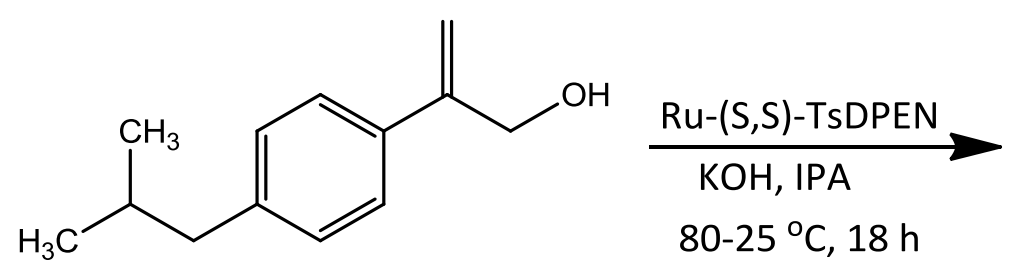

4.16<smiles>CC(C)Cc1ccc([C@@H](C)CO)cc1</smiles>

4.17

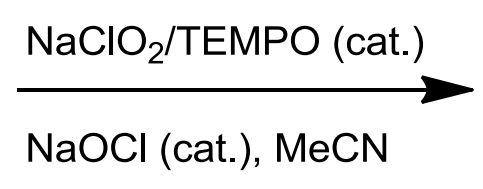

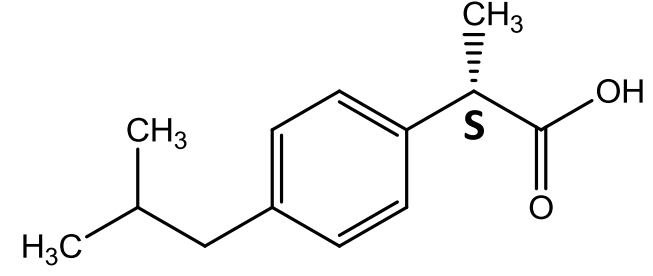

4.18

Scheme 4.3. Proposed synthesis of ibuprofen.

Also, $\mathrm{LTD}_{4}$ is an endogenous agonist, which causes contractions of smooth muscle lining the trachea, leading to inflammation in asthma and allergic rhinitis. ${ }^{7}$ The $\mathrm{LTD}_{4}$ antagonist currently marketed as Singulair $^{\mathrm{TM}}$ is synthesized in about eight reaction steps including a nonenvironmentally friendly key step. ${ }^{8}$ This key step utilizes the organoboron reduction chemistry, involving 6 -chlorodiisopinocampheylborane; a compound known for its sensitivity to air and moisture, as well as its high toxicity and explosive tendencies. ${ }^{9}$ This antagonist compound has a 
single chiral center which can originate from a secondary allylic alcohol. The key step in the de novo total synthesis of Singulair ${ }^{\mathrm{TM}}$ will be to synthesize intermediate 4.23 , a core component of the antagonist, by the optimized ATH reaction shown in Scheme 4.4. If this step can be optimized in high yield and \% ee, then this synthetic design may prove to be an excellent alternative to the current synthesis. Additionally, the proposed synthesis strategy features an initial formation of the allylic alcohol 4.21 through vinylation of the commercially available aldehyde 4.19. The Heck reaction features coupling of 4.21 with 2-iodobenzonitrile 4.22 and is expected to generate the core component of the antagonist; intermediate $\mathbf{4 . 2 3}$. This will be reduced to the chiral alcohol 4.24 through the optimized conditions of the isomerization/ATH reaction developed in this thesis work. Further reaction of $\mathbf{4 . 2 4}$ with dilithio carboxylate and transformation of the nitrile functionality to ketone, will produce the antagonist compound 4.26. This synthetic approach presents two key catalytic steps (the Heck coupling and the isomerization/ATH reaction) that will not only reduce the cost of the synthetic process but are also atom economic. In fact, the current stereoselective step in this synthesis involves a stoichiometric organoborane reduction, which is not as atom economical as the proposed ATH reaction methodology. ${ }^{8}$ 
<smiles>C=CNC(=O)c1cccc(/C=C/c2ccc3ccc(Cl)cc3n2)c1</smiles><smiles>C=CC(O)c1cccc(/C=C/c2ccc3ccc(Cl)cc3n2)c1</smiles><smiles>N#Cc1ccccc1/C=C/C(O)c1cccc(/C=C/c2ccc3ccc(Cl)cc3n2)c1</smiles>

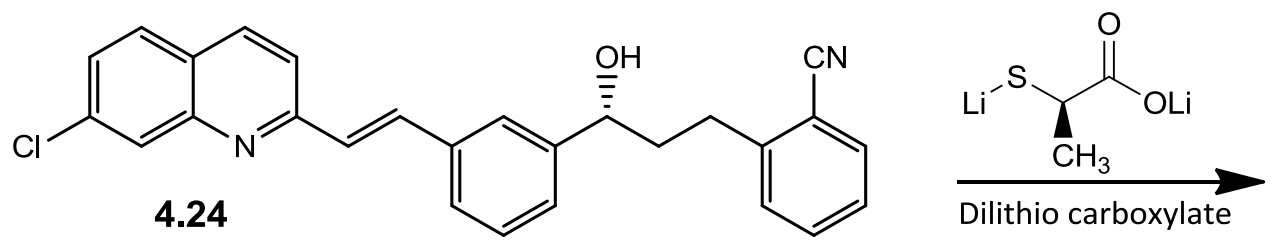<smiles>C[C@@H](CS[C@H](CCc1ccccc1C#N)c1cccc(/C=C/c2ccc3ccc(Cl)cc3n2)c1)C(=O)O</smiles>

4.25<smiles>CC(=O)c1ccccc1CC[C@H](SC[C@@H](C)C(=O)O)c1cccc(/C=C/c2ccc3ccc(Cl)cc3n2)c1</smiles>

4.26

Scheme 4.4. Stereoselective synthesis step for the LTD4 antagonist. 
The reaction steps in these synthetic targets as highlighted in both Schemes 4.3 and 4.4 are based on reactions that are known to function reliably well with high-yielding product outcomes. $^{2,8,10,11,12}$ A careful retrosynthetic analyses will lead to the target components to which isomerization/ATH reaction can be effectively applied.

A careful optimization of this reaction method with the target components could provide a better alternative route to the current syntheses of these bioactive compounds. Moreover, the total synthesis of Singulair ${ }^{\mathrm{TM}}$ (LTD $_{4}$ antagonist) and Ibuprofen ${ }^{\mathrm{TM}}$, is proposed to occur through better atom economy, shortened reaction steps, and environmentally benign processes.

\section{4: Publication and Presentations}

This work has been published as a communication in the European Journal of Organic Chemistry, under the digital object identifier DOI: 10.1002/ejoc.201500075. ${ }^{13}$ This contribution to knowledge has not only expanded the scope of this important reaction but will also lead to new technological developments within the organic, inorganic and organometallic communities.

Additional work that may be published from this thesis work include detailed mechanistic studies of the proposed mechanisms for the ATH reaction of secondary allylic alcohols. The Hammett study of the rates of reaction to quantitatively validate the observed effects of the EWG and EDG groups. This can be used to gain a better understanding of the low selectivity recorded with the ortho- substituted derivatives and di-substituted olefin substrates. 
This work has also been presented as seminal project at a symposium organized by the Catalysis Society of Metropolitan New York, held at Princeton University, Princeton, NJ, in 2013. ${ }^{14}$ It has also been featured at the Petersheim Science Exhibitions in 2013 and 2014, organized by the department of Chemistry and Biochemistry, Seton Hall University, South Orange, NJ.

\section{Reference}

1. T. Slagbrand, H. Lundberg, H. Adolfsson, Chem. Eur. J. 2014, 20, 16102-16106.

2. Wu, R.; Beauchamps, M. G.; Laquidara, J. M.; Sowa, Jr. J. R. Angew. Chem. Int. Ed., 2012, 51, 1-6.

3. (a) Noyori, R. ; Yamakawa, M. ; Hashiguchi, S. J. Org. Chem., 2001, 66, 7931 - 7944. (b) Yamakawa, M. ; Ito, H.; Noyori, R. J. Am. Chem. Soc. 2000, 122, 1466-1478.

4. Van Esch, A.; Van Steensel-Moll, H. A.; Steyerberg, E. W.; Offringa, M.; Habbema, J. D.; Derksen-Lubsen, G. Archives of Pediatrics \& Adolescent Medicine, 1995, 149, 632-637.

5. Kjonaas, R. A.; Williams, P. E.; Counce, D. A.; Crawley, L. R. J. Chem. Educ. 2011, 88, 825-828.

6. (a) Geisslinger, G., Dietzel, K., Loew, D., Schuster, O., Rau, G., Lachmann, G., Brune, K. J. Chrom. B: Biomedical Sciences and Applications, 1989, 491, 139-149 . (b) Reddy, R. Chandiran, S., Jayaveera, K., Koteswara, R. Arch. Apl. Sci. Res., 2010, 2 (3): 101-111.

7. Lipkowitz, Myron A. and Navarra, Tova (2001) The Encyclopedia of Allergies (2nd ed.) Facts on File, New York, p. 178.

8. (a) King, A.O.; Corley, E. G.; Anderson, R. K.; Larsen, R. D.; Verhoeven, T. R.; Reider, P. J. J. Org. Chem. 1993, 58, 3731-3735. (b) Shinkai, I.; King, A. O.; Larsen, R. D. Pure \& Appl. Chem., 1994, 66, 1551-1556. (c) Srebnik, M.; Ramachandran, P. V.; Brown, H. C. J. Org. Chem., 1988, 53, 2916-2920. 
9. Review of MSDS from various manufacturers and suppliers

10. Zhao, M. M.; Li, J.; Mano, E.; Song, Z. J.; Tschaen, D. M. Org. Synth. 2005, 81, 195

11. Briot, A.; Baeher, C.; Brouillard, R.; Wagner, A.; Mioskowski, C. J. Org. Chem., 2004, 69, 1374-1377.

12. (a) Heck, R. F. J. Am. Chem. Soc. 1969, 91 (24), 6707. (b) Heck, R. F. Org. React.,1982, 27 345-390. (c) Beletskaya, I. P.; Cheprakov, A. V. Chem. Rev. 2000, 100 (8): 3009-3066.

13. Shoola, C. O.; DelMastro, T.; Wu, R. and Sowa, Jr., J. R. Eur. J. Org. Chem., 2015, 1670-1673.

14. The Catalysis Society of Metropolitan New York, 2013 Spring Symposium 


\section{Appendix}

\section{Table of Contents}

Figure A1. The chiral HPLC chromatogram of compound $\mathbf{3 . 5}$

Figure A2. The ${ }^{1} \mathrm{H}$ NMR spectrum of compound $\mathbf{3 . 5}$

Figure $\mathbf{A} 3$. The ${ }^{13} \mathrm{C}$ NMR spectrum of compound $\mathbf{3 . 5}$

Figure A4. The FT-IR spectrum of compound $\mathbf{3 . 5}$

Figure A5. The mass spectrum of compound $\mathbf{3 . 5}$

Figure A6. The ${ }^{1} \mathrm{H}$ NMR spectrum of compound $\mathbf{3 . 2 4}$ .121

Figure A7. The ${ }^{13} \mathrm{C}$ NMR spectrum of compound $\mathbf{3 . 2 4}$ .122

Figure A8. The ${ }^{1} \mathrm{H}$ NMR spectrum of compound $\mathbf{3 . 2 5}$ 123

Figure A9. The ${ }^{1} \mathrm{H}$ NMR spectrum of compound $\mathbf{3 . 2 6}$ .124

Figure A10. The ${ }^{13} \mathrm{C}$ NMR spectrum of compound $\mathbf{3 . 2 6}$ .125

Figure A11. The ${ }^{1} \mathrm{H}$ NMR spectrum of compound $\mathbf{3 . 2 7}$ .126

Figure A12. The ${ }^{13} \mathrm{C}$ NMR spectrum of compound $\mathbf{3 . 2 7}$ .127

Figure A13. The chiral HPLC chromatogram of compound $\mathbf{3 . 2 9}$ 128

Figure A14. The ${ }^{1} \mathrm{H}$ NMR spectrum of compound $\mathbf{3 . 2 9}$ .129 
Figure A15. The ${ }^{13} \mathrm{C}$ NMR spectrum of compound $\mathbf{3 . 2 9}$

Figure A16. The FT-IR spectrum of compound $\mathbf{3 . 2 9}$ .131

Figure A17. The mass spectrum of compound $\mathbf{3 . 2 9}$ .132

Figure A18. The chiral HPLC chromatogram of compound $\mathbf{3 . 3 0}$ 133

Figure A19. The ${ }^{1} \mathrm{H}$ NMR spectrum of compound $\mathbf{3 . 3 0}$ .134

Figure A20. The FT-IR spectrum of compound $\mathbf{3 . 3 0}$ .135

Figure A21. The chiral HPLC chromatogram of compound $\mathbf{3 . 3 1}$ 136

Figure A22. The ${ }^{1} \mathrm{H}$ NMR spectrum of compound $\mathbf{3 . 3 1}$ .137

Figure A23. The ${ }^{13} \mathrm{C}$ NMR spectrum of compound $\mathbf{3 . 3 1}$ .138

Figure A24. The FT-IR spectrum of compound 3.31 .139

Figure A25. The mass spectrum of compound $\mathbf{3 . 3 1}$ .140

Figure A26. The chiral HPLC chromatogram of compound $\mathbf{3 . 3 2}$ .141

Figure A27. The ${ }^{1} \mathrm{H}$ NMR spectrum of compound $\mathbf{3 . 3 2}$ 142

Figure A28. The FT-IR spectrum of compound $\mathbf{3 . 3 2}$ .143

Figure A29. The mass spectrum of compound $\mathbf{3 . 3 2}$ .144

Figure A30. The chiral HPLC chromatogram of compound $\mathbf{3 . 3 3}$ .145

Figure A31. The ${ }^{1} \mathrm{H}$ NMR spectrum of compound $\mathbf{3 . 3 3}$ 146 
Figure A32. The ${ }^{13} \mathrm{C}$ NMR spectrum of compound $\mathbf{3 . 3 3}$

Figure A33. The mass spectrum of compound $\mathbf{3 . 3 3}$ .148 


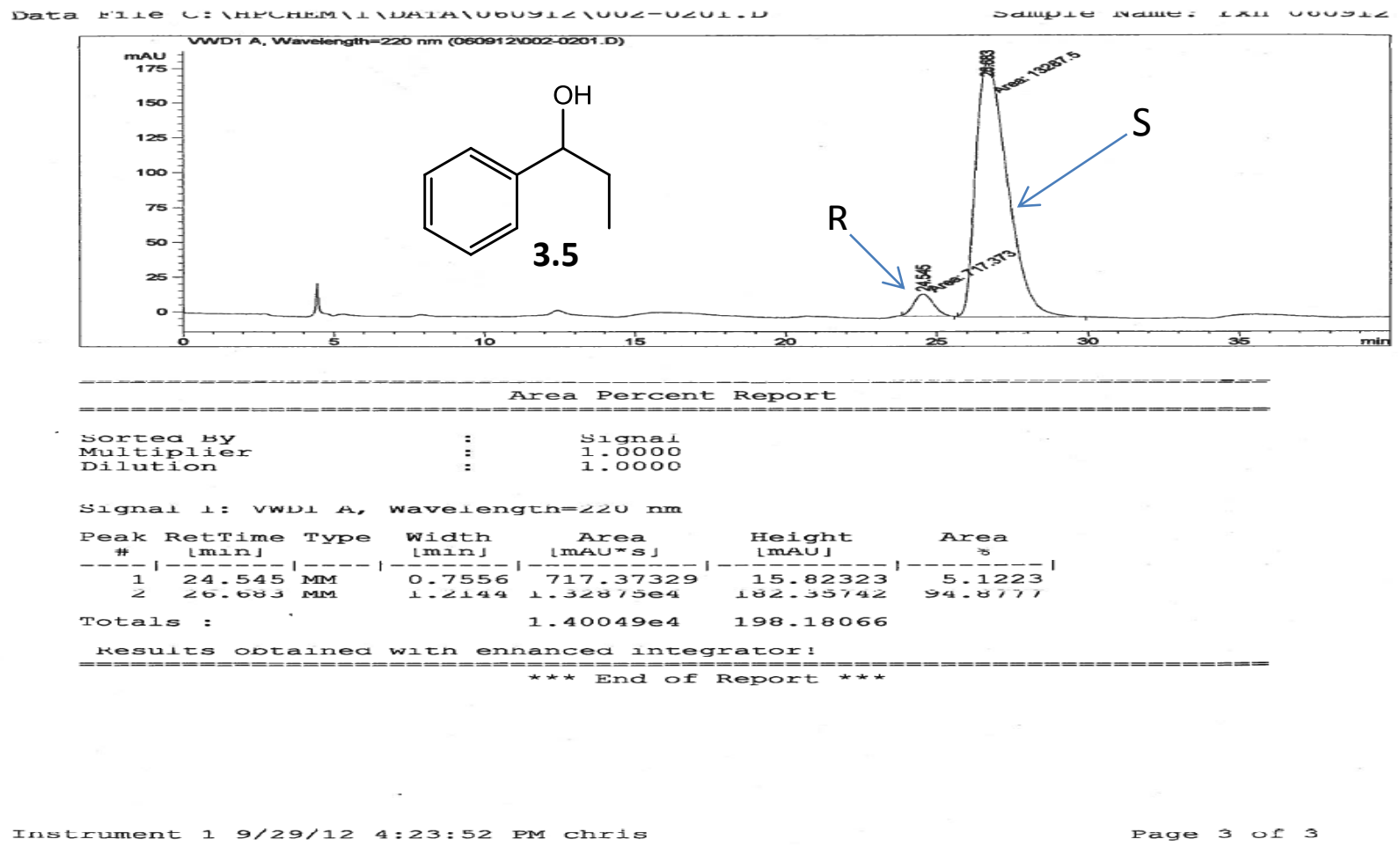

Figure A1. The chiral HPLC chromatogram of compound $\mathbf{3 . 5}$ 


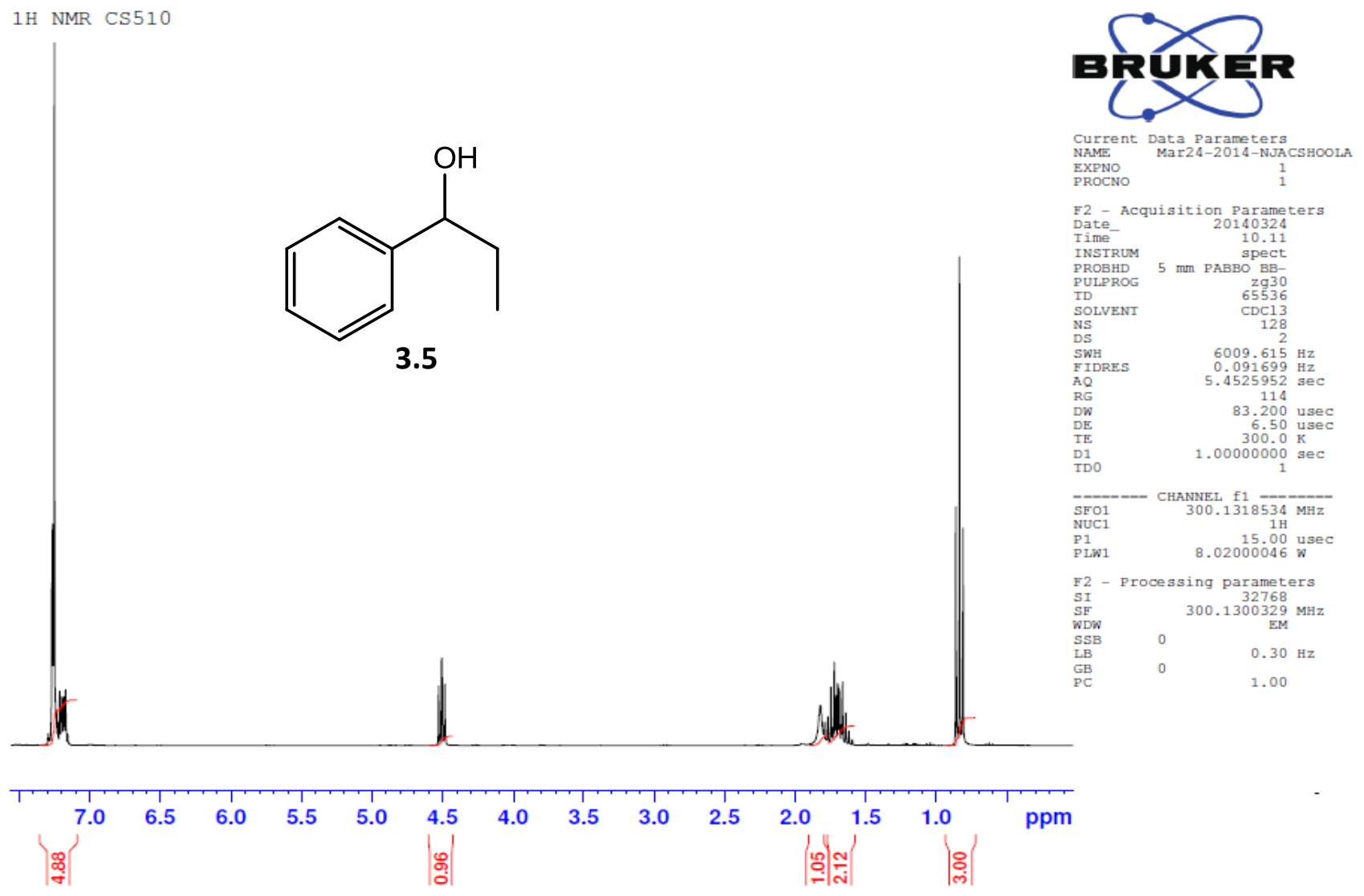

Figure A2. The ${ }^{1} \mathrm{H}$ NMR spectrum of compound $\mathbf{3 . 5}$ 


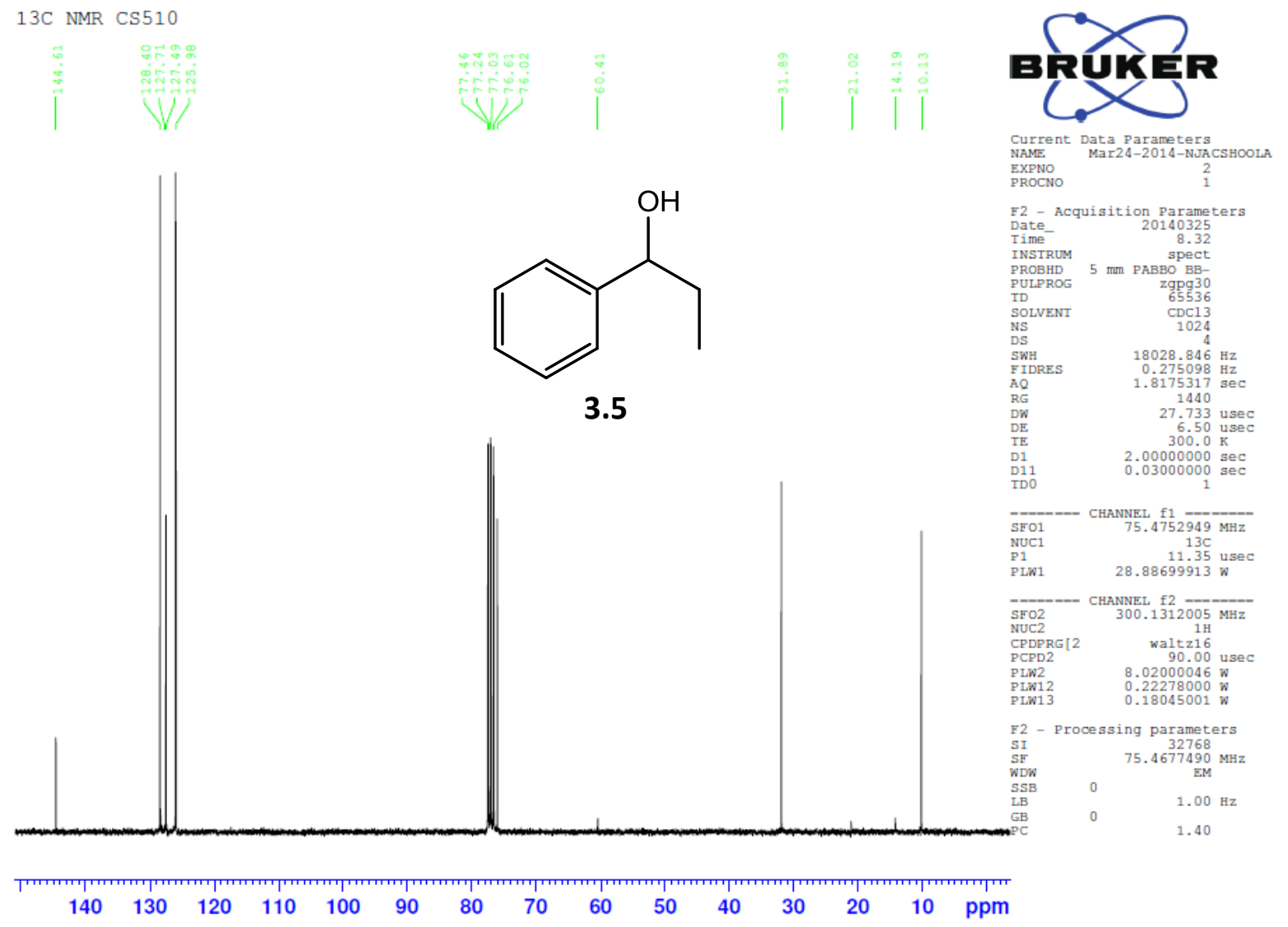

Figure $\mathbf{A} 3$. The ${ }^{13} \mathrm{C}$ NMR spectrum of compound $\mathbf{3 . 5}$ 


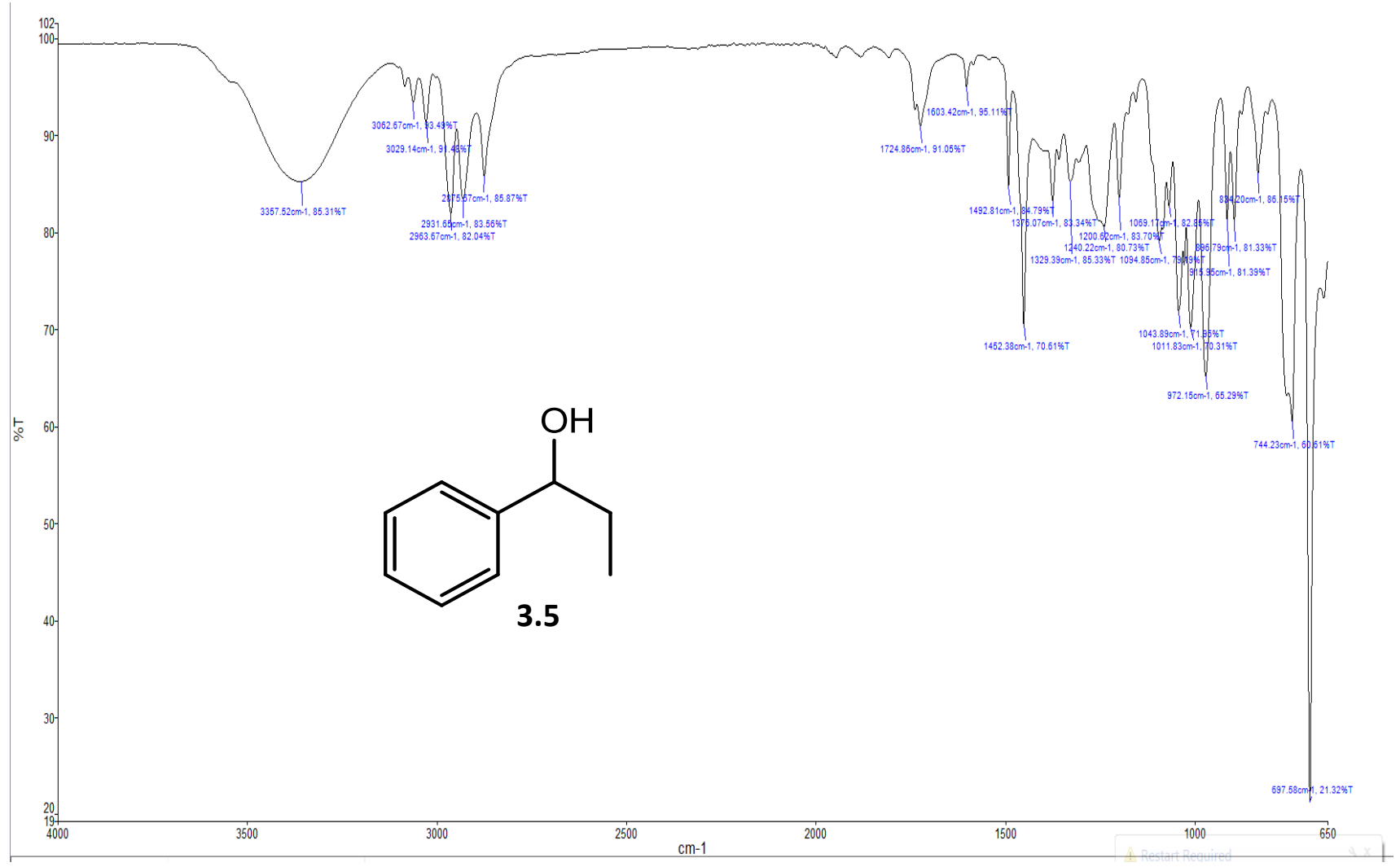

Figure A4. The FT-IR spectrum of compound $\mathbf{3 . 5}$ 


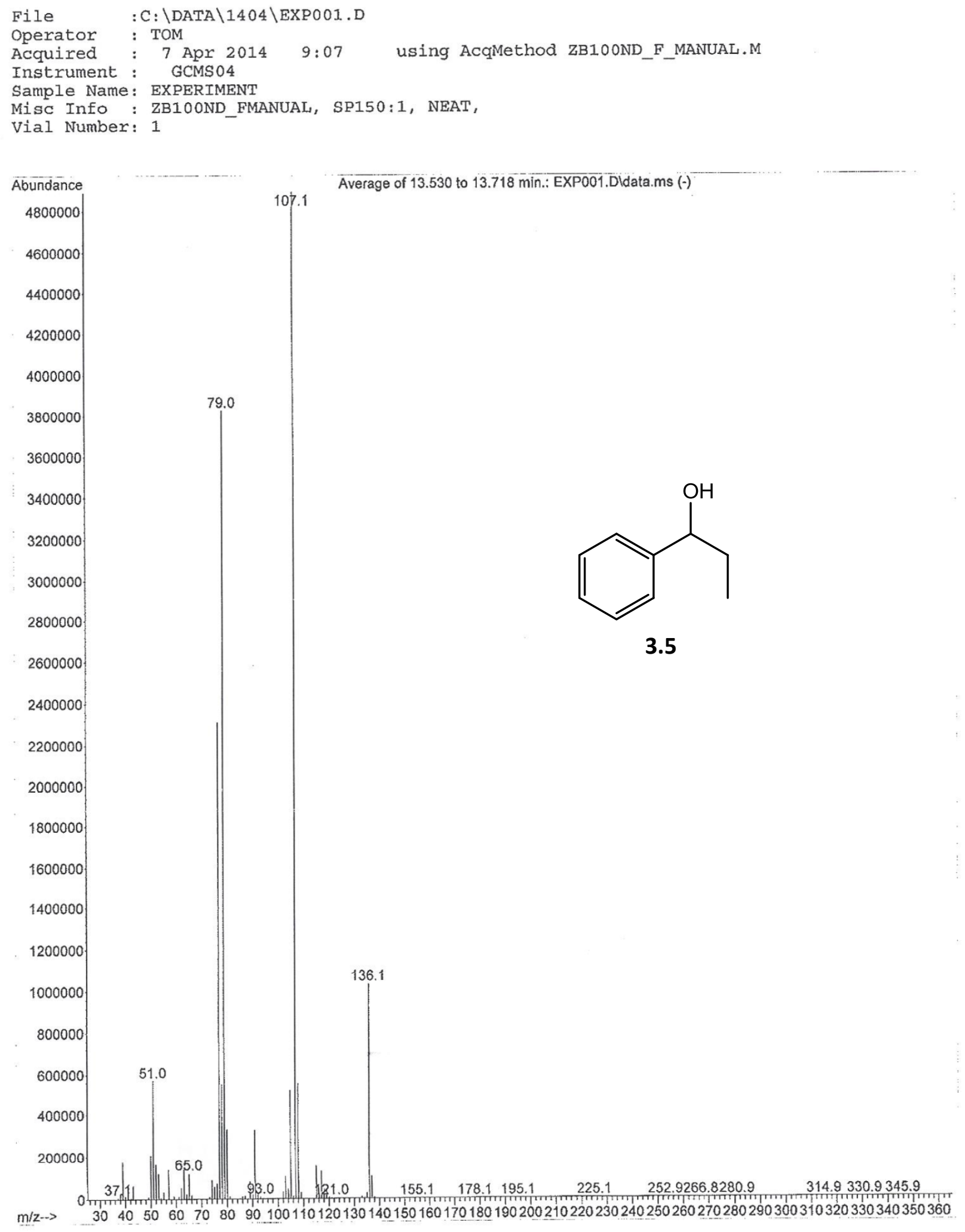

Figure A5. The mass spectrum of compound $\mathbf{3 . 5}$ 


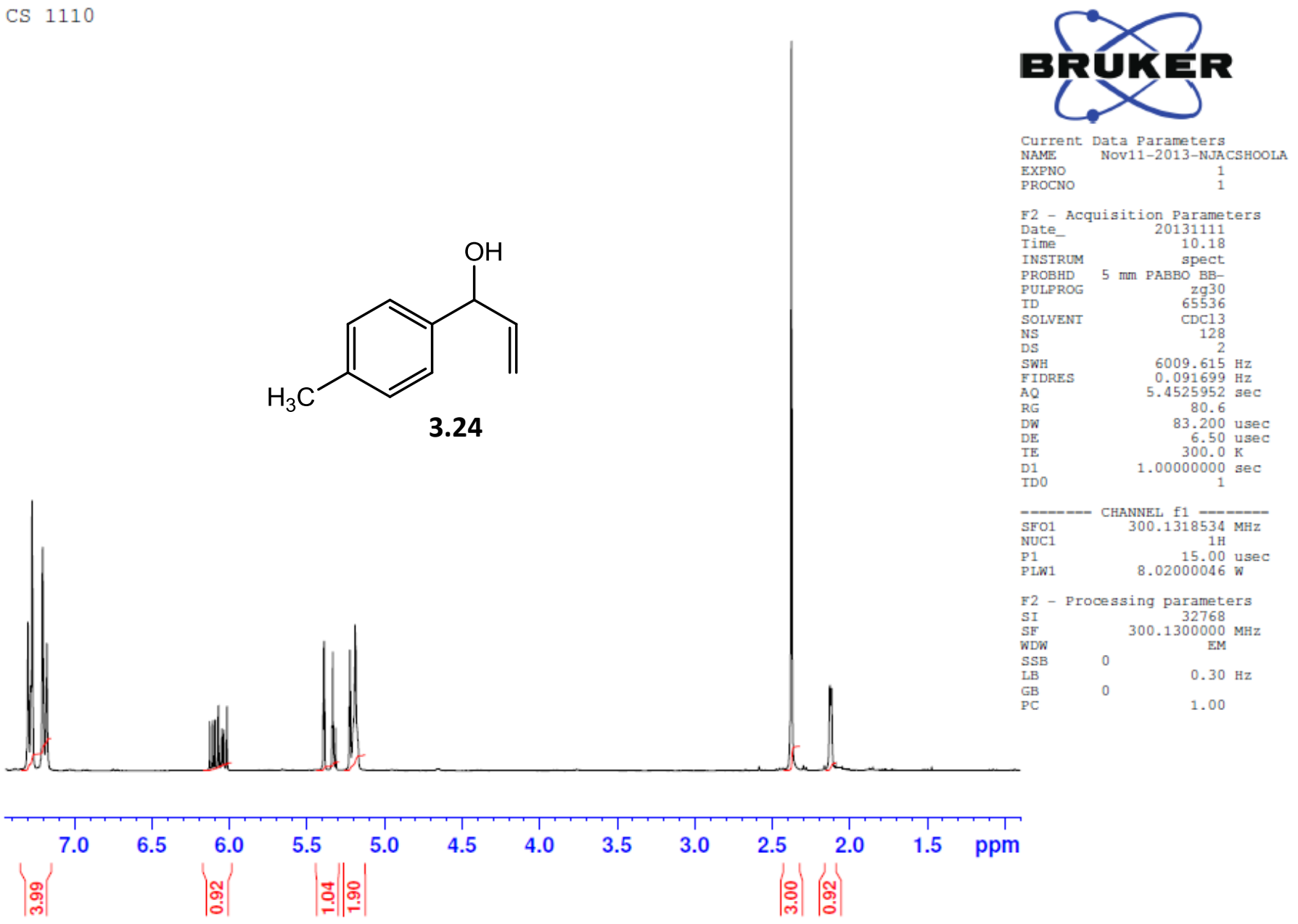

Figure A6. The ${ }^{1} \mathrm{H}$ NMR spectrum of compound $\mathbf{3 . 2 4}$ 


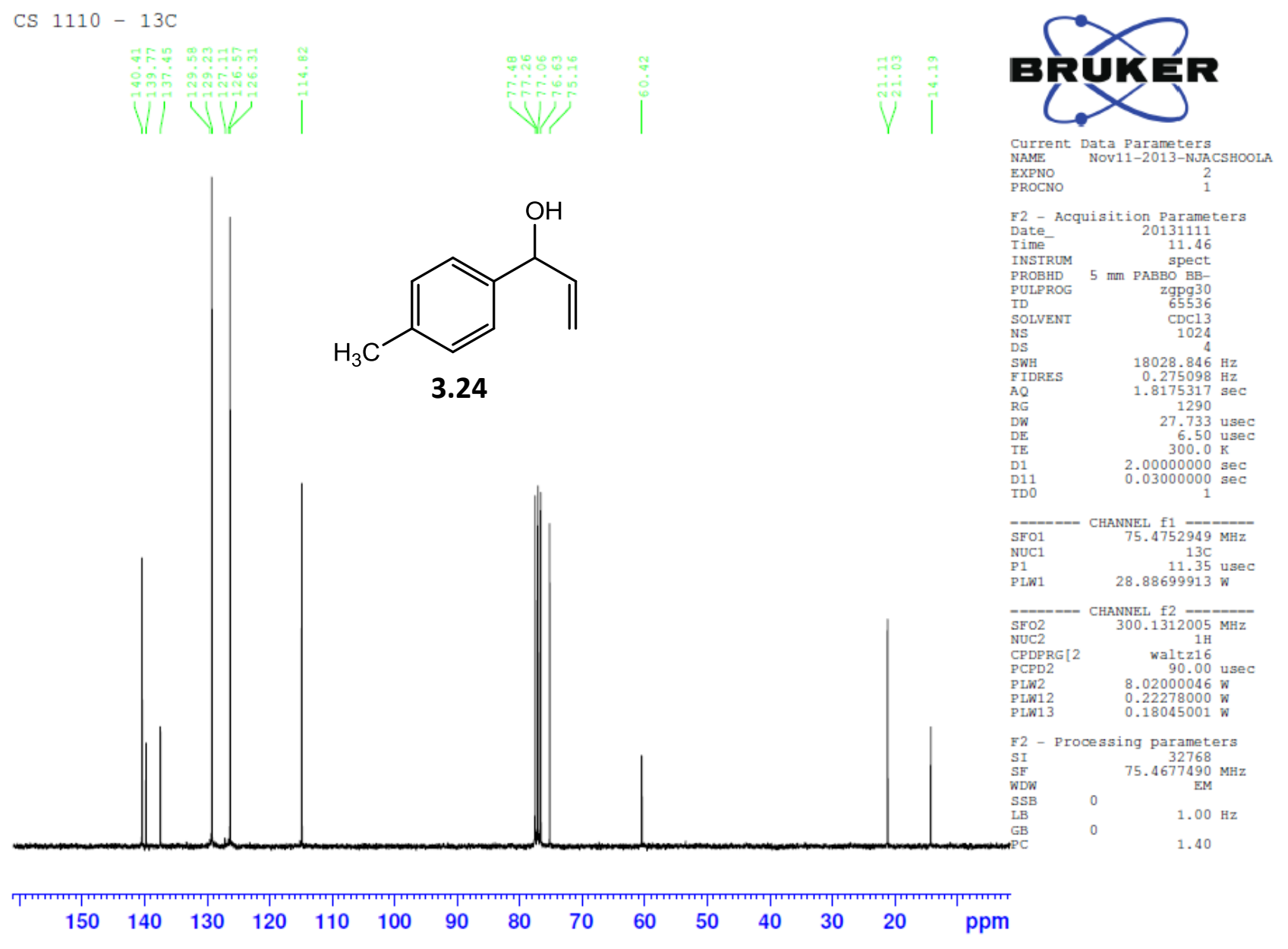

Figure A7. The ${ }^{13} \mathrm{C}$ NMR spectrum of compound $\mathbf{3 . 2 4}$ 


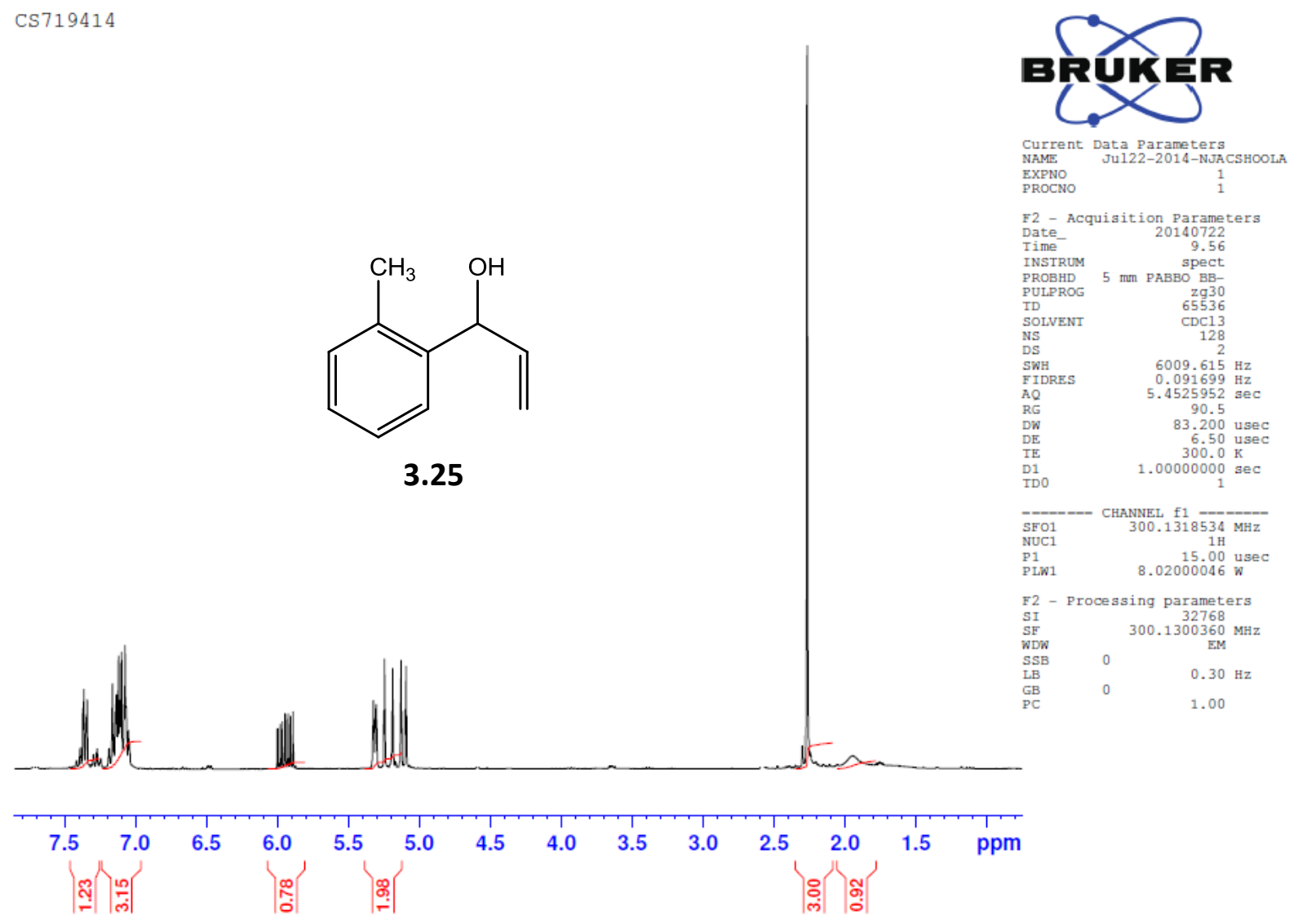

Figure A8. The ${ }^{1} \mathrm{H}$ NMR spectrum of compound $\mathbf{3 . 2 5}$ 


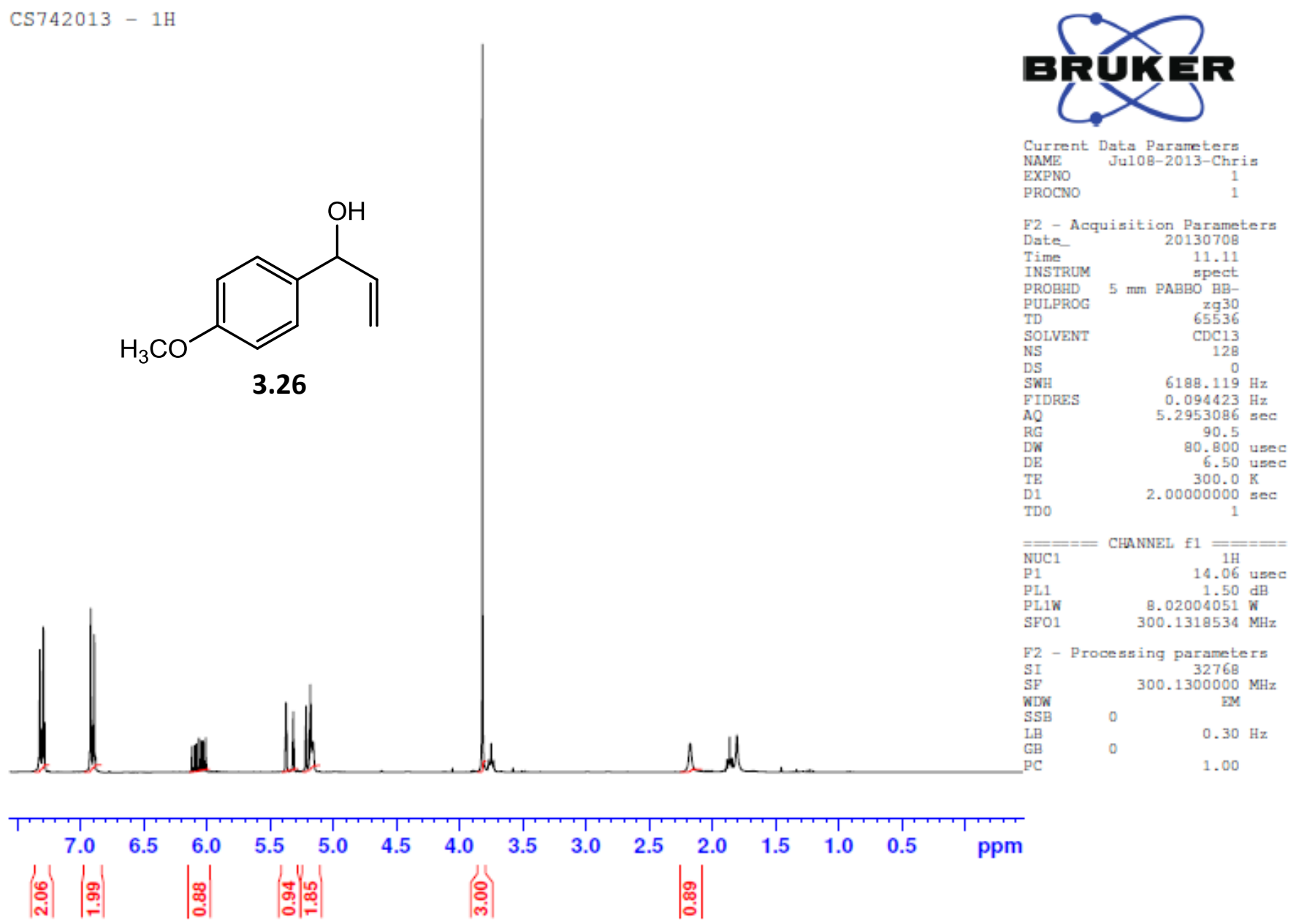

Figure A9. The ${ }^{1} H$ NMR spectrum of compound 3.26 


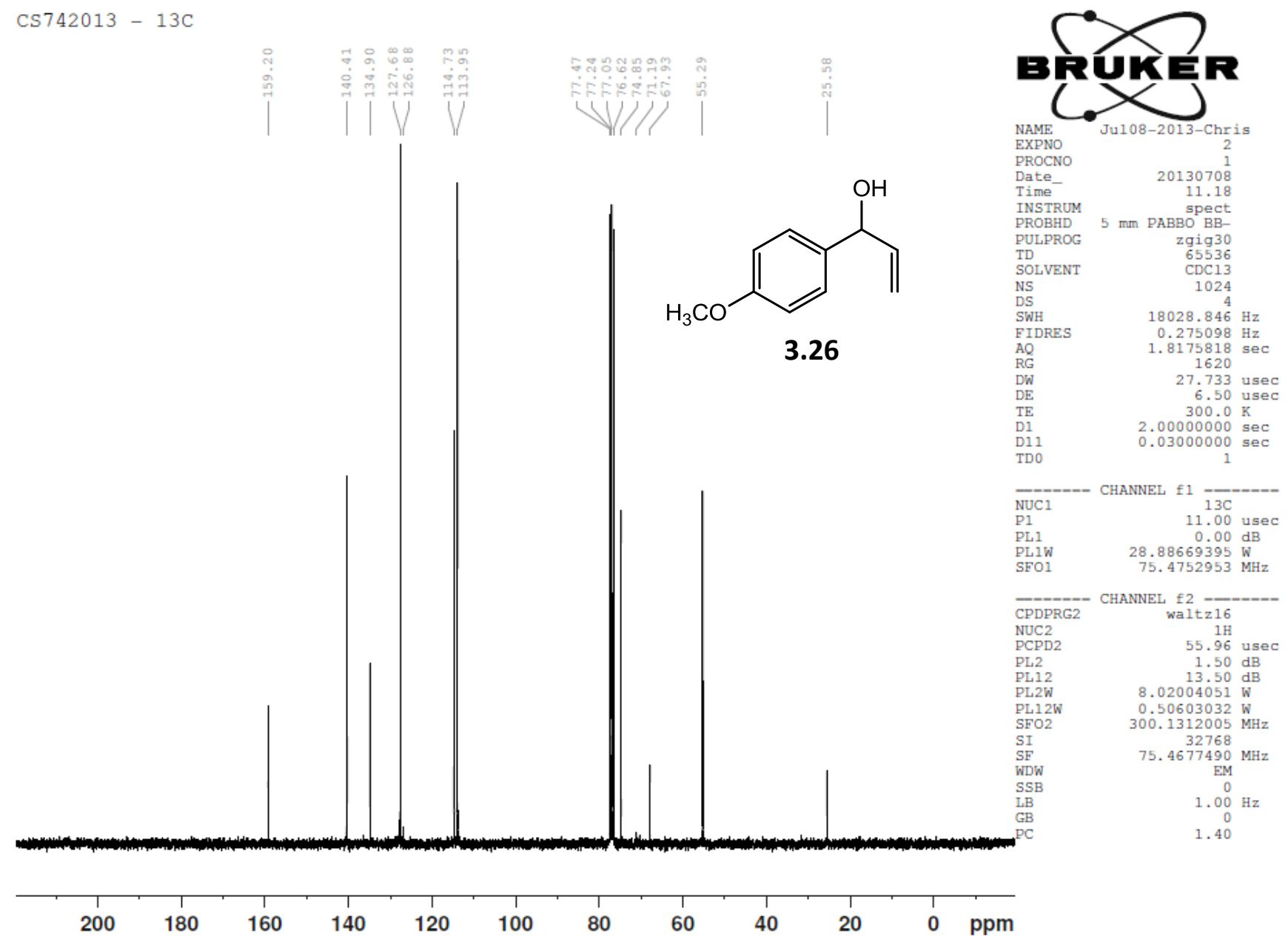

Figure A10. The ${ }^{13} \mathrm{C}$ NMR spectrum of compound $\mathbf{3 . 2 6}$ 

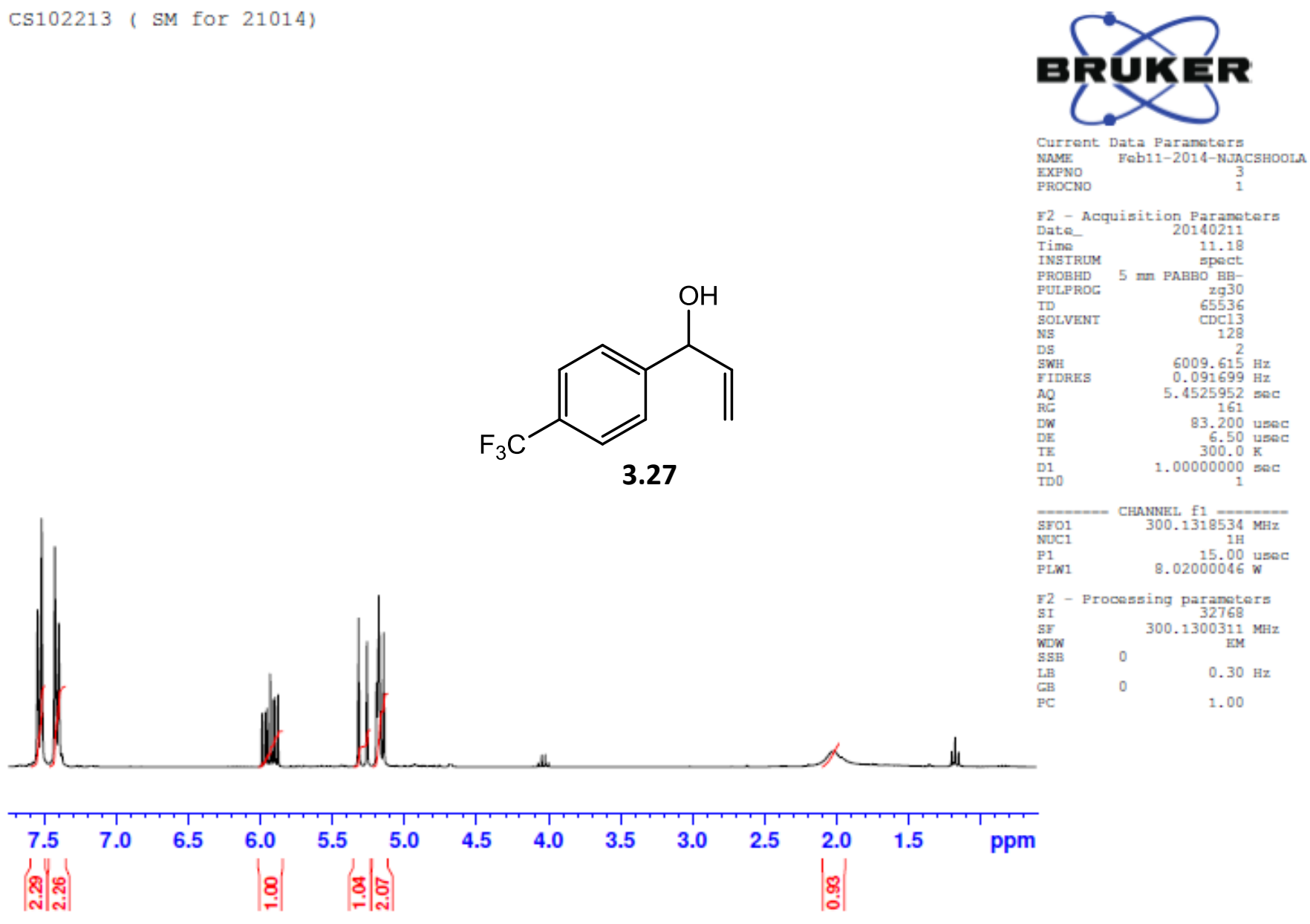

Figure A11. The ${ }^{1} \mathrm{H}$ NMR spectrum of compound $\mathbf{3 . 2 7}$ 


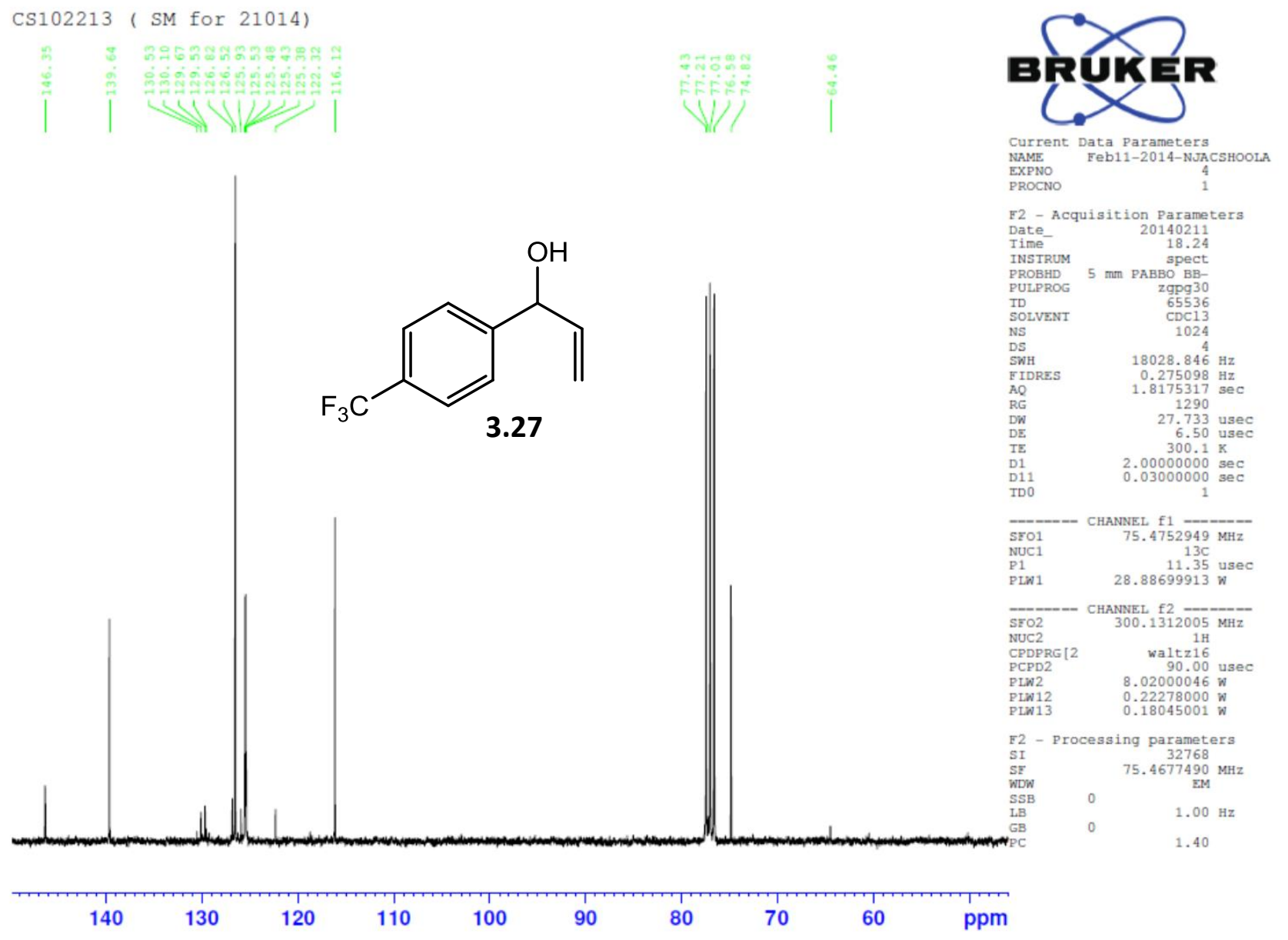

Figure A12. The ${ }^{13} \mathrm{C}$ NMR spectrum of compound $\mathbf{3 . 2 7}$ 
Chemical Formula: $\mathrm{C}_{10} \mathrm{H}_{14} \mathrm{O}$

Exact Mass: 150.10

Molecular Weight: 150.22

$\mathrm{m} / \mathrm{z}: 150.10$ (100.0\%), $151.11(11.0 \%)$
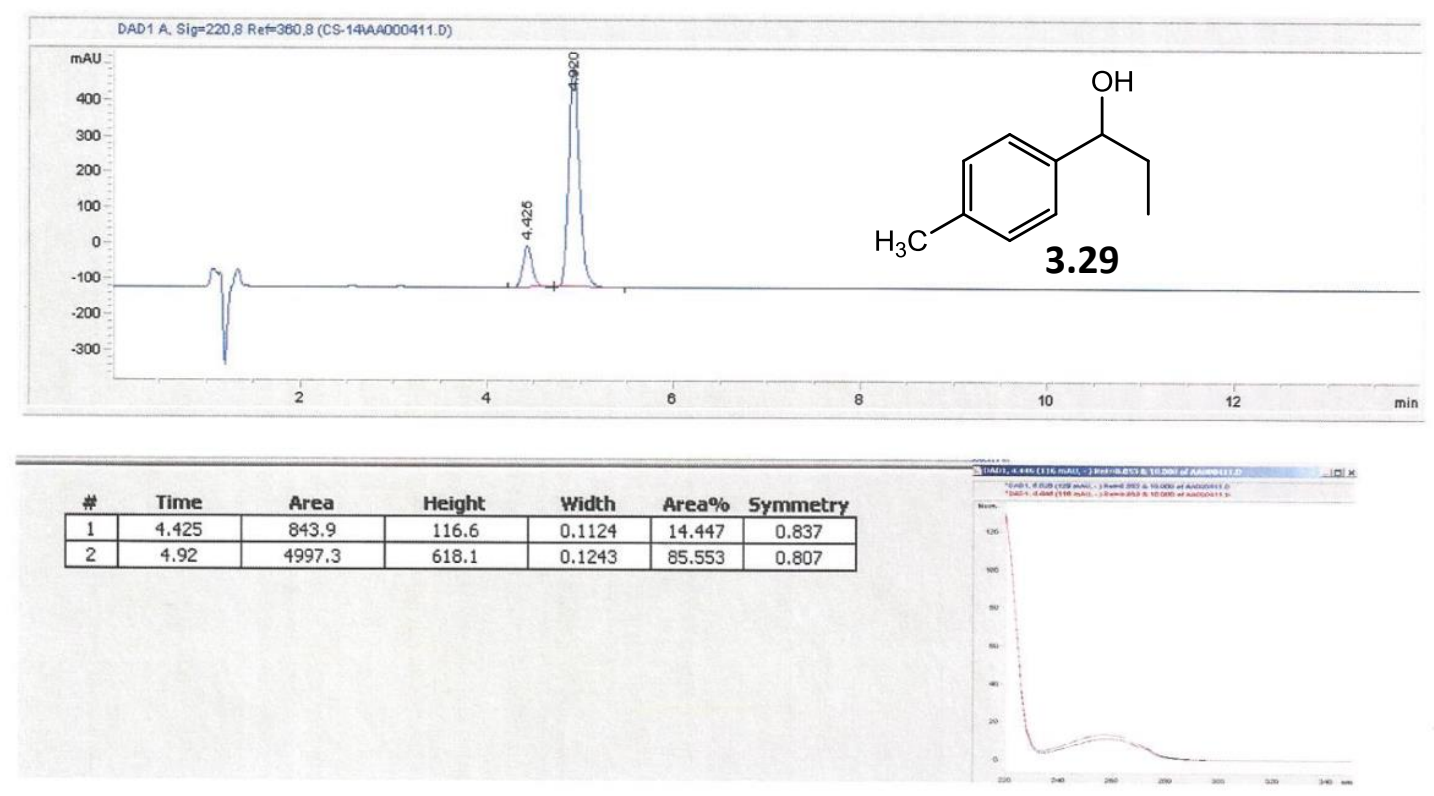

Figure A13. The chiral HPLC chromatogram of compound 3.29 


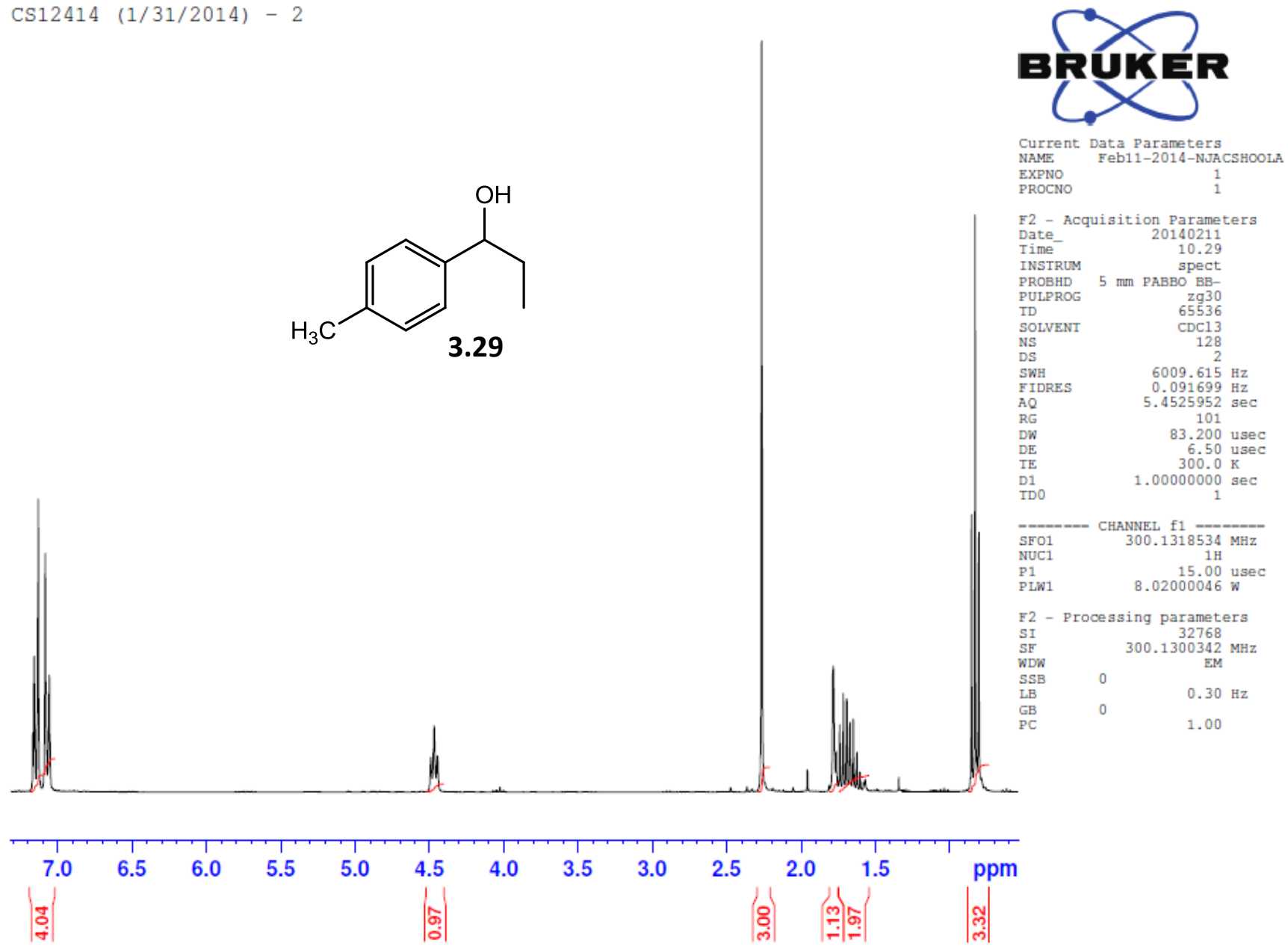

Figure A14. The ${ }^{1} \mathrm{H}$ NMR spectrum of compound $\mathbf{3 . 2 9}$ 


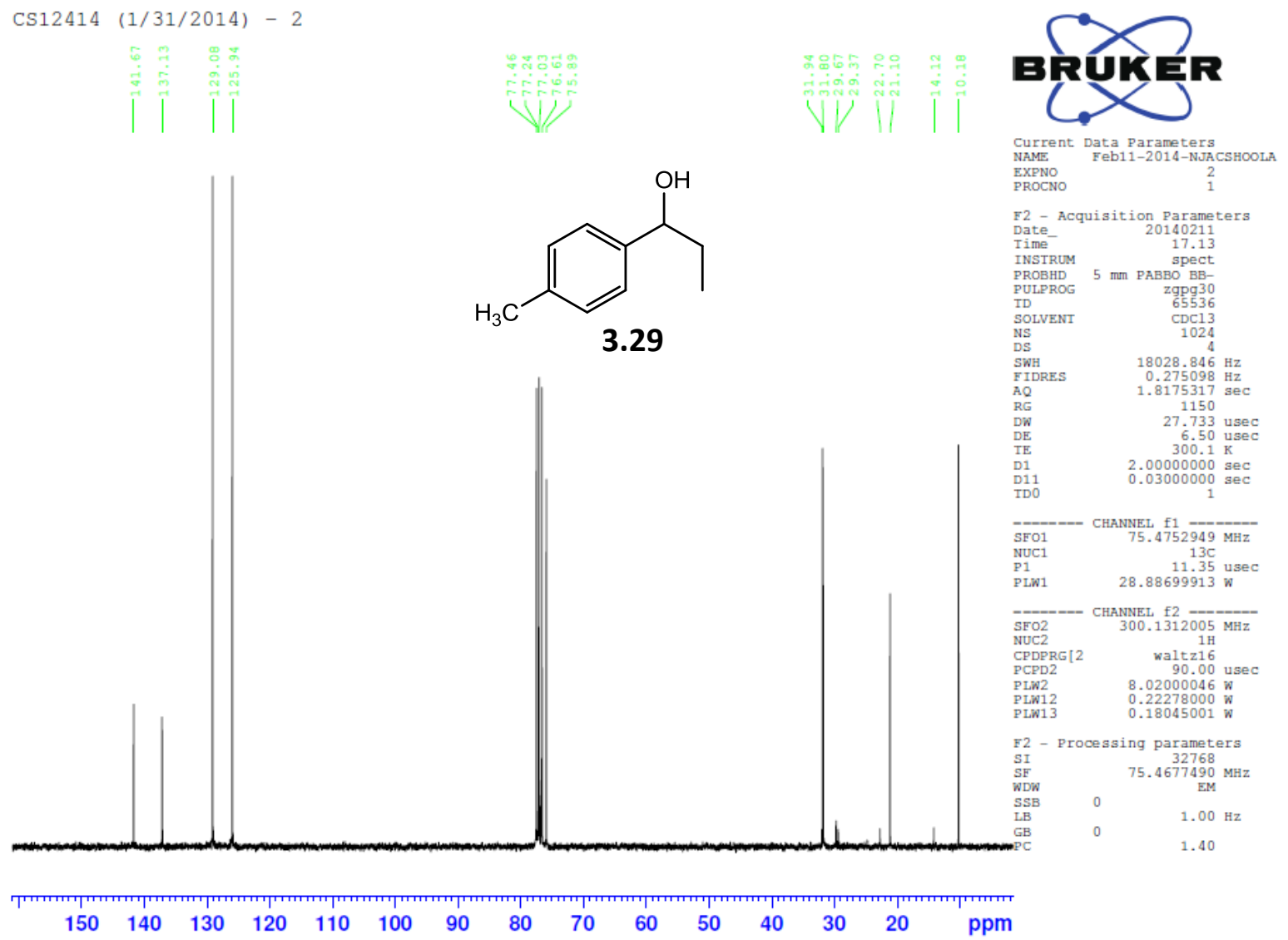

Figure A15. The ${ }^{13} \mathrm{C}$ NMR spectrum of compound $\mathbf{3 . 2 9}$ 


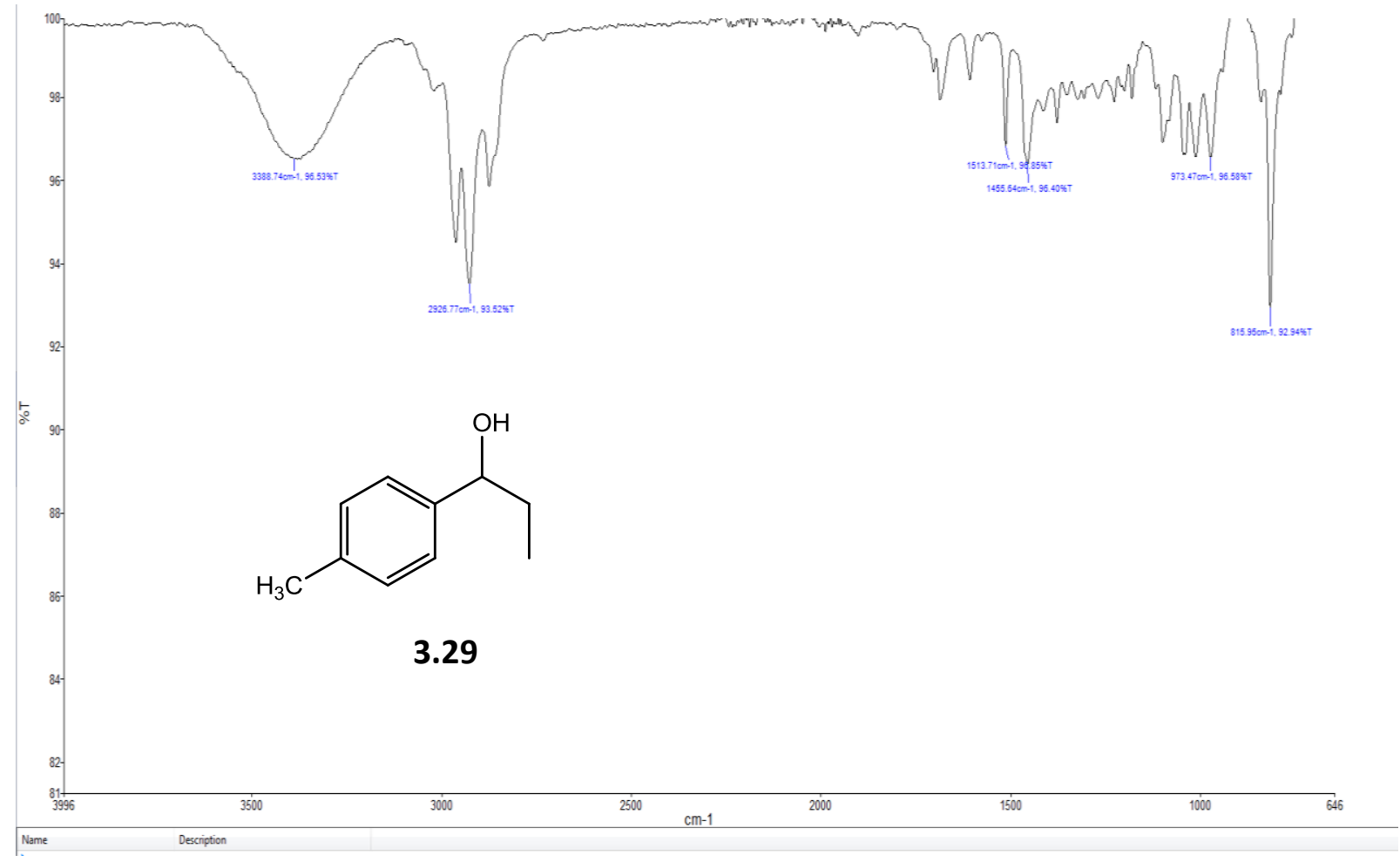

Figure A16. The FT-IR spectrum of compound $\mathbf{3 . 2 9}$ 


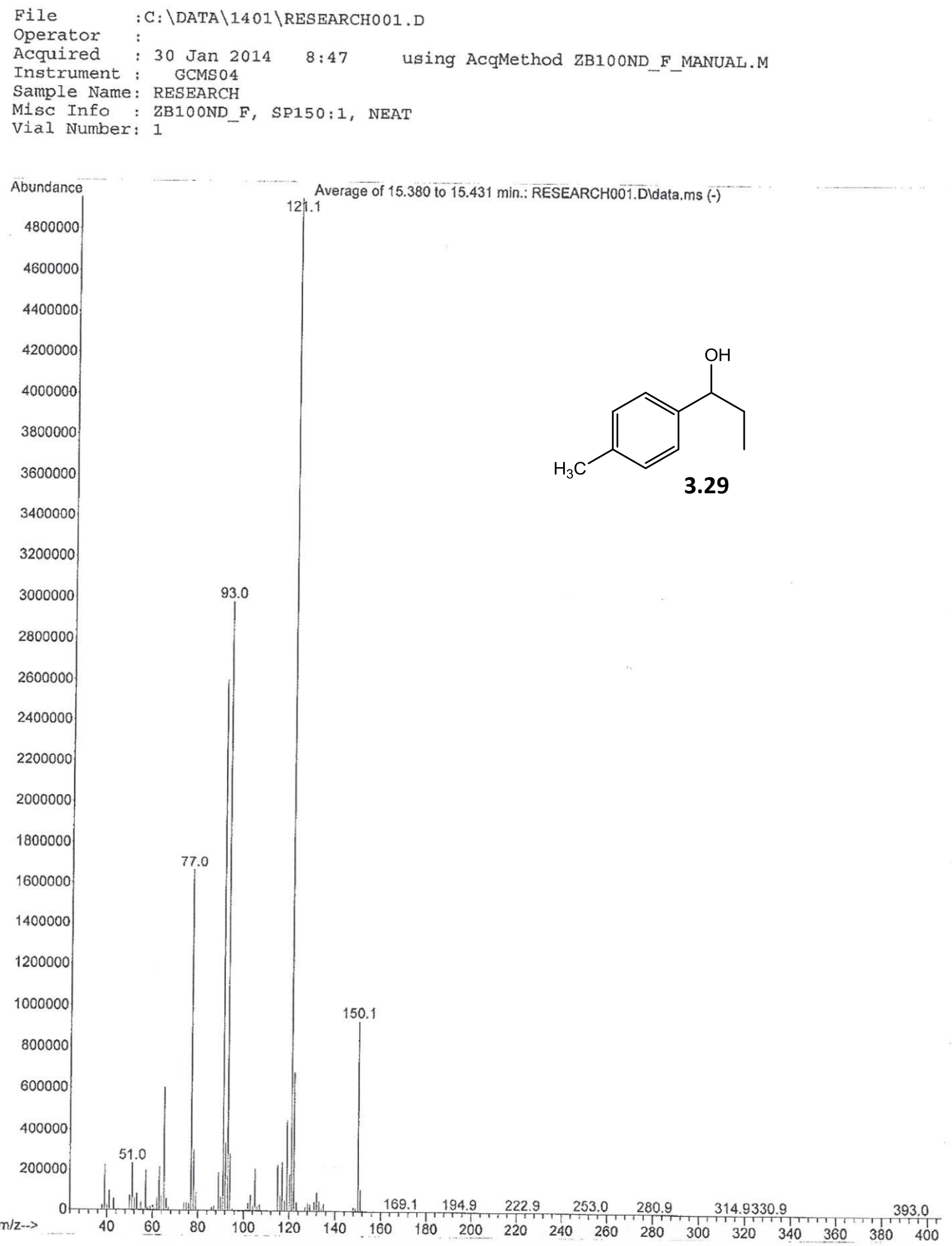

Figure A17. The mass spectrum of compound $\mathbf{3 . 2 9}$ 
Chemical Formula: $\mathrm{C}_{10} \mathrm{H}_{14} \mathrm{O}$

Exact Mass: 150.10

Molecular Weight: 150.22

m/z: 150.10 (100.0\%), 151.11 (11.0\%)
\# $\quad$ Time Area Height Width Area\% Symmetry

$\begin{array}{lllllll}1 & 5.639 & 546.8 & 143.8 & 0.0604 & 34.817 & 0.974\end{array}$

$\begin{array}{lllllll}2 & 5.994 & 1023.6 & 254.4 & 0.0649 & 65.183 & 0.931\end{array}$

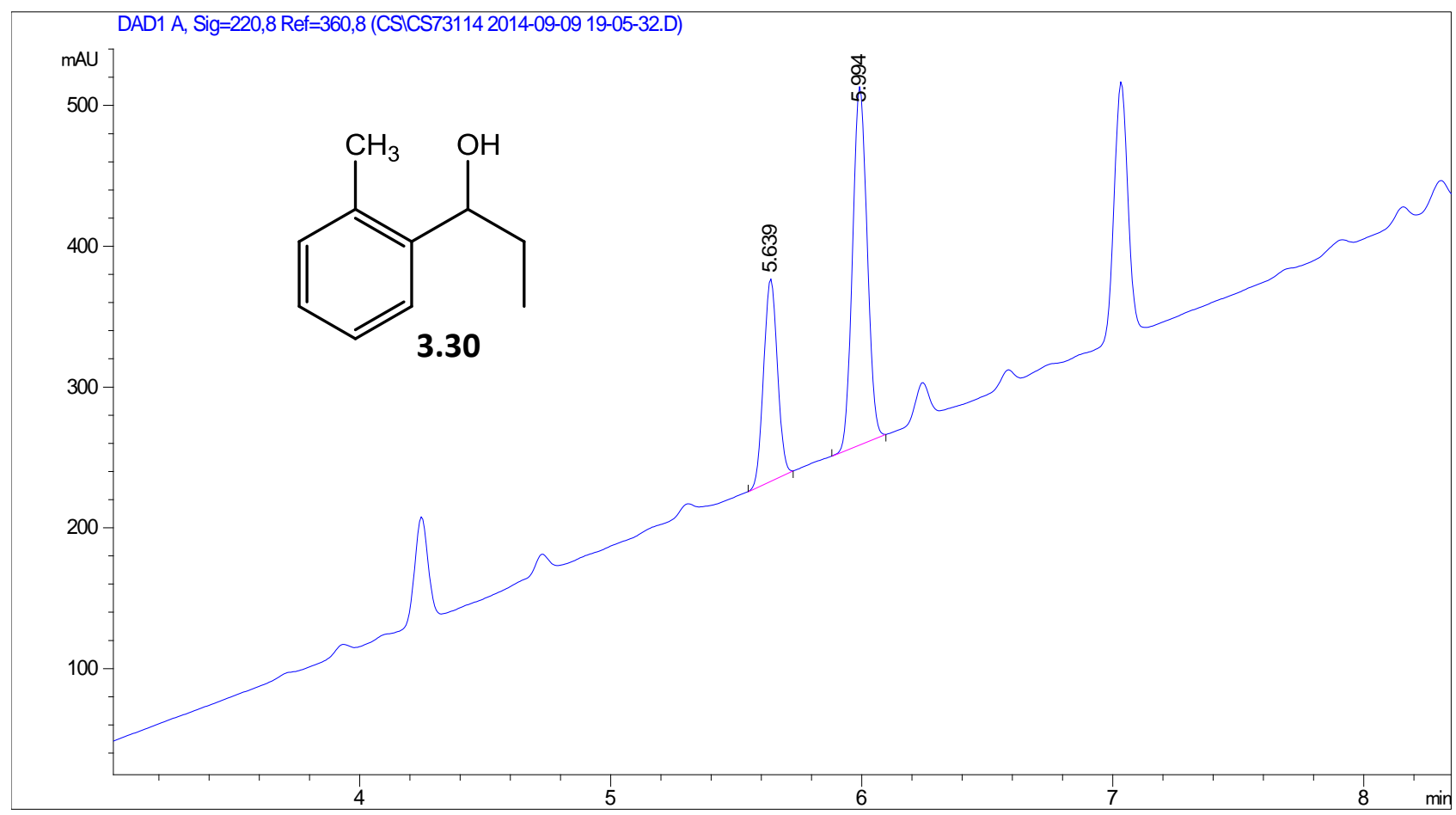

Figure A18. The chiral HPLC chromatogram of compound $\mathbf{3 . 3 0}$ 


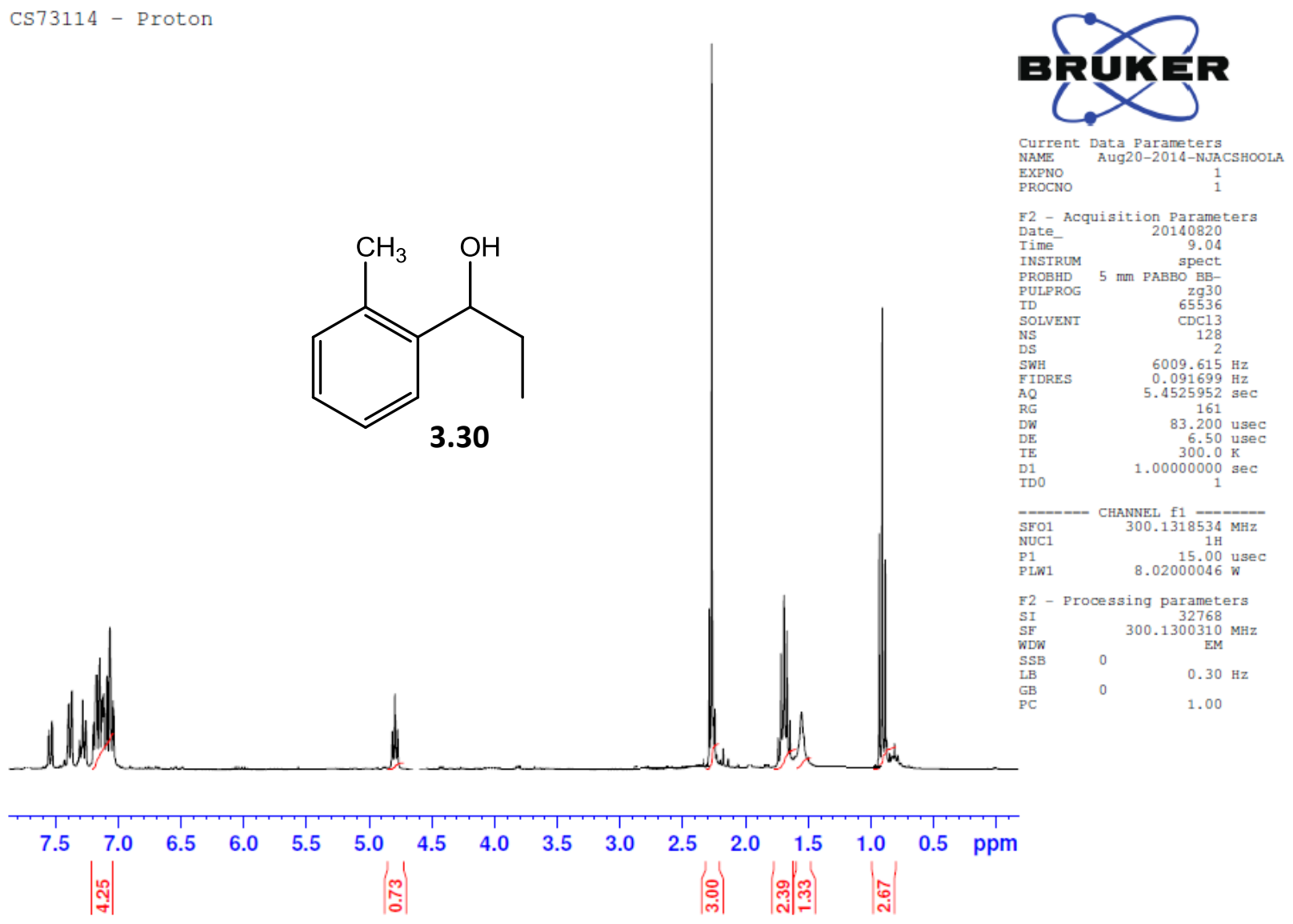

Figure A19. The ${ }^{1} \mathrm{H}$ NMR spectrum of compound $\mathbf{3 . 3 0}$ 


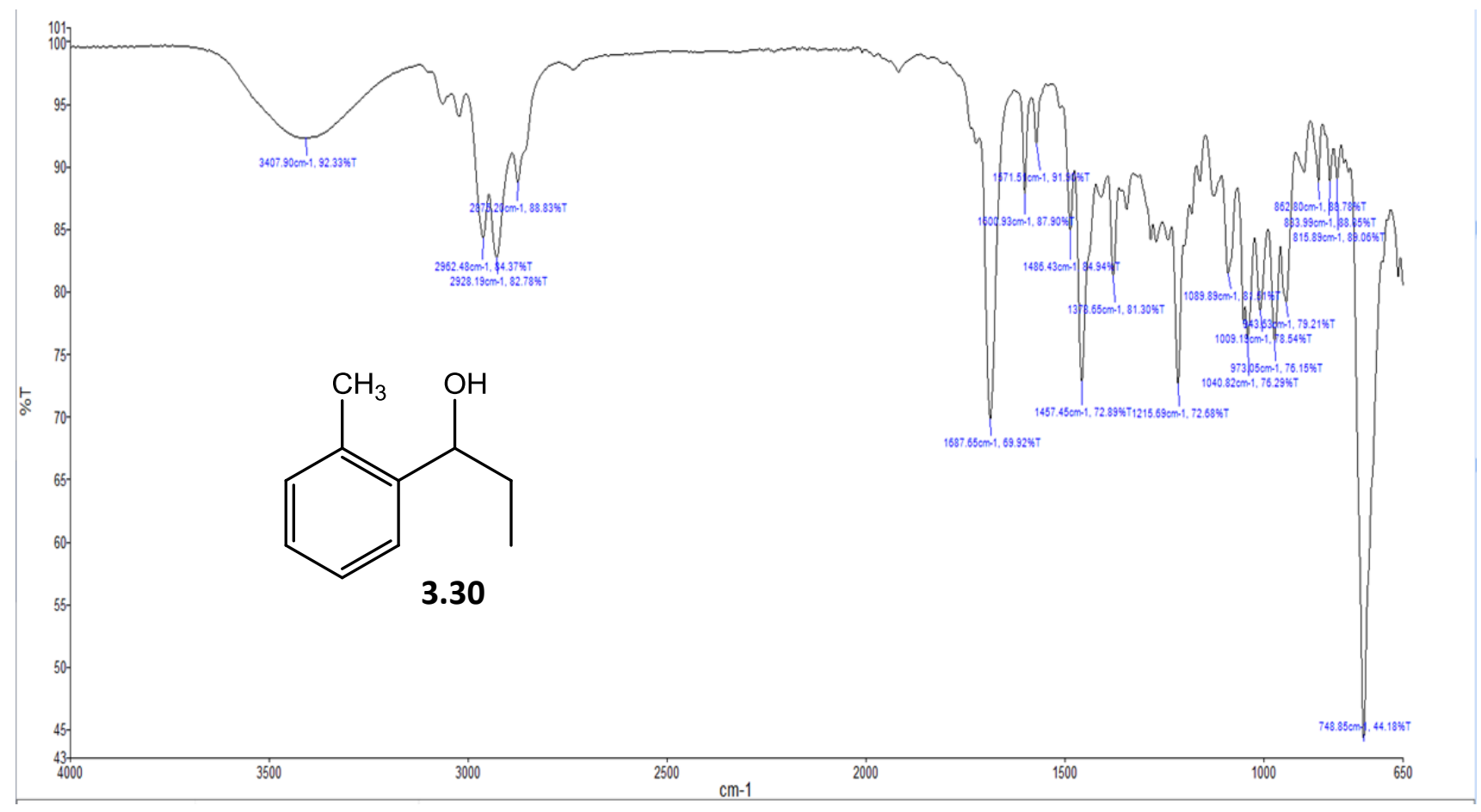

Figure A20. The FT-IR spectrum of compound $\mathbf{3 . 3 0}$ 


$\begin{array}{cccccccc}\begin{array}{c}\text { Chemical Formula: } \mathrm{C}_{10} \mathrm{H}_{14} \mathrm{O}_{2} \\ \text { Exact Mass: } 166.10\end{array} & \# & \text { Time } & \text { Area } & \text { Height } & \text { Width } & \text { Area\% } & \text { Symmetry } \\ \begin{array}{c}\text { Molecular Weight: } 166.22 \\ \mathrm{~m} / \mathrm{z}:\end{array} & 1 & 5.305 & 44.4 & 10.1 & 0.0694 & 3.492 & 1.548\end{array}$

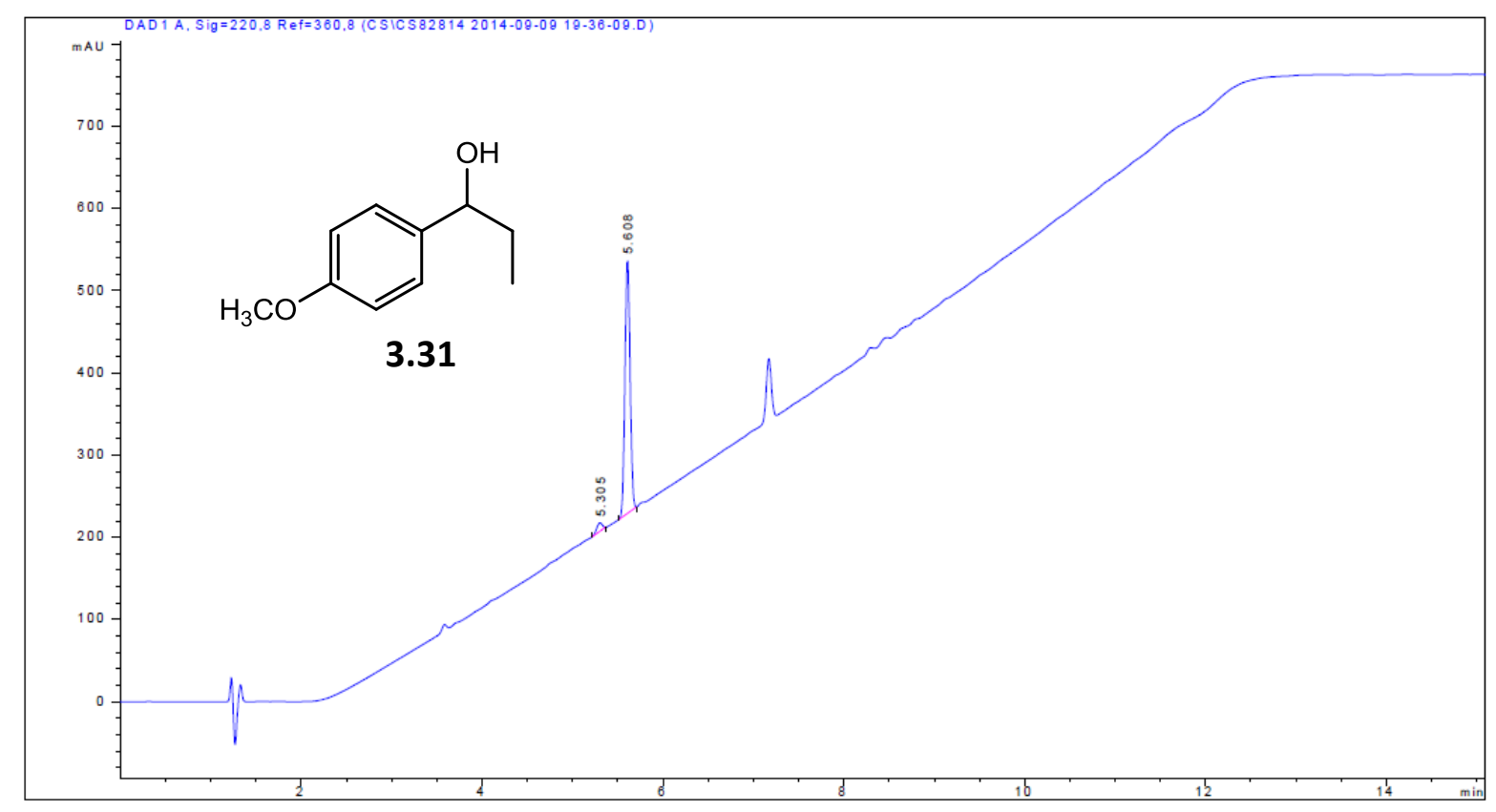

Figure A21. The chiral HPLC chromatogram of compound $\mathbf{3 . 3 1}$ 


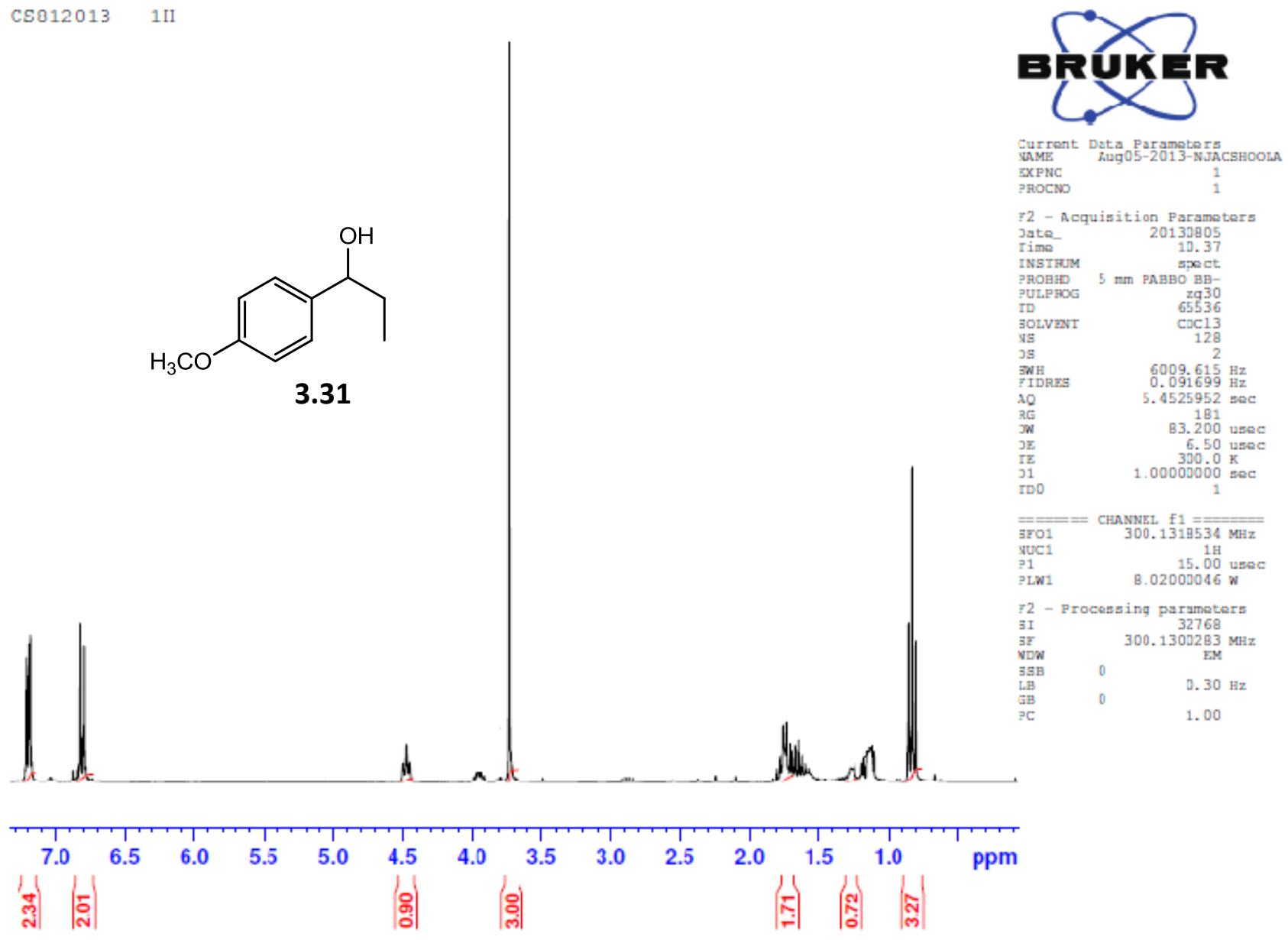

Figure A22. The ${ }^{1} \mathrm{H}$ NMR spectrum of compound $\mathbf{3 . 3 1}$ 


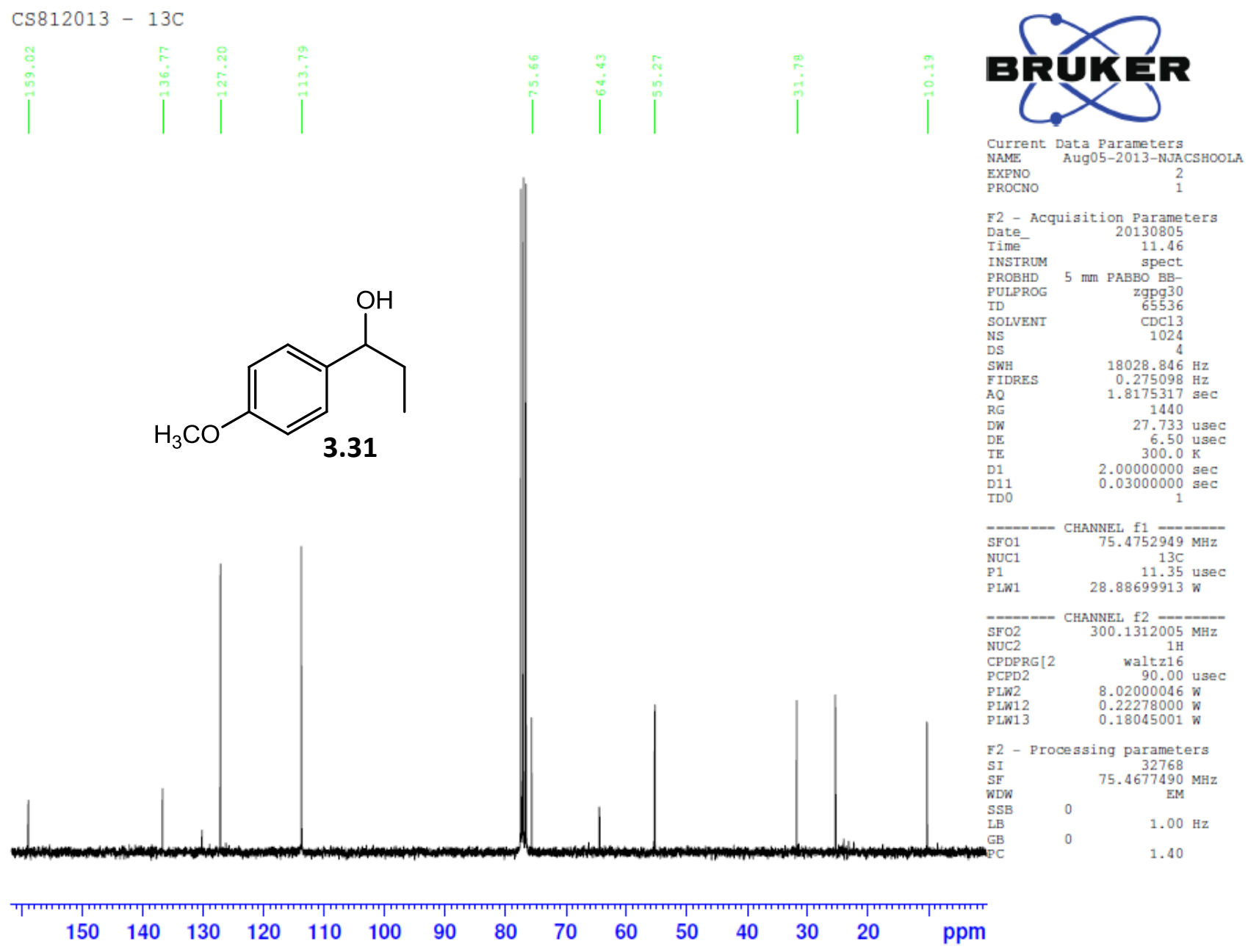

Figure A23. The ${ }^{13} \mathrm{C}$ NMR spectrum of compound $\mathbf{3 . 3 1}$ 


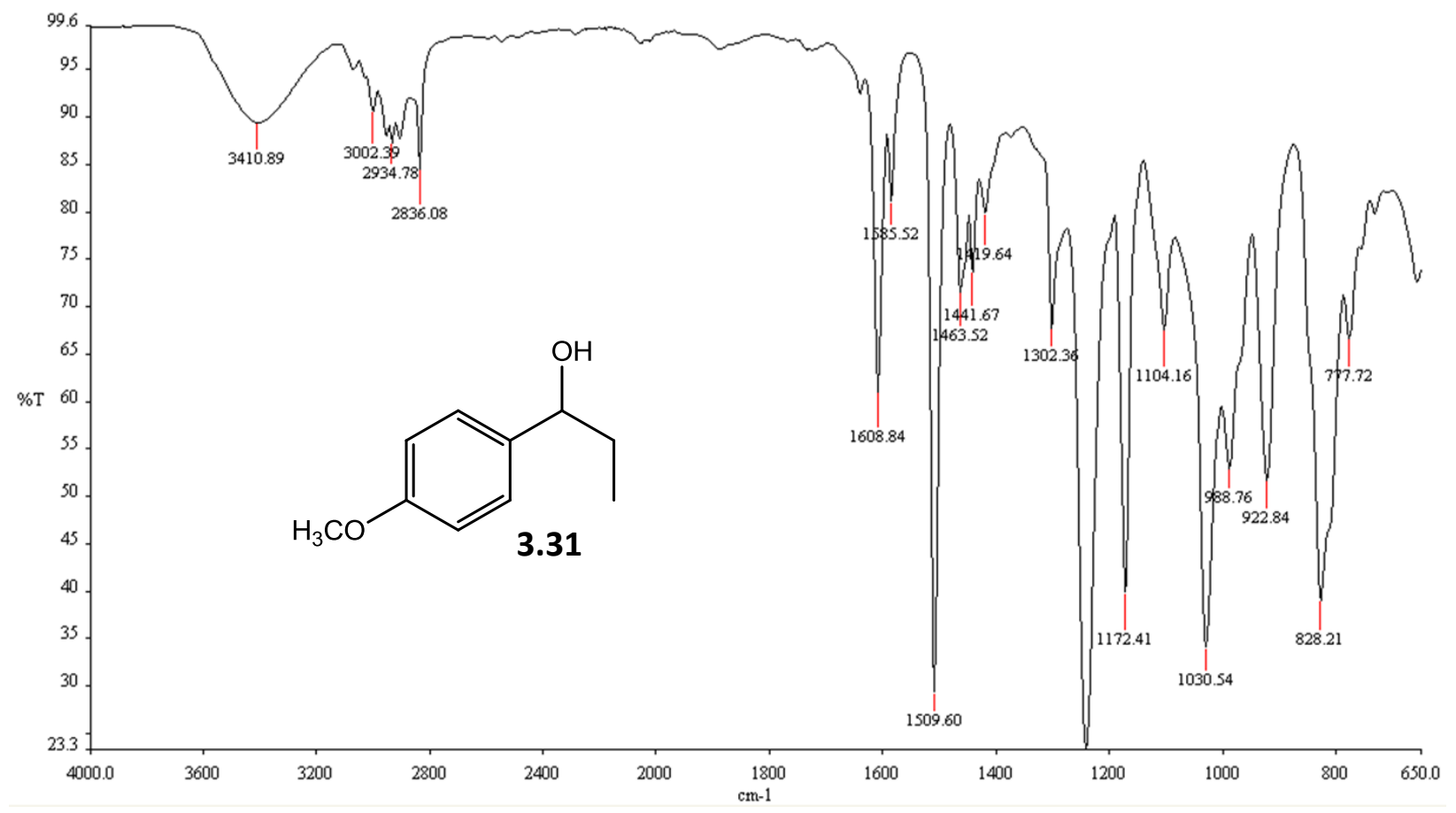

Figure A24. The FT-IR spectrum of compound $\mathbf{3 . 3 1}$ 


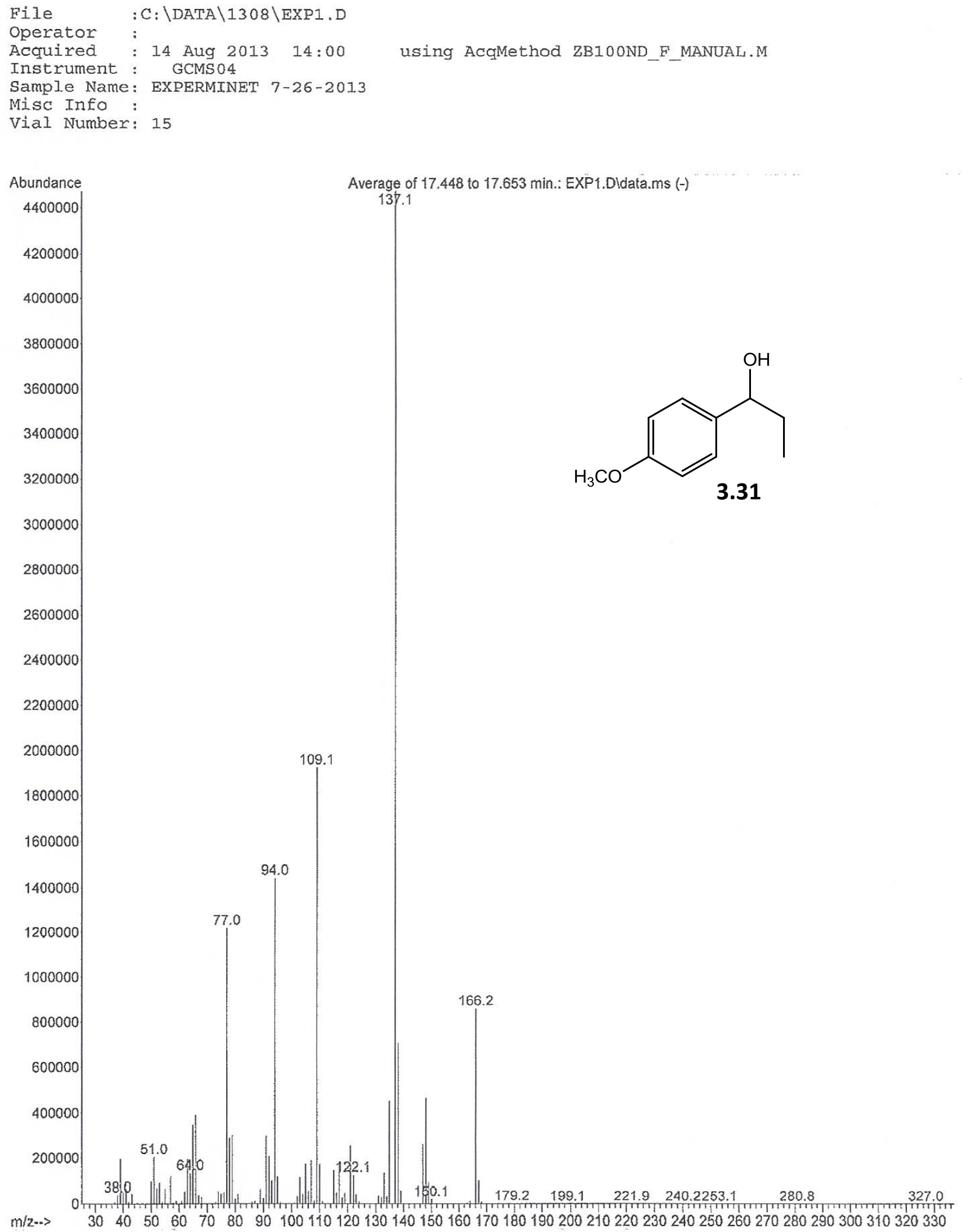

Figure A25. The mass spectrum of compound $\mathbf{3 . 3 1}$ 
Chemical Formula: $\mathrm{C}_{10} \mathrm{H}_{11} \mathrm{~F}_{3} \mathrm{O}$

Exact Mass: 204.08

Molecular Weight: 204.19

m/z: 204.08 (100.0\%), 205.08 (11.0\%)

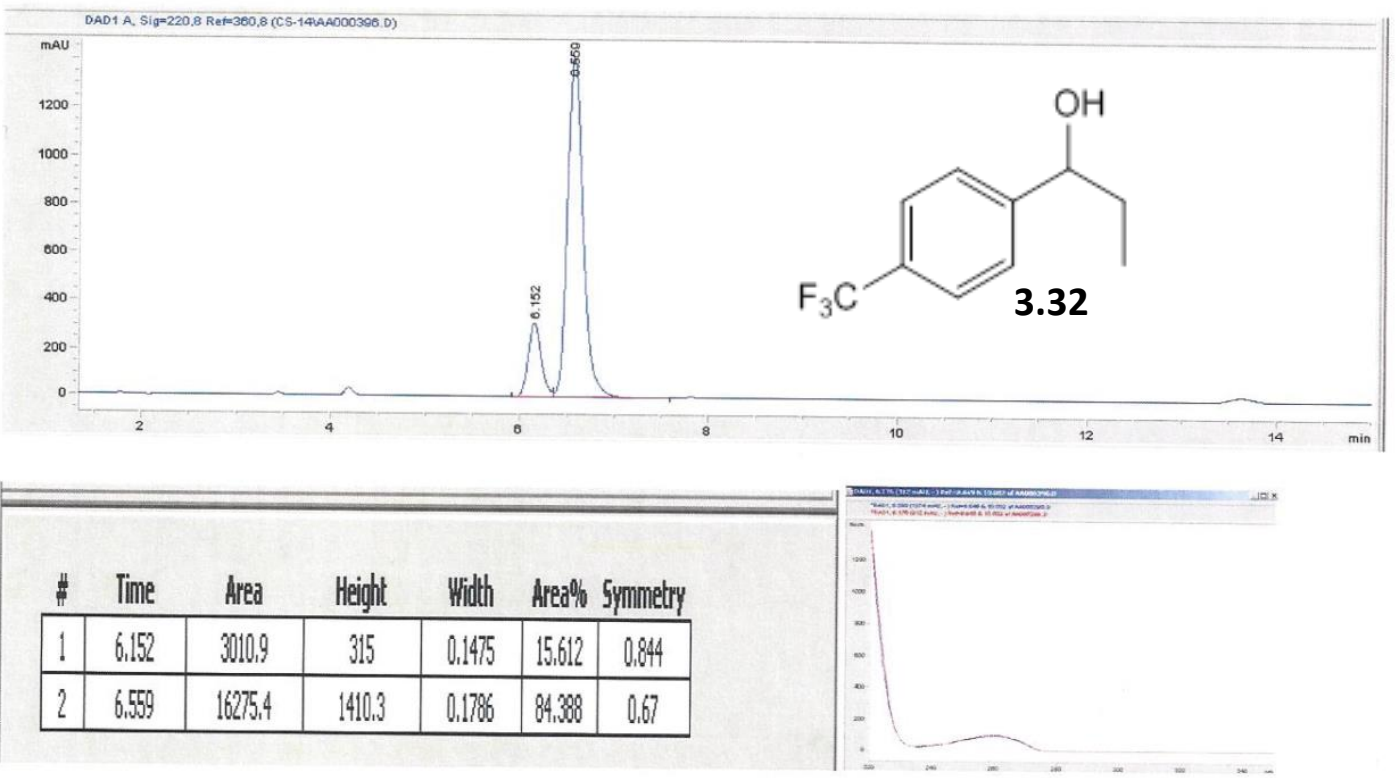

Figure A26. The chiral HPLC chromatogram of compound $\mathbf{3 . 3 2}$ 


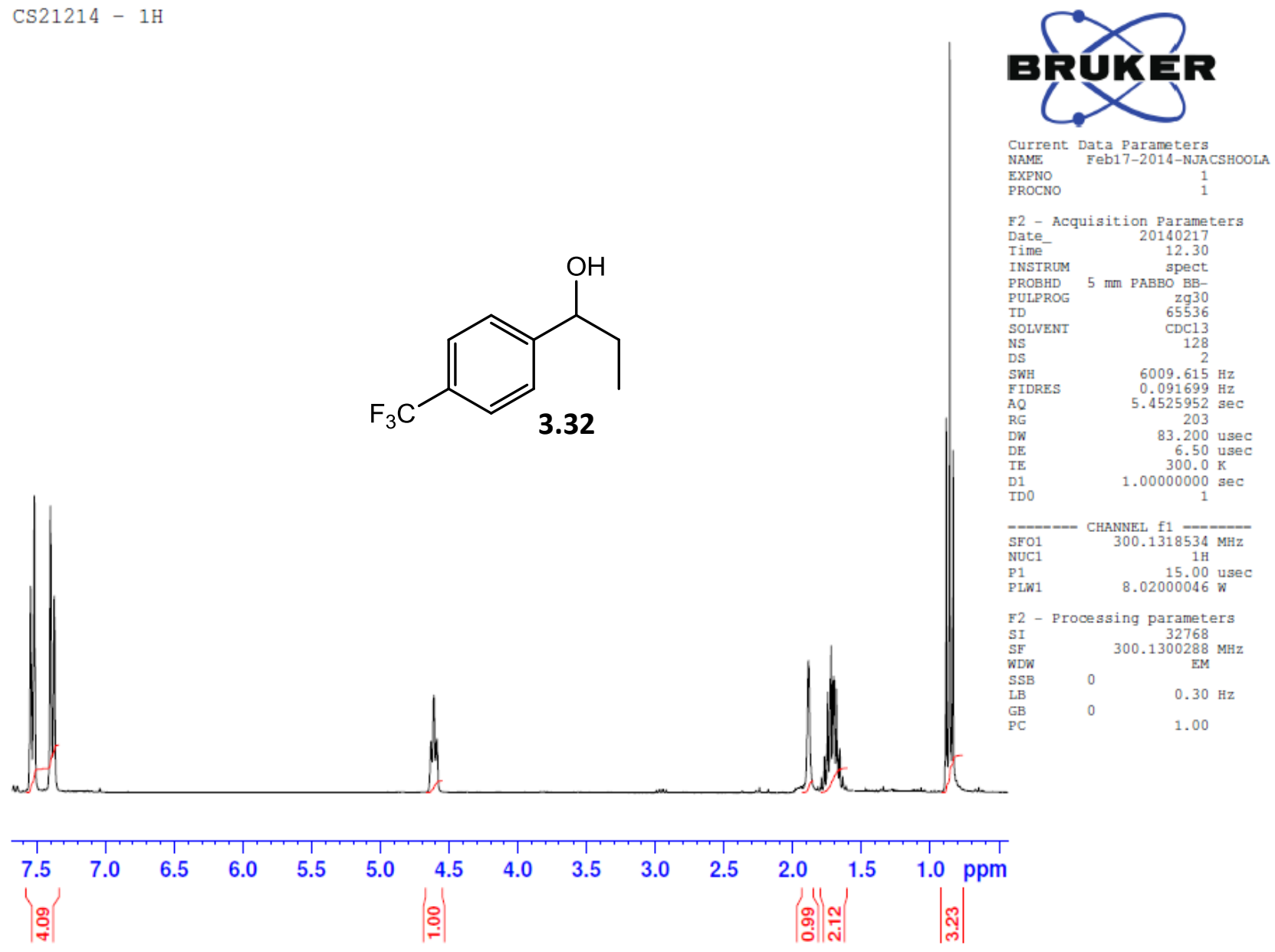

Figure A27. The ${ }^{1} \mathrm{H}$ NMR spectrum of compound $\mathbf{3 . 3 2}$ 


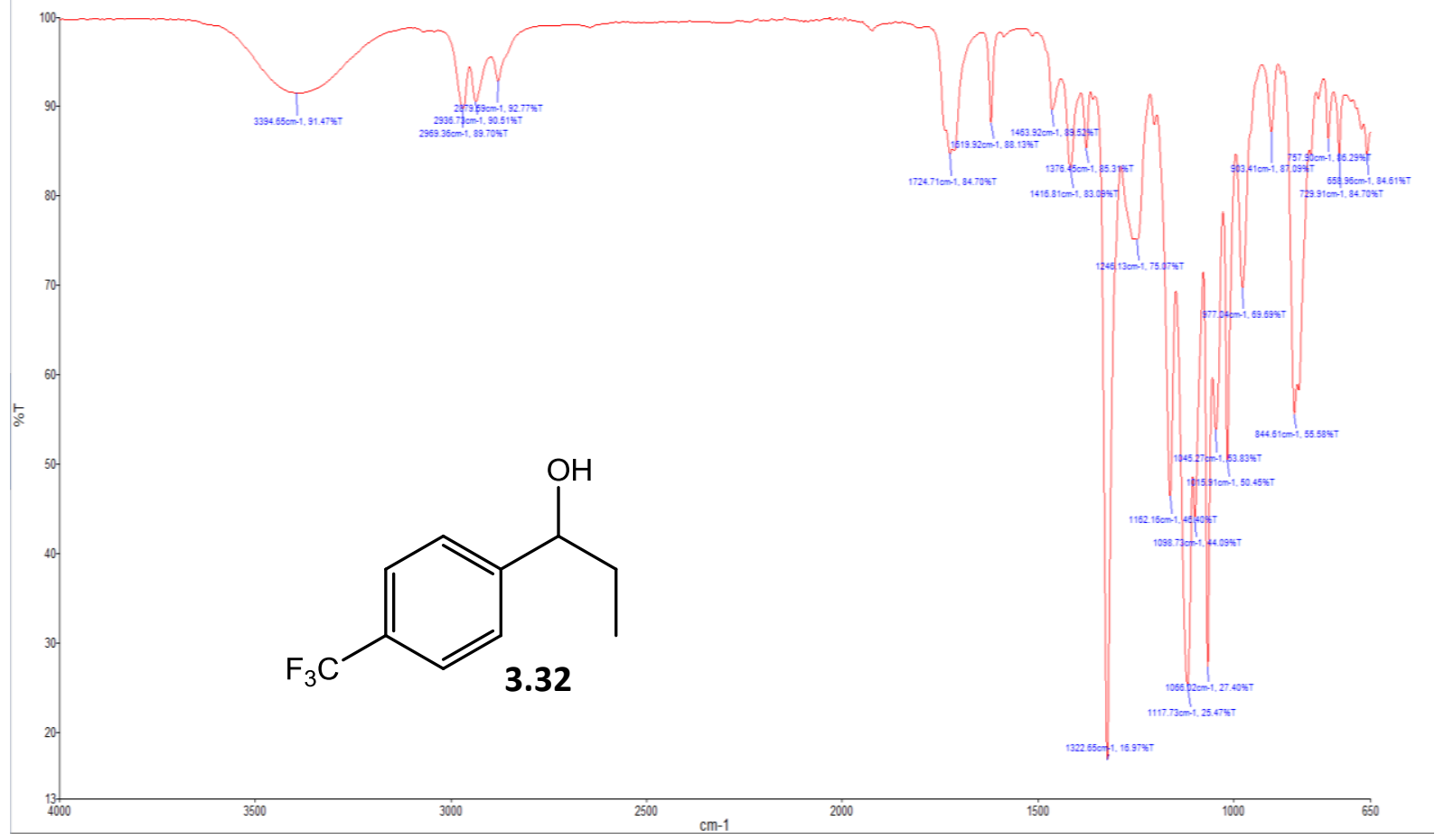

Figure A28. The FT-IR spectrum of compound $\mathbf{3 . 3 2}$ 


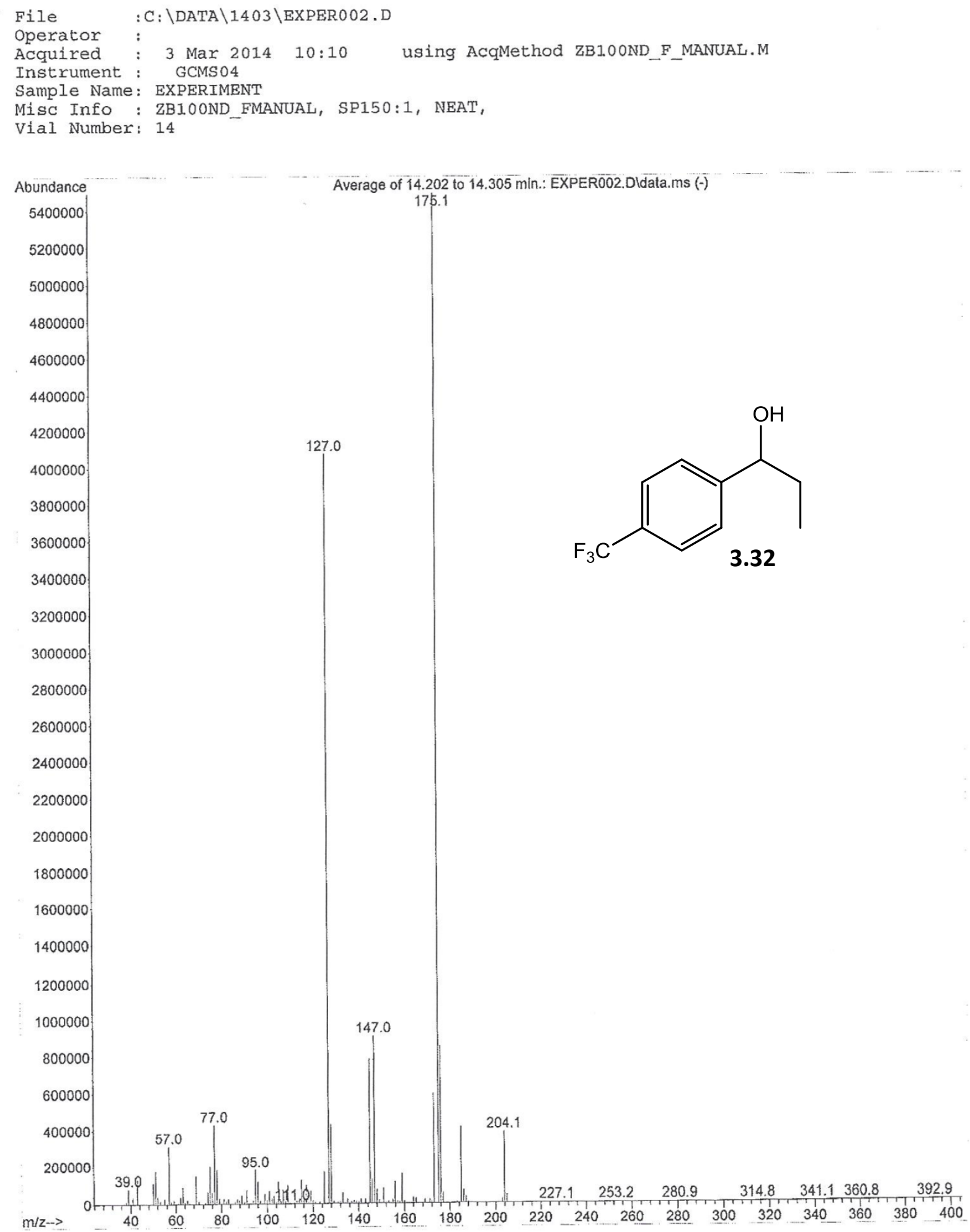

Figure A29. The mass spectrum of compound $\mathbf{3 . 3 2}$ 


$$
\begin{gathered}
\text { Chemical Formula: } C_{15} I_{16} O \\
\text { Exact Mass: } 212.12 \\
\text { Molecular Weight: } 212.29
\end{gathered}
$$

$\mathrm{m} / \mathrm{z}=212.12(100.0 \%), 213.12(16.3 \%), 214.13(1.3 \%)$
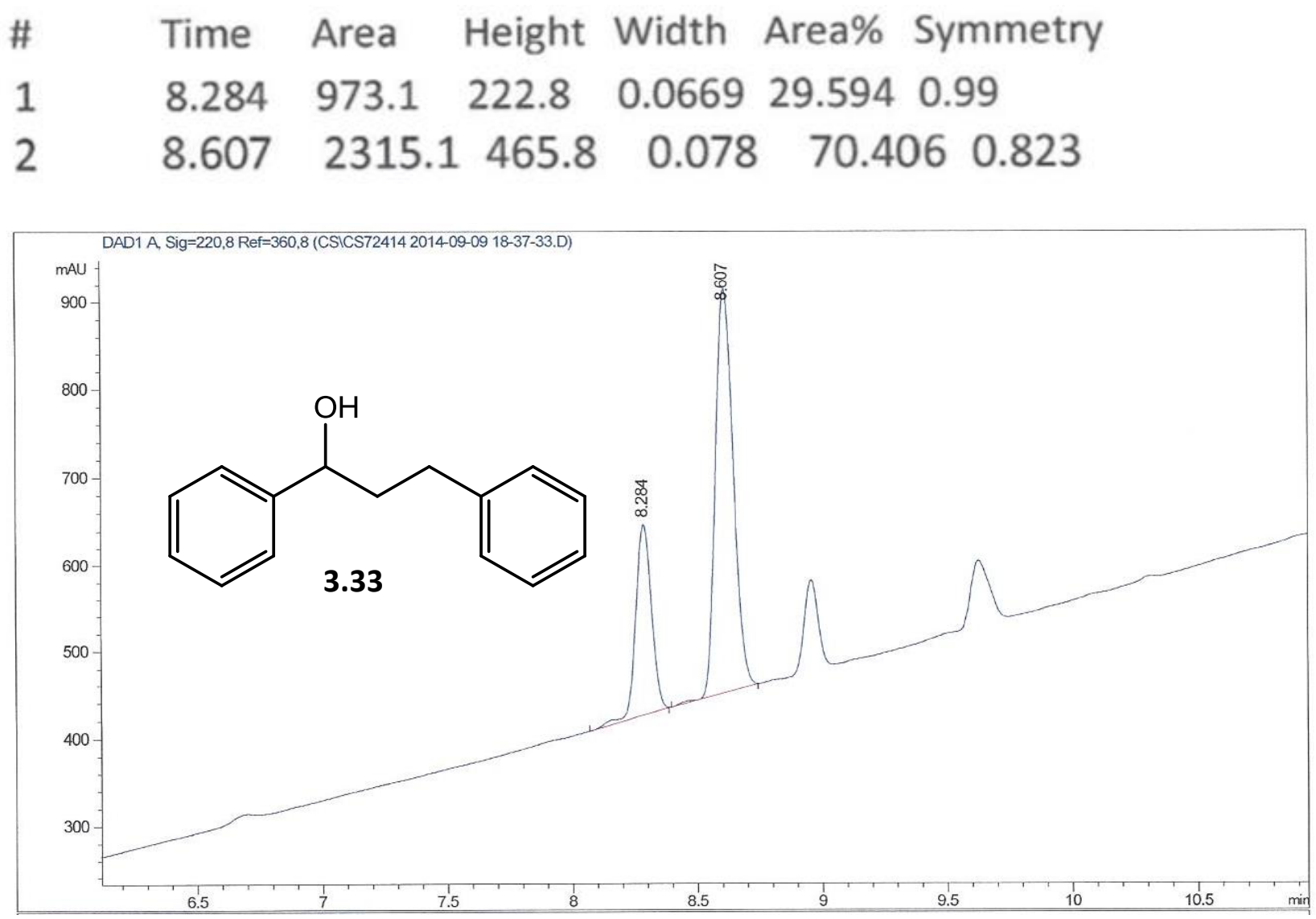

Figure A30. The chiral HPLC chromatogram of compound $\mathbf{3 . 3 3}$ 


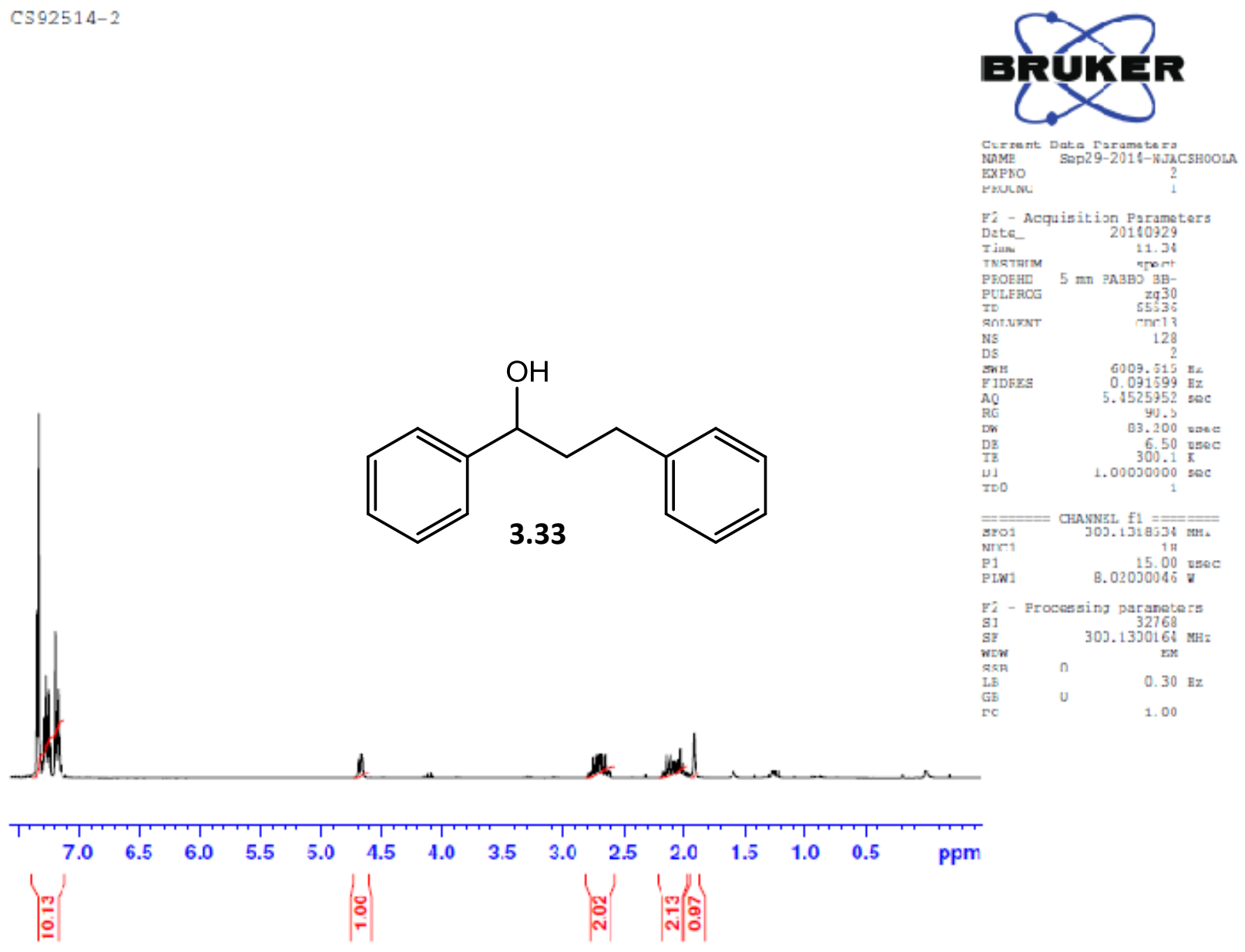

Figure $\mathbf{A} 31$. The ${ }^{1} \mathrm{H}$ NMR spectrum of compound $\mathbf{3 . 3 3}$ 


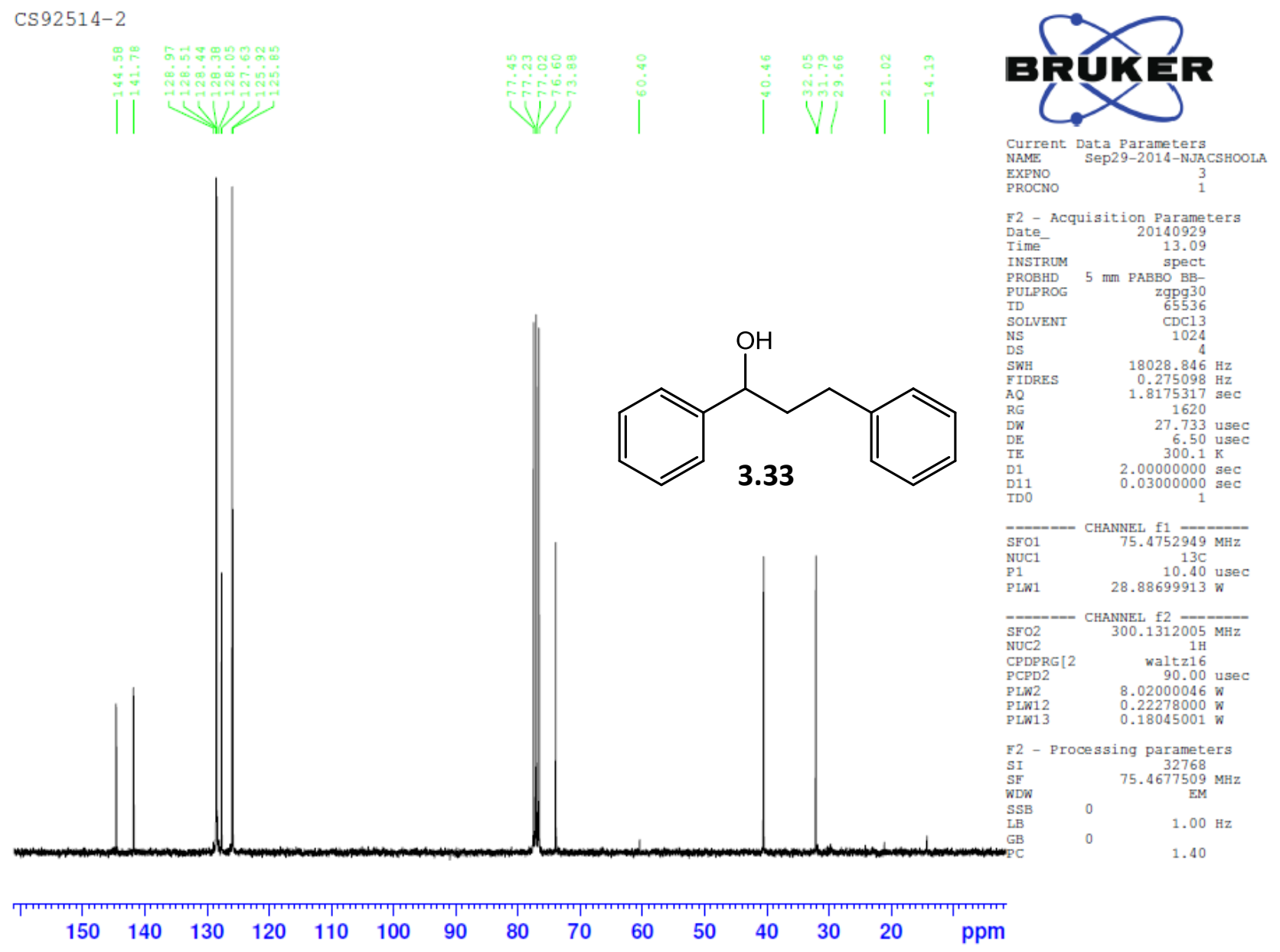

Figure $\mathbf{A} 32$. The ${ }^{13} \mathrm{C} N M R$ spectrum of compound $\mathbf{3 . 3 3}$ 


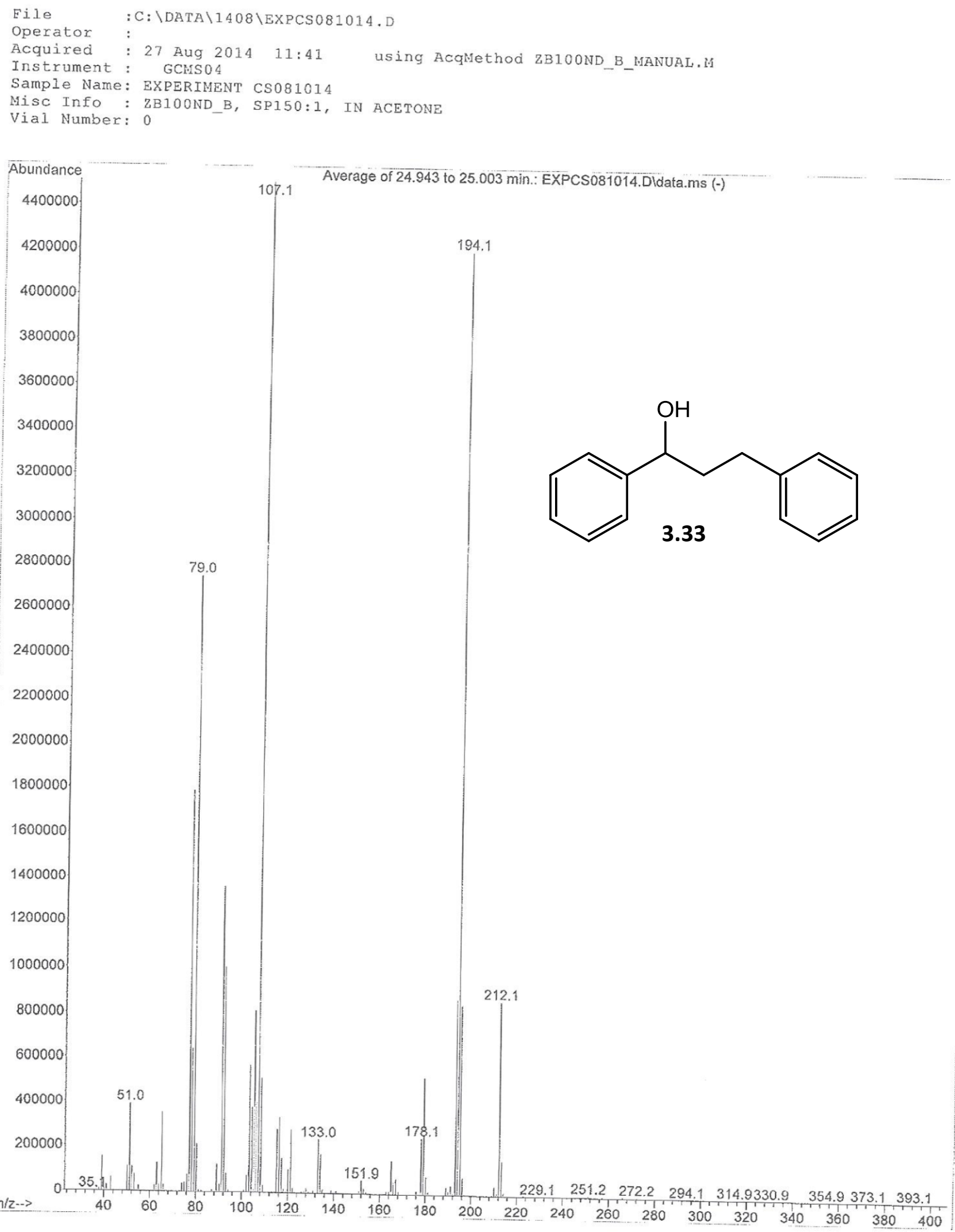

Figure A33. The mass spectrum of compound $\mathbf{3 . 3 3}$ 


\section{A Final Thought....}

"If you would cause your view... to be acknowledged by scientific men; you would do a great service to science. If you would even get them to say yes or no to your conclusions it would help to clear the future progress"

- Michael Faraday 
To God be the glory, for His mercy endureth forever.

Christopher Olugbenga Olusegun Shoola, Ph.D. 